Portland State University

PDXScholar

Spring 6-9-2015

\title{
Empowering All Who Teach: A Portrait of Two Non- Native English Speaking Teachers in a Globalized 21st Century
}

Rosa Dene David

Portland State University

Follow this and additional works at: https://pdxscholar.library.pdx.edu/open_access_etds

Part of the Bilingual, Multilingual, and Multicultural Education Commons, and the Other Linguistics Commons

Let us know how access to this document benefits you.

\section{Recommended Citation}

David, Rosa Dene, "Empowering All Who Teach: A Portrait of Two Non-Native English Speaking Teachers in a Globalized 21st Century" (2015). Dissertations and Theses. Paper 2298.

https://doi.org/10.15760/etd.2295

This Thesis is brought to you for free and open access. It has been accepted for inclusion in Dissertations and Theses by an authorized administrator of PDXScholar. For more information, please contact pdxscholar@pdx.edu. 
Empowering All Who Teach:

A Portrait of Two Non-Native English Speaking Teachers in a Globalized $21^{\text {st }}$ Century

by

Rosa Dene David

A thesis submitted in partial fulfillment of the requirements for the degree of

Master of Arts
in
Teaching English to Speakers of Other Languages

Thesis Committee:

Kimberley Brown, Chair

Priya Kapoor

Kathy Harris

Shawn Smallman

Portland State University

2015 
(C) 2015 Rosa Dene David 


\begin{abstract}
One of most prevalent issues surrounding English education internationally is the differentiation between Native English-Speaking Teachers (NESTs) and Non-native English-Speaking Teachers (NNESTs). What is sometimes termed the "Native speaker fallacy" is the notion that in order to be a proficient teacher of the English language one must either be a native speaker or possess native like fluency (Phillipson, 1992). This position is furthered by Holliday's "Native Speakerism," (Holliday, 2006) which suggests that within the field of English Language Teaching (ELT) there is an assumption that NESTs are better equipped to teach English language learners due to language proficiency and Western teaching methodology. Today, instructors who are native speakers of English are more sought after on the international market than their nonnative English-speaking counterparts. NNESTs have less access to employment, fair wages and job security due to the perceived differences in language ability (Barry, 2011). The distinction between the two classes of teachers underscores the belief that NNESTs are often treated as second-class citizens (Braine, 1999). Subsequently, when employers and colleagues note the differences between English variety and dialect NNESTs' social and teacher identity in the classroom may be jeopardized (Varghese et al., 2005).
\end{abstract}

The purpose of this qualitative, ethnographic case study is to explore the sociohistorical lives of two NNESTs living in the Pacific Northwest. Specifically, this study is concerned with the way in which two NNESTs perceive their social and teacher identity in relation to being bilingual speakers teaching English. 
This study attempts to explore in a non-dichotomous fashion the manner in which these two actors describe and interpret their roles and positions as NNESTs. 


\section{Dedication}

This thesis is dedicated to my grandfather, whose life's work has been my inspiration, and to my mother and grandmother who have always shown me unconditional love and support. 


\section{Acknowledgements}

I would first and foremost like to thank my advisor, Kimberley Brown, for all of her support and guidance during the two years I spent researching and writing this thesis. Without her continual mentoring and compassion for my efforts, I would not have found the strength to see this study reach its full potential. Kim, you have become like family to me, and I am so grateful that I have been able to study with you. I would like to thank Priya Kapoor for acting as a co-advisor. Priya, your innate understanding of identity and ethnographic research has been invaluable, and I will forever be grateful to you for your continual encouragement and guidance. I would also like to thank my other two committee members, Kathy Harris and Shawn Smallman, for taking the time to read and review this thesis. Kathy, our conversations about learning differences have been a great source of joy for me this year. Shawn, you were my first professor at Portland State University, and I am so grateful that I was able to work with you again as a graduate student. Writing this thesis has truly been my greatest accomplishment, and I would have not have been able to do it without the support of my committee.

I would like to thank Jasmine and Anna for participating in this study. It has truly been a gift to document your lives. I hope that I co-constructed your narratives in a manner in which you are proud of and will be able to share it with those you love. Your voices will stay with me for the rest of my life.

Finally, I would like to thank my family, especially my father, Donald David, and my uncle, Graham Shepfer, for their love and support. I would also like to thank Manuel Huffman, Dr. Eric Hussey, Dr. Bradley Coffey, the Department of International Studies and the Department of Applied Linguistics for their ongoing encouragement. 
Table of Contents

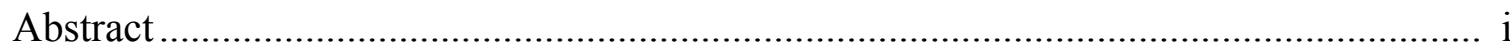

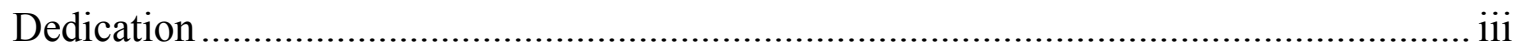

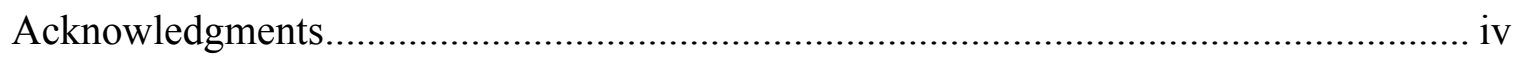

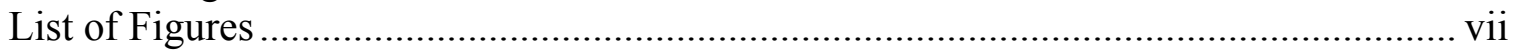

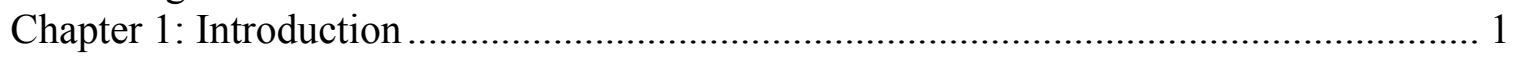

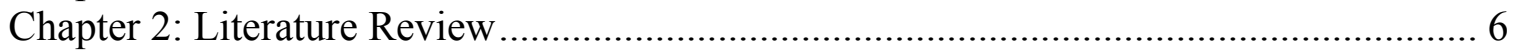

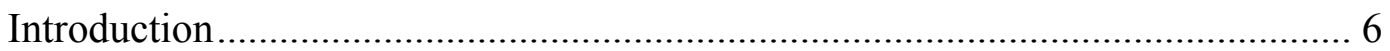

Differentiation Between English Teachers ...................................................... 8

World Englishes and the Spread of English Internationally ................................ 9

The Critical Perspective .............................................................................. 12

The American Education System and the English Debate ............................... 15

Teacher Differentiation and the Construction of Identity ................................ 18

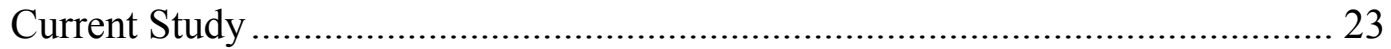

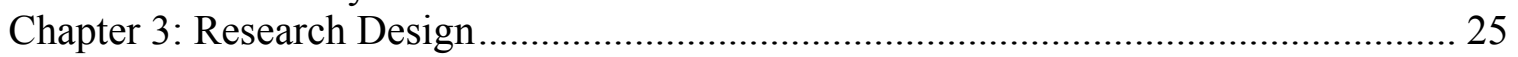

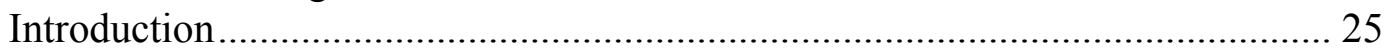

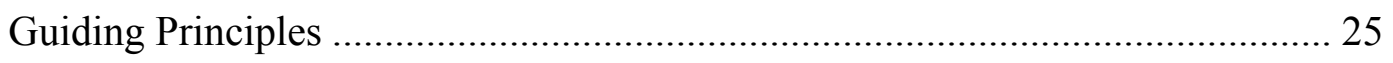

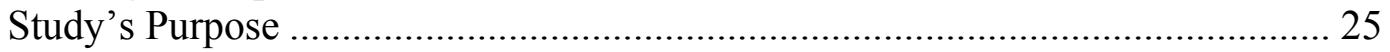

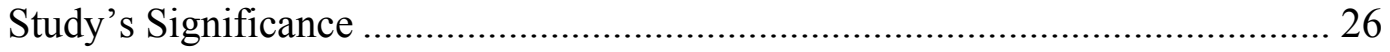

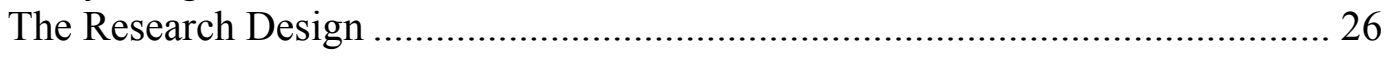

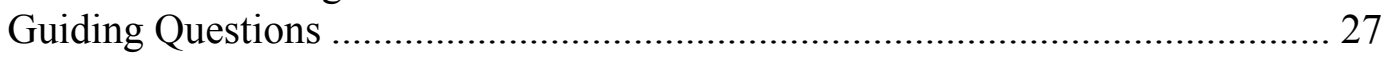

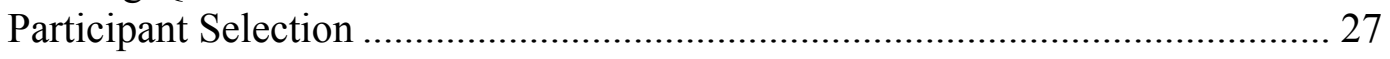

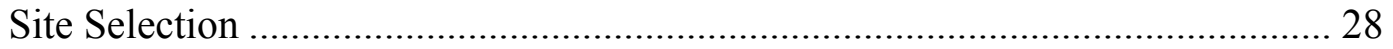

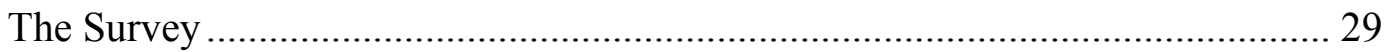

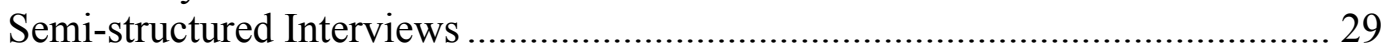

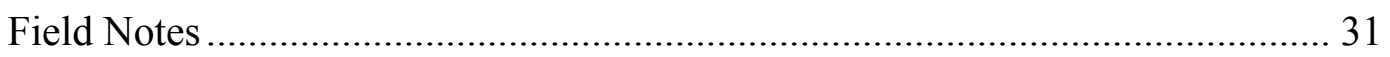

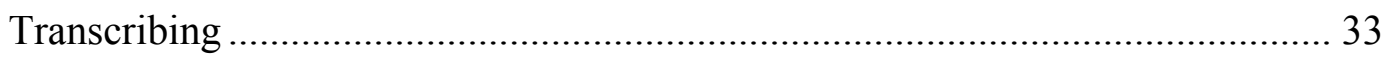

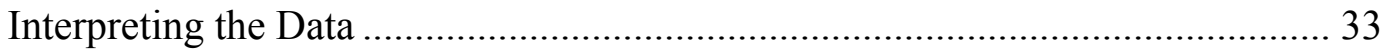

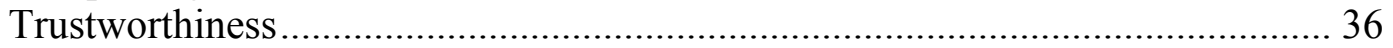

Limitations of the Study ......................................................................... 38

Chapter 4: Jasmine's Portrait as an English Language Teacher ................................... 40

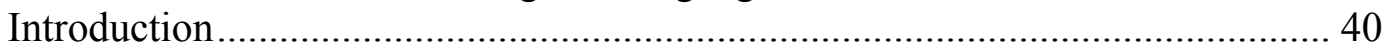

The History of English in My Life .......................................................... 41

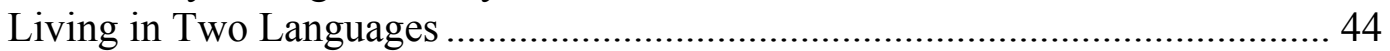

Higher Education and Teacher Training ....................................................... 48

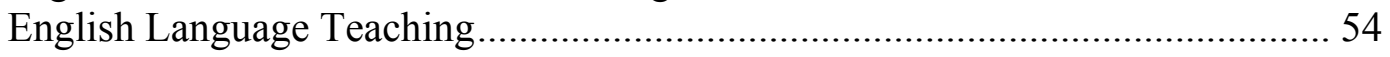

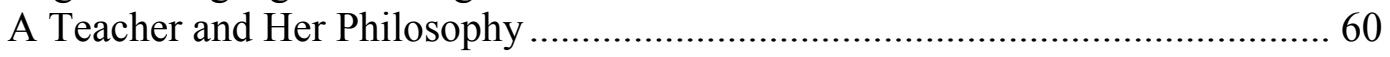

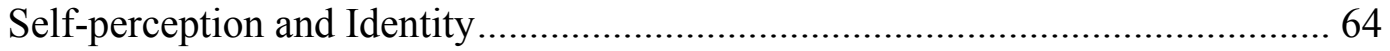

World Englishes and English Language Education......................................... 74

Chapter 5: Anna's Portrait as an English Language Teacher ......................................... 79

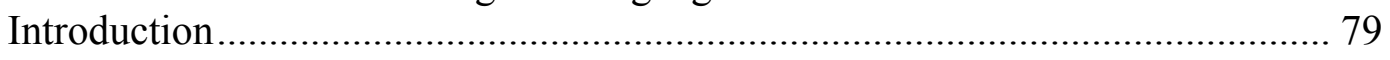

The History of English in My Life ........................................................... 80

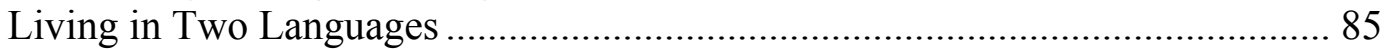

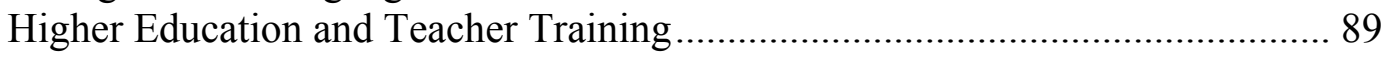


vi

English Language Teaching......................................................................... 91

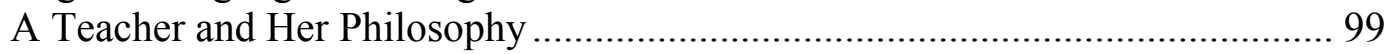

Self-perception and Identity........................................................................ 104

World Englishes and English Language Education ..................................... 110

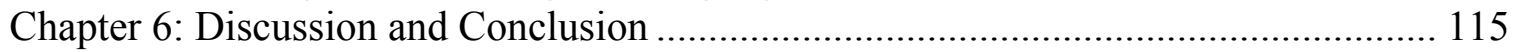

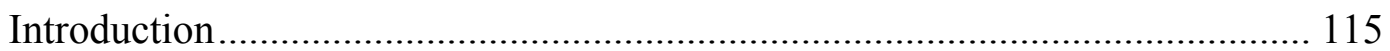

Revisiting the Guiding Question: Teaching Practices ................................... 118

Revisiting the Guiding Question: Identity ................................................... 124

Conclusion: Internationalization of TESOL ............................................... 129

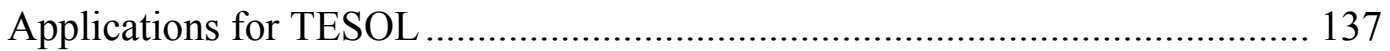

Directions for Future Study ......................................................................... 138

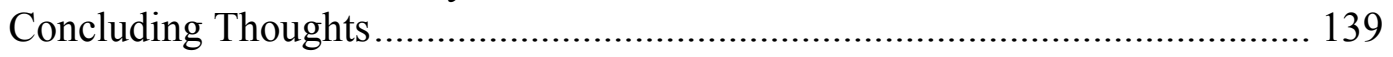

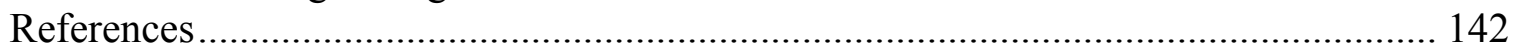

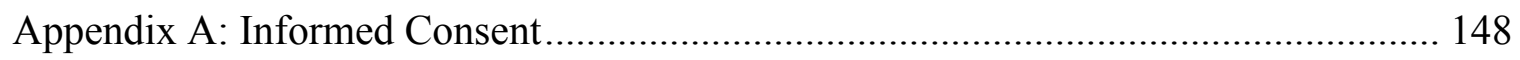

Appendix B: Demographic Questions ................................................................ 150

Appendix C: First Interview Questions ................................................................. 151

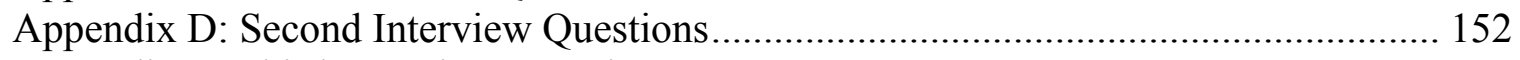

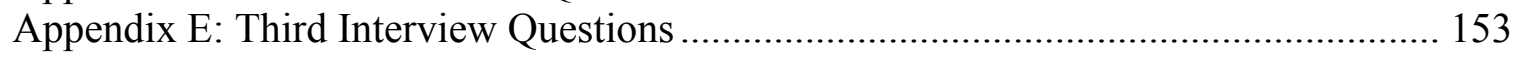




\section{List of Figures}

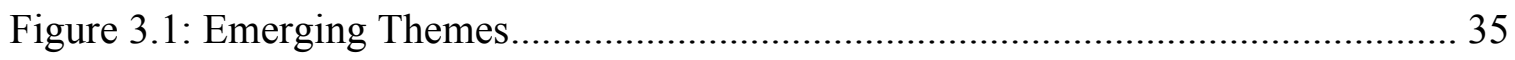

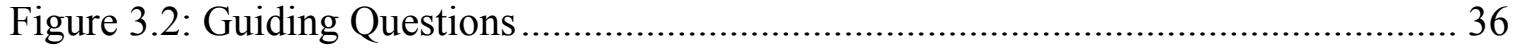




\section{Chapter 1: Introduction}

Globalization is progressively more "omnipresent" and, as Tapias (2008) has illustrated, a "global tsunami" is washing flows of people and information into new spaces transnationally (Ritzer \& Dean, 2015, p. 2; Tapias, 2008). The English language has acted as a vehicle for the transport of people and information. Historically, we have looked towards what Kachru terms "Inner Circle" countries, i.e. those where English has been the native language (U.K., U.S., Canada, Australia, New Zealand), to guide the training of teachers and delivery of English instruction (Kachru, 1985). Scholars within Applied Linguistics and English language teaching (ELT) argue that favoring the native speaker has created a division among not only what varieties of English are sought after

on the international market, but by doing so, ELT "has diverted attention away from the solution of urgent pedagogical questions and prevented the flourishing of local pedagogical initiative which could build on local strengths and linguistic realities" (Phillipson, 1992, p. 199). Still other academics within the field have argued that the privileging of the native speaker is beginning to diminish in these same settings (Braine, 1999; Paikeday, 1985). Other theoreticians have called for a move away from the negative terminology of native and non-native speaker, contending that such jargon calls for a division in labor practices (Butcher, 2005; Leung, Harris, \& Rampton, 1997).

It is widely accepted in English education that the differentiation between native and non-native English speaking teachers has created a division in class and in labor. Robert Phillipson coined the term "native speaker fallacy" to suggest that "the ideal teacher is a native speaker, somebody with native speaker proficiency in English who can serve as a model for the pupils" (Phillipson, 1992, p. 193). Relying on native speaker 
intuition and supposing that native English speaking teachers (NESTs) are the ideal models for English language learners drastically affects non-native English speaking teachers' (NNESTs) roles within ELT. Holliday explains that division between teachers "can be seen in many aspects of profession life, from employment policy to the presentation of language" (Holliday, 2006 p. 385). Other scholars understand that the subsequent divide between teachers has negative consequences on NNESTs, including less access to employment opportunities, fair wages and job security due to perceived differences in intelligibility and proficiency (Barry, 2011; Berns, 2005).

The international education model further problematizes which speakers should be the model for the growing number of non-native English speakers internationally. Western universities have placed themselves in a position of power by constructing themselves as being in the "center of the international student exchange network" (Chen \& Barnett, 2000, as cited in Devos, 2003, p. 161) that deciphers academic excellence. Moreover, English language education can be understood as a "site of struggle and identity revamping where knowledge about the cultural politics associated with colonialism, imperialism, modernity, development theories and globalization and about the powerful dichotomies of Self and Other is questioned" (Chowdhury \& Phan, 2014, p. 13). Thus, the essence of English education internationally should come under scrutiny in relation to its role in creating discriminatory practices.

In the United States, we have begun to direct legislation against those "aliens among us" who are perceived to be in the U. S. illegally or perceived to be taking jobs away from white, monolingual users of English (Castellanos, 1983; Canagarajah, 1999; Mckay \& Bokhorst-Heng, 2008; Oboler, 2010; Ruiz, 1988). Some academics have 
argued that a historic colonial relationship has been transferred to a neo-colonial relationship (Canagarajah, 1999; Holliday, 2006; Phillipson, 1992). One of the most recent examples of a discriminatory state-led policy occurred in the state of Arizona, where teachers who were reported to speak an accented variety of English were required to be removed from classrooms where there were students still learning how to speak the English language (Diniz de Figueiredo, 2011; Obobler, 2010). In this context, the ideal teacher of English continues to be a monolingual U.S. citizen, born and raised on American soil. But as demographics change, scholars have argued that a more diverse group of teachers should deliver instruction to diverse learners (McLaren \& Farahmandpur, 2004).

In the case of the NNESTs, English instruction can be shaped by the perception and identity inferred by creating a divide between teachers according to language variation. It has been noted that pre-service NNESTs feel anxiety and fear when they contemplate their overall language ability in comparison to NESTs (Greis, 1985). NNESTs are prone to feeling inferior to NESTs and sometimes in the English language teaching (ELT) context do not recognize that speaking the same native language as their students could be in their favor (Tang, 1997). Instead, NNESTs are often more concerned with their students' perceptions and opinions of their ability to teach English coherently with precision. Thus, NNESTs struggle with constructing and negotiating a positive identity within the English classroom (Amin, 1997).

As previous research has indicated, identity is a dynamic process that is both assigned and claimed (Varghese et al., 2005). The negotiation of identity is an ongoing process between the social positions that individuals claim for themselves and the social 
positions that are assigned by those they come in contact with (Blackledge \& Pavenko, 2001). In relation to English language education, teacher identities "develop in connection with the social contexts where they have learned, used and taught languages" (Menard-Warwick, 2014, p. 3). Thus, the construction of teacher identity has a direct correlation to the distinctions placed upon NNESTs perceived language differences because it situates the non-native speaker within a socially oppressive constructed identity (Pavlenko, 2003).

Almost completely absent from the debate have been the voices of non-native English teachers whose lived experiences inside the English language classroom are directly affected by the pillars of inequality that have been put in place by discriminatory practices in TESOL. Menard-Warwick reminds us that there are metaphoric "discursive faultlines" within English education "where tensions, stresses and collisions occur between discourses" that can dramatically impact critical English language pedagogies (Mendard-Warwick, 2014, p. 2). Few studies have sought to use ethnographic methods to create narratives of NNESTs living across cultural and linguistic barriers (Arva \& Medgyes, 1999; Dimova, 2011; Llurda and Huguet, 2003; Menard-Warwick, 2014).

This study explores the lives of two bilingual individuals whose first language is not English. They are both teachers of English to speakers of other languages. They are valued, successful, and independent. They are the future. Their individual lived histories serve to illustrate the complexities that NNESTs endure as English language professionals.

The current study consists of six chapters. In the second chapter, I discuss the existing literature on differentiation between native and non-native English speaking 
teachers, and present my guiding questions. In doing so, I illustrate that my research inquiry supports the documentation of NNESTs' narratives within English language education. In the third chapter, I describe the background of my study and the methods I used for the data collection and analysis. In the fourth and fifth chapter, I co-construct portraits of Jasmine and Anna (pseudonyms), noting how they have navigated their lives in two languages and two cultures. Furthermore, I visit Jasmine and Anna's teaching philosophies and how they perceive themselves in the eyes of others. In the sixth chapter I close with a discussion of my results, noting implications for TESOL and future areas for research. I conclude this study with the voices of Jasmine and Anna, who each shared a root-metaphor for their lives in two languages and a piece of advice for pre-service teachers. 


\section{Chapter 2: Literature Review}

\section{Introduction}

Over the past twenty years, Tapias (2008) has argued that we have seen a "global tsunami” of people and information washing into new spaces. The English language has been used as a medium to support these flows of people and information from one place to another. With the rise of English internationally comes a myriad of "cultural practices, ideologies and commodities ranging from free-market capitalism and neoliberal democracy to fast food and rap videos" (Menard-Warwick, 2014, p.1). For many scholars, the rise of English as an international language has created an overabundance of negative consequences that support Western dominance internationally and are hegemonic in practice (Pennycook, 2003; Phillipson, 1992). Western English standards have also drastically affected how English education is taught and idealize monolingual speaker English (Phillipson, 1992). The arguments over what varieties of English ought to be modeled in the English language classroom have brought with them a divide between native English speaking teachers (NESTs) and Non-native English speaking teachers (NNESTS). Almost absent from these debates have been the voices of NNESTs, who arguably are most affected within the English language classroom as their instruction and proficiency come into question (Phan, 2008; Menard-Warwick, 2014).

The purpose of this study is to explore the lived experiences of two Non-native English Speaking Teachers' (NNESTs) while they navigate their lives as comprehensible speakers of the English language. As the English language continues to spread globally, it is essential that the lived histories of NNESTs be documented to provide detailed accounts of what it means to be a bilingual speaker teaching English across linguistic and 
cultural borders. Driving this research is the belief that as English language educators increase their own awareness of language, culture and identity in relation to the documentation of NNESTs' personal narratives as cross-cultural informants, they will be able to make informed decisions about English language variation. Further, they will most likely ascribe to the ideas that the English language is a universal construct within an ever-changing world (Menard-Warwick, 2014; Ramanathan, 2005).

In this chapter, I outline the division between native and non-native English speaking teachers, noting the adverse effect the division has had within English language education. Next, I provide a contextual view of the World Englishes paradigm, illustrating how English has risen as lingua franca and how English has been categorized by the three circle model. Then, I visit the work of critical scholars (Canagarajah, 1999; Pennycook, 2003; Phillipson, 1992) who argue that English has systematically been used as a tool of the West to uphold colonial practices that are now deeply rooted new brand of neo-colonialism. Next, I look at the role of English education within the international education system, noting how the Western education model has constructed itself as the global provider of education and TESOL has been used to safeguard the education business model. Next, I discuss the relationship between English and the American education system, noting how the English-only agenda problematizes which varieties of English belong in the K-12 school. Finally, I discuss the connections between NNEST teacher identity and the sociopolitical underpinnings that create a sense of Othering in the English language classroom. While all of the above information pertaining to NNESTs is useful, there is still insufficient information about the lived experiences of NNESTs teaching in the ELT classroom. This literature review illustrates that there needs to be 
more documented accounts of the NNEST experience and this thesis serves to offer two individual portraits of Jasmine and Anna who have navigated their lives on a "discursive faultline" (Menard-Warwick, 2014).

\section{Differentiation Between English Teachers}

The differentiation between Native English Speaking Teachers (NESTs) and Non-native English Speaking Teachers (NNESTs) has become a predominant issue within the field of English Language Education (ELT). Robert Phillipson coined the term the "native speaker fallacy," to suggest that a distinction between NESTs and NNESTs was problematic internationally (Phillipson, 1992). His theory noted that within English education that there has been an inherent belief that in order to be a proficient teacher of the English language one must either be a native speaker or possess native-like fluency. This subsequent divide between NESTs and NNESTs has been supported by other theorists who have argued that NNESTs have less access to employment opportunities, fair wages and job security due to perceived differences in intelligibility and proficiency (Barry, 2011; Berns, 2005). Others scholars have noted that the perceived differences between the two classes of teachers has had a negative affect on NNESTs because it places an emphasis on Western varieties of spoken English, Western culture and Western teaching methodologies (Canagarajah, 1999; Holliday, 2006; Lui, 1999). Thus, native speakers of English are afforded the gift of the historical accident of which they were born: mother tongue and education give shape to this native speaker fallacy (Berns, 2005). This debate within the field of ELT between NESTs and NNESTs has pointed out the numerous ways in which NNESTs are treated as second-class citizens (Braine, 1999). 


\section{World Englishes and the Spread of English Internationally}

Scholars within the field of World Englishes have also distinguished between different varieties of English in order to illustrate that the English language is not bound solely to the dominant varieties' discourse displayed in the West. Furthermore, the English language serves many different roles within the international arena that are not tied to one variety of discourse (Kachru, 1985; Jenkins, 2009; McKay 2002). Today, the English language internationally either holds official or special status in over seventy countries; is spoken by over one fourth of the world's population; non-native speakers of English outnumber native speakers by three to one; and there are thirty countries that have a million or more speakers of English (Barry, 2011; Crystal, 1997; Graddol, 2006). It is proposed that non-native English speakers living outside of English speaking countries will use English to communicate with other non-native speakers more often than they will to communicate with native speakers (Graddol, 2006). The rise of English internationally will continue to bring with it a need for intercultural acceptance that can only be exhibited through recognizing different varieties of discourse as comprehensible and intelligible starting at the institutional level.

Braj Kachru's three circle model can best explain the rise of the English language and its role internationally. According to this model, the usage of the English language can be categorized into three concentric circles: the Inner Circle, the Outer Circle and the Expanding Circle (Kachru, 1992). For Kachru, the three circles, "represent the types of spread, the patterns of acquisition and the functional allocation of English in diverse cultural contexts" (Kachru, 1992, p. 356). Historically, there have been two dispersions of the English language. The first diaspora involved the migration of around 25,000 
people from the south and east of England primarily to America and Australia. This migration of people into these regions created "new mother-tongue varieties of English" (Jenkins, 2014, p.6). The first diaspora created the Inner Circle of English and is composed of the United States, Great Britain, Canada, Australia, and New Zealand. Today, the Inner Circle varieties of English now set the standard internationally for what an English speaker ought to sound like. Thus, Inner Circle speakers are often thought of as norm providing or setting the standard of what other speakers ought to sound like (Jenkins, 2009).

Demographically, the regions that compose the Outer Circle of English were created by the second diaspora of English, which occurred during the eighteenth and nineteenth centuries (Jenkins, 2009). The spread of English during the second diaspora is directly linked to Great Britain's imperial expansion into the continents of Africa and Asia. Today, the English language does not serve as the natal tongue, but is commonly used as a lingua franca within these complex and multilingual societies. The Outer Circle is composed of countries such as India, Singapore, and the Philippines. The third circle in the Three Circles Model is referred to as the Expanding Circle, which is comprised of countries where the English language has not played an historic or governmental role, but English is still extensively used as a medium for communication both domestically and internationally (Jenkins, 2009). Within the Expanding Circle, English is commonly studied as a foreign language (EFL) and English acts as a lingua franca (Jenkins 2009). Countries such as China, Japan and Russia make up the Expanding Circle, as well as the majority of European nations. What exactly these circles provide is not merely a way to interpret the different varieties of the English language, but to decipher which speakers 
are most sought after or which varieties of English continue to be the norm. The World Englishes paradigm clearly exemplifies why certain varieties of English are more favorable on the international market than others.

The World Englishes paradigm and Kachru's notion of three circles seek to remove the linguistic stigmas that create social categorization, stereotyping, ethnocentrism and Othering that occur among English speakers both inside and outside the ELT classroom. The work of Kachru tells us that the English language belongs to those who choose to use English as a medium for communication (Kachru, 1985). The implication is that non-native speakers should not be shunned due to the variety of English they speak nor should NNESTs experience differentiation in employment and as instructors. By moving away from social norms that build upon the dominant English discourses, ELT instructors are essentially developing a sense of intercultural competence inside the ELT classroom that supports the founding principles of Teaching English as an International Language (EIL).

As the role of ELT changes in order to meet the growing demand for English speakers internationally it is also necessary to question the traditional teaching practices that were once in place. Today, cultural sensitivity is being framed by a new approach in ELT known as Teaching English as an International Language, which upholds principles of cultural sensitivity, communicative competence and multilingualism (Matsuda \& Friedrich, 2011; Matsuda, 2012). Matsuda states:

The sociolinguistic landscape of the world presents a picture of English that is linguistically and culturally diverse, and the recognition of such diversity complicates the way we approach ELT, which traditionally constructed English as a more static and monolithic entity. (2012, p. 3) 
From this position, instructors within the field of ELT should reassess their current pedagogy so that it reflects the role of English as an International language while encompassing discourse communities outside of the dominant Inner Circle.

\section{The Critical Perspective}

Critical theorists within the field of Applied Linguistics find it difficult to hypothesize that the ELT structure is indeed moving away from teaching principles that do not incorporate different varieties of English and multilingual educators. Theorists such as Phillipson, Holliday, Pennycook and Canagarajah have argued that the English language and the rise of globalization has been a key factor in the West's hegemonic position throughout world history (Canagarajah, 1999; Holliday, 2006; Pennycook, 2003; Phillipson, 1992). Furthermore, these theorists maintain that ELT pushes the West's agenda through language education. Holliday coined the term "native-speakerism" and defines the division between the classes of teachers as:

A pervasive ideology within ELT, characterized by the belief that that 'nativespeaker' teachers represent a 'Western culture' from which spring the ideals both of the English language and of the English language teaching methodology. (2006, p. 385)

For Holliday, the predominant role of native-speakerism is apparent throughout the entire structure of the ELT education system. Native-speakerism is present in the way in which employment policy is designed and exists in the presentation of language, dictating how we teach and learn the English language. English education becomes an international commodity and is bought and sold on an international market and for those students who cannot study in an Inner Circle country, NESTs are exported to them and are defined as the ideal speaker. 
Alastair Pennycook has criticized the World Englishes paradigm noting that scholars within this field generally ascribe to the belief that the rise of English illustrates that the English language is becoming localized and thus, is creating different varieties of English across the globe. Pennycook argues that this perspective has its shortcomings, stating:

Indeed there is a constant insistence on the neutrality of English, a position that avoids all the crucial concerns about both the global and local politics of language. Furthermore, by focusing on the standardization of local versions of English, the World Englishes paradigm shifts the locus of control but not its nature, and by doing so ignores power and struggle in language. (2007, p. 9)

Thus, for Pennycook the definitive effect of globalization on the use of the English language cannot be defined by either homogenization or heterogenization but by "a fluid mixture of cultural heritage" and the predominant "popular culture" that is integrated into the change of tradition across that encompasses ethnic affiliation, global appropriations and local contextualization, (Pennycook, 2003, p. 10). From Pennycook's perspective, the English language has strategically been employed as a tool of oppression. His interpretation of the role of English within society differs from Crystal (1997), who interprets English's predominance and pervasiveness as a positive characteristic of globalization.

In relation to TESOL and the international education model, the English language has become a part of the West's pursuit to construct itself as the global provider of academic excellence. International education is intrinsically linked to globalization as it provides a rationale for the flows of people and information from one part of the world to another. During the 2010-2011 academic school year the United States grossed nearly 22.7 billion dollars from international students alone, illustrating that international 
education is a global business that brings in high dividends (Chowdhury \& Phan, 2014). The rise of the English language as a lingua franca has brought with it unequal ownership of the language, which in turn creates a disunion between Inner Circle varieties of English, and the Outer and Expanding Circle varieties. The English-speaking West holds soft power over its former colonies and this is exemplified through the English education model. As the former colonizers who mandated the English language into government, the Inner Circle countries still choose which standard of English ought to be recognized as superior and used as the educational model (Phillipson, 1992). Countries within the Expanding and Outer Circles generally accept that the Western standard of English is superior and will export students to learn Western varieties of English, while importing native speakers to teach students domestically (Canagarajah, 2005; Chowdhury \& Phan, 2014; Pennycook, 1998, 2001, 2003; Phillipson, 1992). The media also supports market abuse and exploitation within English education as it implicitly illustrates what variety of English should be the model. American films highlight what some categorize as neutralized English dialect and create a sense that standard American English ought to be the model (Chowdhury \& Phan, 2014; Pennycook, 2003).

Placing an emphasis on the Western varieties of English along with the Western education model supports the differentiation of NESTS and NNESTs because it places an emphasis not only on Western varieties of spoken English, but also on Western culture, and Western teaching methodologies (Canagarajah, 1999; Chowdhury \& Phan, 2014; Holliday, 2006; Lui, 1999). The prevalent question is whose variety of English will set the standard for language learners and how will this directly affect the identity and 
perception of NNESTs as they provide instruction for the next generation of English speakers?

\section{The American Education System and the English Debate}

In the context of the United States, the debate about which varieties of English belong in the ELT classroom is apparent within bilingual education programs across the country. There have been several studies that illustrate the adverse effects the native speaker fallacy has within institutional policies (Canagarajah, 1999; Lui, 1999). The United States does not have a national language policy and by not having an official language creates a space of contention regarding the role of English as a national, uniforming language. Furthermore, without an official status, the English language serves to subjugate what languages ought to be deemed appropriate in the K-12 classroom along with what varieties are acceptable for students to hear and learn inside the classroom. One example of a state-imposed policy was recently documented in the state of Arizona which noted that teachers who spoke an accented variety of English were required by the law to be removed from classrooms where English language learners were present (Diniz de Figueiredo, 2011; Oboler, 2010).

According to proponents of the English-only campaigns, bilingual education programs should transition English language learners into monolingual English speakers (McKay \& Bokhorst-Heng, 2008). The two most profound issues within the public sphere include the English-Only movement and bilingual education. According to McKay and Bokhorst-Heng, there has been a general reluctance to have an official language policy in the United States; however since the 1980's there has been a slow shift towards establishing English as the official language of the United States. Now 
deceased, Samuel I. Hayakawa, a Republican senator who served during the Reagan administration, influenced this shift by proposing a constitutional amendment known as Senator Joint Resolution 72 on April 27, 1981. The goal of the amendment was to declare English as the official language of the United States. McKay and Bokhorst-Heng state that:

The amendment would have allowed languages other than English to be used in "educational instruction" and as a "transitional method of making students who use a language other than English proficient in English." (McKay and BokhorstHeng, 2008, p.98)

While Senator Joint Resolution 72 did not pass, numerous states passed legislation to declare English their official language. Only Hawaii and New Mexico have dual official languages. As of the writing of this thesis, legislation is on the books to make English Oregon's official language.

Bilingual education in the United States has constantly been under attack politically. This can be clearly demonstrated by the Bilingual Educational Act of 1968 (BEA). BEA sought to address the educational needs of non-native English speaking children by providing instruction both in English, as well as in the student's native language. By 1974, BEA was amended to narrow its definition. BEA stated that children would be taught in their L1, "to the extent necessary to allow a child to progress effectively through the education system," (Castellanos, 1983, p. 120). However, this definition has caused a battle among educators, scholars and politicians. The real issue here is not merely the fact that all minority language speakers should benefit from equal education, but rather that controversy circles around the use of minority languages in the bilingual classroom (McKay \& Bokhorst-Heng, 2008). Opponents of bilingual education 
generally perceive ethnic pride and consciousness as impairing students from being able to gain proficiency in English (McKay \& Bokhorst-Heng, 2008). Also, opponents of bilingual education commonly are supporters of the English-only movement within the American education system; thus they understand the goal of bilingual education as a move towards language assimilation or monolingualism (McKay \& Bokhorst-Heng, 2008). The English-only movement supports what Phillipson refers to as "the monolingual bias" (Phillipson, 1992). Thus, opponents of bilingual education have rarely considered what it must be like to learn and teach within a bilingual environment nor do they consider what would happen without teacher support in the students' L2. All of these nuances and debates within the educational system reinforce the native speaker fallacy, the notion that that the standard of English ought to match a variety that is in sync the predominant variety of English and is best taught by a monolingual teacher.

Lawmakers need to be reminded that it is unrealistic to infer that a teacher's accent in the English language classroom will inhibit a student's ability to learn how to speak the English language proficiently. The apparent divide between what varieties of English are acceptable and which speakers are incomprehensible creates a divide within the education system and has an adverse affect on students and teachers alike. By creating a division between English dialects, the education systems is essentially upholding which speakers should be thought of as models and which speakers are inferior. This in turn allows for the construction of negative stigmas to be placed upon non-native speakers who speak non norm-providing varieties of English. It is no wonder that NNESTs often self-discriminate and second-guess their position as comprehensible speakers with an important place in the ELT classroom. This also feeds into the idea that 
NNESTs are often misrepresented as ineffective teachers or as incompetent speakers of the English language.

Education policies in the United States and abroad solidify how problematic the idea of a native-speaker is within the educational system. However, theorists like Thomas M. Paikeday try to remind us that the idea of a native speaker is as elusive concept as the notion of the abominable snowman (Paikeday, 1985). In his book entitled, The Native Speaker is Dead, Paikeday dissects the term native speaker, noting that the true meaning of a native speaker is not someone whose first language is necessarily English but is a "proficient user of the language" (Paikeday, 1985, p. 84). From this position, language competence, comprehensibility and intelligibility have little if anything to do with being a native speaker. This bias within ELT has created a divide within the workforce that reinforces the idea that NESTs and NNESTs are different from one another based on the variety of English they speak. It should be duly noted that every speaker of English, regardless of his or her country of origin, still speaks an accented version of English, as there is not an un-accented variety of English. Therefore, the notion of a native speaker is based on rhetorical ideologies that supplement the need for a differentiation between language variation and furthermore the preferred English-speaking role model for the ELT classroom.

\section{Teacher Differentiation and the Construction of Identity}

In the context of ELT education, the discussion of native vs. non-native speaker continues to have negative implications on the identity of NNESTs internationally. More clearly, the division between native and non-native speaker and their implications for identity issues in particular have been considered problematic by several scholars within 
the fields of Applied Linguistics and TESOL. Simply the terminology native and nonnative indicates that there is a perceived difference among speakers as it puts in place a national identity that separates groups of speakers (Butcher, 2005; Diniz de Figueiredo, 2011; Leung, Harris and Rampton, 1997). Scholars such as Leung, Harris and Rampton (1997) have sought to move away from denoting differences in teachers' English variation noting that the terminology "native" and "non-native" creates a subsequent divide that is extremely problematic noting:

Members of minority groups are not simple inheritors of fixed identities, ethnicities, cultures and languages but are instead engaged in a continual collective and individual process of making, remaking, and negotiating these elements. (Leung, Harris, \& Rampton, 1997, p. 547)

Because identity is not fixed and is a dynamic and ongoing process that is affected by others' perception in the socialization process (Jackson, 2014) it becomes apparent that the division between classes of teachers continues to hinder one's self-perception. It is important to note that identity is both avowed and ascribed, meaning that identity is constantly being renegotiated through both verbal and nonverbal discourse (Jackson, 2014; Oetzel, 2009). Individuals take on a particular identity (avowed) that may or may not match the identity they are given by others (ascribed). Similarly, Leung, Harris and Rampton (1997) believe that terminology such as native and non-native speaker can have adverse effects on teachers' perceptions of self. Leung, Harris and Rampton argue that instead of using terms such as native speaker to signify which teachers should be sought after, that professionals within ELT "should be concerned with the question about language expertise, language inheritance, and language affiliation” (1997, p. 543). Thus, 
by moving away from problematic definitions, ELT professionals can move towards a more comprehensive understanding of English education.

Relatively few studies within the field of ELT have investigated the relationship between NNESTs perception of self and anxiety within the ESL classroom. One of these studies indicated that pre-service NNESTs self-reported a sense of fear and anxiety in relation to how they believe their students perceive their non-nativeness. Greis noted that all pre-service teachers experience anxiety, but the degree to which teachers feel anxious multiplies stating:

Anxiety may be felt by any beginning teacher, whether native of non-native. However, when put next to native speaker, the non-NETs \{non-native ESOL trainees $\}$ often experience a strong sense of fear that they will not attain the same level of proficiency and that the ESL students may reject them preferring a native speaker as a teacher. $(1985$, p. 318$)$

For pre-service NNESTs, teaching English in the classroom poses another threat of not being fully competent speakers of the English language or a feeling of lacking a skillset that demonstrates command over the language.

It has also been indicated in previous research that NNESTs tend to feel inferior to their NESTs counterparts. Tang argues that NNESTS can feel a certain degree of "threatened confidence and authority" regardless of the possible advantages they have due to sharing the same native language as their students (1997, p. 578). Amin reinforced the idea of "threatened confidence and authority," (1997, p 578) stating that NNESTs often believe that they may lack authority in the English language classroom due to their students opinions that only a native speaker truly can speak English properly. For Amin:

When the students give the message that they consider their teacher to be a nonnative speaker of English and therefore on who cannot teach them the English 
they want of feel they need, minority teacher are unable to effectively negotiate a teacher identity. (1997 p. 581)

The negative perception of self therefore can create self-discrimination that has the ability to hinder a teacher's ability in and outside of the classroom. The NNEST's own selfperception can influence how he or she believes others perceive them and can have an adverse affect not only on the NNEST but also on the students, who not only need English instruction, but a role model within the acquisition process.

Amin, like many scholars, also asserts that race is a key component in the NNEST struggle. Amin argues that there is a direct correlation between being a white and being perceived as a native speaker, which influences how non-white teachers are perceived and treated their language learners (Amin, 1997). Kubota and Lin also believe that racial discrimination is associated with language differentiation within ELT. For Kubota and Lin, by pairing the NESTs with whiteness and NNESTs with non-whiteness supports "the discrimination experienced by teachers who do not fit this formula" (Kubota \& Lin, 2009, p. 8), which also includes native English speakers of English who do not have Anglo features or may speak varieties of English from the dominant West but to not possess that predominant spoken discourse. Racism within ELT has the potential to reinforce negative perceptions of self.

Teacher identity is deeply ingrained into how individuals subjectively understand who they are and their placement in society (Varghese et al., 2005). The construction of social and occupational identity is directly related to the distinctions placed upon NNESTs in the classroom because of the implied notion that being a member of a different class produces a socially oppressive constructed identity (Pavlenko, 2003). 
Occupational identity can be defined as the process by which a person learns to adopt, develop and display the actions and behaviors typical of and unique to a specific profession (Isbell, 2008; Merton, 1957). Since occupational identity is a social process that is negotiated, colleagues, administrators and students can potentially challenge their teacher's identity intentionally and unintentionally. However, as Lui (1999) points out, "people can have multiple social identities." These identities can change with new experiences and new social interactions, according to people's needs and their readiness to "accept how they are perceived by others" (Lui, 1999, p. 95). Thus it can be concluded that individual socially constructed identity can either tear away at an individual's selfworth or reaffirm personal strengths inside the classroom.

Limited studies have drawn upon qualitative methods to investigate NNESTs perception of self in the ELT classroom. Fewer studies have explored the role of language proficiency and English variation and English instruction in relation to NNEST identity (Arva and Medgyes, 1999; Dimova, 2011; Llurda and Huguet, 2003; MenardWardwick, 2014). One of these studies (Dimova, 2011) investigated the teaching behaviors of Macedonian NNESTs and analyzed differences in teaching behavior noting that even though, "Macedonian NNESTs rated their English proficiency high, they expressed their uncertainties of feelings of inferiority, comparing themselves to native speakers" (Dimova, 2011, p. 80). Most recently Menard-Warwick (2014) explored the development of teacher identity through interviews and observation and argues that there are "discursive faultlines" that affect teacher identity and the cultural pedagogies that are enacted in their classrooms. This current study follows the same faultlines, posing questions that relate directly to social and teacher identity in the classroom. This study 
draws from previous research that has focused on teaching behaviors, self-perception and identity in the English as a foreign language context in order to explore the subjective understanding of two NNESTs of self across cultural and linguistic borders.

\section{Current Study}

The objective of the present study is to understand how NNESTs working in the American education system perceive their identities in relation to their experiences teaching in their home country, studying in the American education system, their current teaching environment, their relationships with coworkers and administrators and how they believe their students perceive them as English educators. For the purpose of this investigation, identity will be defined two ways: (1) avowed identity which refers to "the process of telling others what identity(ies) you wish to present or how you see yourself;" and (2) ascribed identity, which signifies "the process of assigning in another person what you think his or her identity should be" (Oetzel, 2009, p. 62). Thus, identity is understood as a social process of continual negotiation with the self and with others. These fluid ways of interpreting social and teacher identity will be used to explore the lived histories of two NNESTs teaching English in the Pacific Northwest. In order to paint individual portraits of Jasmine and Anna (pseudonyms) as bilingual speakers whose first language is not English, it is necessary to investigate how they understand their individual identity in relation to their perception of self, and how they believe their students and colleagues perceive their NNEST status by employing the following guiding questions as indicated by the previous work of Arva and Medgyes (1999), Dimova (2011), and MenardWarwick (2014): 
1. How do NNESTs understand their teaching philosophies and practices inside the English language classroom?

2. How do NNESTs understand how their language proficiency and variety of English affects how they teach English (in relation to others perspectives of them as intelligible speakers of English)?

3. How do NNESTs understand their identity as English language teachers? 


\section{Chapter 3: Research Design}

\section{Introduction}

This chapter describes the research methodology as well as the criteria used to determine trustworthiness of the research design. It is organized into the following sections: guiding principles, purpose and significance of the study; guiding research questions; participant selection; site selection; data collection (including the survey, interviews, and field notes); transcription process, coding, and finally, trustworthiness. In the coming pages, I address the qualitative methodology I used to conduct this research by covering how the data for this paper were collected to ensure that trustworthiness and rigor were upheld throughout the entire process.

\section{Guiding Principles}

In order to explore the life histories of two NNESTs, a qualitative design was employed because of its ability to provide complex and textual descriptions of personal histories, while taking into account an arguably more humanistic understanding of its participants.

\section{Study's Purpose}

The purpose of examining some dimensions of the lived experiences of two NNESTs is to explore how language and bilinguality affect professional English language educators' sense of self. Specifically, this study is concerned with the way in which two NNESTs perceive their social and teacher identity in relation to being multilingual speakers teaching English. NNEST teacher identity is an underexplored topic within the field of TESOL. Relatively few studies have sought to explore the role of social and occupational identity of teachers (Arva \& Medgyes, 1999; Dimova, 2011; 
Menard-Warwick, 2014). This study attempts to explore how these two participants describe and interpret their roles and positions as NNESTs. Specifically this study is concerned with the way in which the participants' attitudes and beliefs are influenced by how they view themselves as instructors. Qualitative research will allow me to investigate the multiple constructed realities of each participant in a holistic manner through the implementation of interviews and observations. Thus, this study seeks to explore the tacit knowledge and subjective understandings of two NNESTs' lived experience through exploring the process of social identity.

\section{Study's Significance}

It is hoped that this study will increase the TESOL community's knowledge about NNESTs in relation to teacher self-perception and identity. It is also hoped that this study may be useful to teacher educators by examining how NNESTs articulate their teaching philosophies and approaches to teaching. In addition, this study has sought to add more authentic accounts of what the lived experience of NNESTs are and to explore the degree to which these academic structures promote inequality.

\section{The Research Design}

In order to explore the life histories of the two participants, this study has been designed a two individual case studies. For the purpose of this study, all the data that was collected came in the form of interviews. The research questions sought to explore how the participants perceive themselves as English language educators in relation to their cultural and linguistic background as bilingual speakers. The interviews sought to go deeper into the teacher paradigm by exploring pedagogy, teaching approaches and practices, and the role of language variation in the classroom. I relied on the participants 
to explain and elaborate on their experiences throughout each interview to provide insight about the identified categories and other categories that have emerged during the data collection process.

\section{Guiding Questions}

The guiding questions sought to explore the participants' subjective understanding of their role as English teachers in relation to their teaching philosophies, pedagogical beliefs, and lived experiences as illustrated below. The following three guiding questions are repeated from chapter two for reader convenience and provide individual portraits of the participant's understanding of themselves in relation to their academic professions as indicated by the previous work of Arva and Medgyes (1999), Dimova (2011), and Menard-Warwick (2014).

1. How do NNESTs understand their teaching philosophies and practices inside the English language classroom?

2. How do NNESTs understand how their language proficiency and variety of English affects how they teach English (in relation to others perspectives of them as intelligible speakers of English)?

3. How do NNESTs understand their identity as English language teachers?

\section{Participant Selection}

The two participants that were selected for this study are NNESTs teaching English as a Second Language to adult language learners at two higher education institutions located in the Pacific Northwest. The participants were primarily selected due to their willingness to participate in the study, along with their overall command, proficiency and expertise working in English language education. As illustrated in the 
upcoming chapters, the life histories of each of the participants are very different, yet they share a similar historic background.

Both Anna and Jasmine (pseudonyms) are women from Latin American and they share the same nationality and native language. Though they vary in age, they were born in the same province and have taught English both in their home country and in the United States. They have also each completed at least a Master of Arts in TESOL while residing in the United States. Each participant has taught English for over a ten-year period. They have worked in a variety of different educational contexts, with individuals with different levels of English proficiency and ages. Though Anna and Jasmine share many similarities, their lived experiences illustrate who they are as individuals and as teachers.

\section{Site Selection}

Interviews were conducted at two different higher education institutions in a metropolitan area located in the Pacific Northwest. Both of these sites are state-accredited public institutions that have English as a Second Language Programs (ESL). These two sites have been chosen due to the proximity, direct access to participants, and permission to conduct the study by the chair of each ESL department.

In order to protect the anonymity of the participants, limited information will be revealed about the two sites. One of the two sites for this study is a university that has an intensive language program offering various English programs including pre-entry English courses and academic preparation for undergraduates and graduate students. 
The other site selected for this study is a two-year community college that has an ESOL program for adult learners offering courses ranging from preliterate education to advanced English language instruction.

\section{The Survey}

The two participants for this study were asked to complete a short survey composed of eleven questions. The survey questions were derived from the previous work of Arva and Medgyes (2000). The questions were demographic in nature and provided background information prior to the interview process, thus allowing me to make maximum use of my time with each participant. I felt that in order to gain an understanding of the participants' positions as teachers, I needed to gather some information on who they were as professional educators without detracting from the interview process. Questions in this survey included highest level of education completed, time working in the field, participation in in-service training, number of classes taught per term, class levels taught, work history, home country and languages spoken (See Appendix B).

\section{Semi-structured Interviews}

I conducted a set of three interviews per participant with roughly one week between the first and second interview and two weeks between the second and third interview. The first interview sought to explore how the participants understand themselves as teachers and how this has changed over the course of their careers, both teaching in their home country and in the United States. The initial interview also had a component that asked the participants to draw a graphic that illustrated their language life history. Though, this detail was of great interest to me as a researcher, the participants 
seemed uncomfortable with the drawing element and this piece of the data collection was eliminated from the following interviews.

The following two interviews were designed around the emerging categories that surfaced during the first interview, while integrating the guiding questions throughout the interview process. Each interview consisted of six questions. The duration of the interviews varied between forty-five minutes to an hour and a half. The interviews were audio-recorded on two separate devices in order to ensure that data would not be lost. After recording devices were turned on, they were placed outside of direct view. This step was taken in hopes that the participants would feel secure and be able to speak in a natural setting and without the continual reminder that they were being recorded.

The first two interviews occurred bi-weekly in order to ensure that I had sufficient time to complete thorough transcriptions. The final interview was spaced three weeks after the second interview. This was intentionally crafted so that there would be ample time for reflection by both the researcher and the participant. Furthermore, the spacing of the interviews gave me time to begin sifting through the interviews in order to look for emerging themes and choose to revisit areas that had not yet been addressed.

The initial interview sought to address how each participant viewed their life as a user of two languages and navigated through the use of language and instruction in their home country and in the United States. This structure provided a framework for the entire interview process, as I was able to better understand their perception of self in these various contexts. In preparation for the second interview, I reviewed the transcripts from the previous interview to decide what areas that I wanted to explore or expand on in the second interview. The second interview crossed into a few different themes including 
how each participant viewed themself as a language educator in their home country and in the United States, how their teaching practices changed after completing professional education programs and how others perceive them in relation to their bilinguality. After the second interview, I followed a similar process. I reviewed the transcripts and looked for areas that needed to be explicated in the final interview. The final interview sought to bring the interview process full circle by looking at the role of different variations of English in the English language classroom, and what each participant wanted their students to understand about fluency, accuracy and intelligibility. This interview gave the participants a chance to reflect on their position as English language educators as they were asked if they had any advice that they would want to share with other pre-service teachers.

\section{Field Notes}

For this study, field notes were an essential part of the data collection process. Note taking occurred two times for each interview. As an active participant in the interview, I chose to take very loose notes during the interview process. My rationale for this was twofold. First, due to the nature of the interviews, I wanted my participants to feel as comfortable as possible, so that the interviews felt similar to a natural conversation with a friend or colleague. By not writing extensively in front of them, I kept the conversation more authentic. Similarly, I wanted to move away from the formulaic interviewer/interviewee paradigm to establish an atmosphere that allowed my participants to create speak openly and causally about their experiences as NNESTs.

Within one to two hours after each interview, I allotted myself a one-hour period to articulate my experiences in the interview. This allowed me to reflect on the interview 
while it was still fresh in my mind. However, it should be noted that this part of the notetaking process was heavily influenced by my perceptions and that is why I incorporated a third field note element. This aspect was of extreme importance to me as a researcher. In an article for the Journal of Marriage and Family, sociologist Annette Lareau (2012) wrote a critical reflection about the problems she encountered as a doctoral candidate working on her dissertation. Lareau's words would be interpreted as a warning for all novice researchers and before structuring my study, I revisited her work. What stood out from her article was the premise that a researcher should not enter the field without the guarantee of completing field notes within seventy-two hours of the interview. Lareau's words of caution also propelled the final step of my field notes as described below.

Again, following Lareau's words of advice, the second step of the note-taking process always occurred within twenty-four to seventy-two hours after each interview. Within this period, I listened to the audio from the interview and revisited both sets of my notes (the notes I took during the interview and the notes I took within one to two hours of the interviews). After revisiting all of the material, I condensed my initial notes and often tried to systematically think about the direction for the upcoming interview. This third component was essential to overall understanding of the interview at hand, because it allowed me, as the researcher, to revisit materials with a new understanding. In essence, creating a three-step field note process allowed me to gain a deeper understanding of the data before transcribing. Thus, I was able to submerge myself within the data and gain a greater understanding of it. It also should be noted that I chose to write all of my field notes by hand in two separate notebooks, one for each participant. This allowed me to maintain a personal connection to each speaker. By keeping two separate journals, I was 
able to keep separate logs of each participant and therefore I did not weave together their personal narratives. These decisions shaped the way I viewed the process of taking concise field notes. In doing so, I was also able to gain a certain confidence in the overall process by adhering to my own set of strict guidelines.

\section{Transcribing}

In order to ensure that transcriptions were completed in a timely fashion, the interviews were conducted at least one week apart from one another. This allowed ample time for each interview to be fully transcribed prior to conducting the subsequent interviews. It was also necessary for transcriptions to be completed before each subsequent interview, as both participants' responses in the previous interviews led to the

next stage of inquiry. Due to the nature of this ethnographic account, the $2^{\text {nd }}$ and $3^{\text {rd }}$ interviews were used to revisit themes in the previous interview and build upon the participants' previous explorations of self. In order to draft the next interview questions my advisor requested copies of both participants' transcriptions in order to collaboratively construct questions that revisited emerging themes in the participants' responses while moving in the direction of the guiding questions. As a novice researcher, I was able to improve my skills as an interviewer and become more immersed in previous knowledge and the current project. In doing so, I was able to understand how the life histories of Anna and Jasmine illustrated previous findings while their authentic accounts also provided a glimpse into gaps in the research.

\section{Interpreting the Data}

The data from this study have been analyzed using grounded theory and have drawn from previous research on teaching behaviors, self-perception and identity in 
English language education (Arva \& Medgyes, 1999; Dimova, 2011). As previously mentioned, this study consisted of a three-part interview analysis. After each interview, I reviewed the transcripts line-by-line with my advisor to look for emerging categories. This allowed each participant's personal narrative to be compared and contrasted with her own subjective understandings of self in relation to past and present teaching perceptions, and in relation to their identity as teachers and bilingual speakers. We are also able to see the stark similarities and differences between the participants. Reviewing the emerging themes prior to the following interview provided the foundation for the upcoming interview.

Once all interview data were collected and transcribed, I coded each participant's words individually. In order to complete the first step of the coding process, I chose one speaker to focus my analysis on. Then, I worked through each interview individually coding line-by-line in order to look for emerging themes while compiling short memos. These short memos were the beginning of emerging themes that would later become encrypted inside of the participant's individual codebook (Charmaz, 2006). After the completion of initial codes for each individual interview, short memos were reviewed and transcribed into codes that represented underlining themes that could group ideas together. This process became the basis of analysis for the codebook. Each codebook was created in a Word document. I used the review panel along with track changes to write memos in the margins of the text and I color-coded the themes as they emerged. In doing so, I was able to paraphrase the participants' responses and track when different themes emerged in the interviews. These themes are shown in figure 3.2. 
Once the individual codebooks were in place for each participant, a separate analysis was conducted to identify similarities and differences between participants. The initial themes created a semiotic pattern, which became the foundation of each participant's individual portrait, and though their experiences, perceptions, and understandings differ at times, the overall structure of Chapter Four and Chapter Five mirror one another to provide a contextual understanding of each participants' lived experience a NNEST.

The analysis of the interviews has occurred inductively; however some of the preliminary codes were predetermined by the work of Arva and Medgyes (1999) and Dimova (2011). In doing so, I was able to make some conscious decisions about the role of the guiding questions and categories that had emerged in similar studies. After themes emerged through my discussion with both Kimberley Brown and Priya Kapoor, I looked for those themes in the subsequent analyses:

Figure 3.1: Emerging Themes

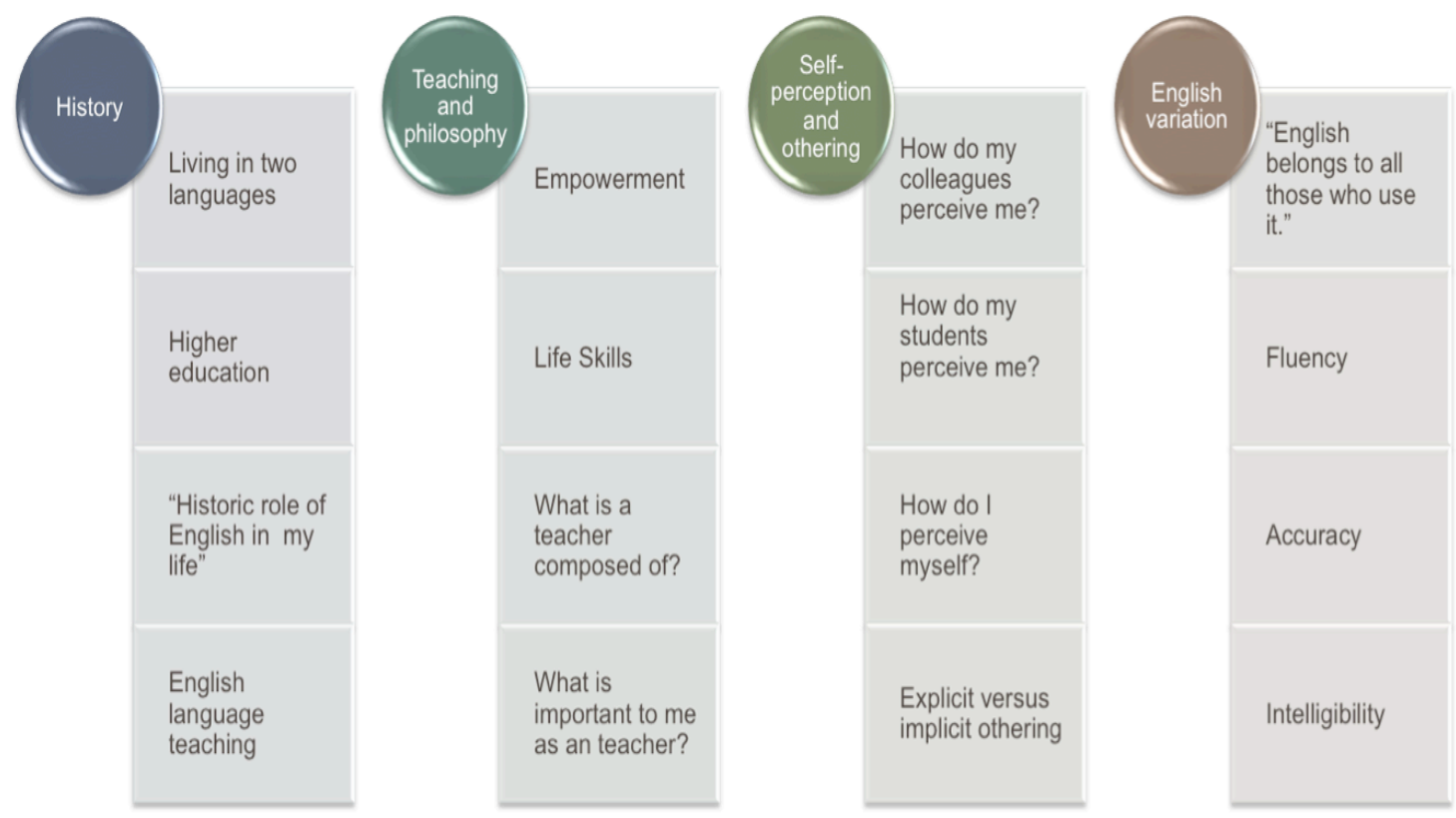


The preliminary analysis looked for emerging themes in the follow areas (figure 3.2):

Figure 3.2: Guiding Questions

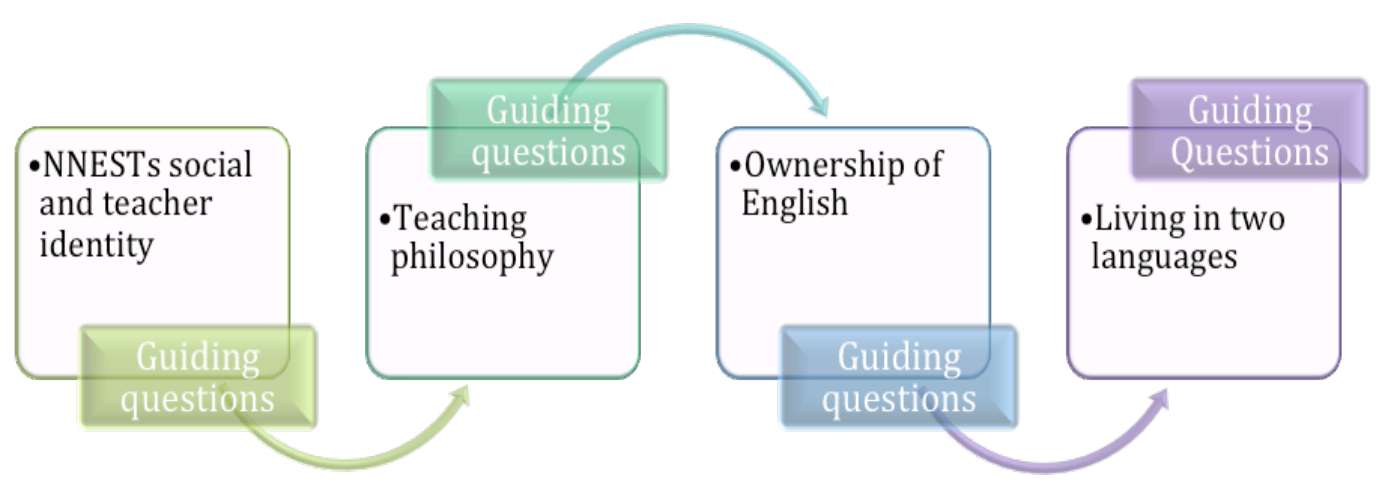

The rationale to use these preliminary codes is twofold. First, due to the subject manner and the structure of the guiding questions, these codes supported areas being explored throughout the interview process. Secondly, this current study was based on similar studies, which explored NNESTs' interpretation of identity as teachers in relation to others' perceptions. Having described the research process I followed, it now becomes possible to focus on aspects of ethics and trustworthiness.

\section{Trustworthiness}

The typical quantitative dimensions of reliability and validity are best satisfied in this qualitative study by Lincoln and Guba's (1985) evaluative criteria for establishing trustworthiness: credibility, transferability, dependability and confirmability. Credibility seeks to build confidence in the truth of the findings. Transferability illustrates that the findings have applicability in other contexts. Dependability shows that the findings are 
consistent and could potentially be repeated. Finally, confirmability is concerned with the degree of neutrality, or the extent to which the findings of a study are shaped by the respondents and are not influenced by researcher bias or self-interest (Lincoln \& Guba, 1985).

For the purpose of this study, credibility, or the confidence in the truth of findings, has been established through member-checking. Throughout the interview process, the participants have had access to all collected materials and have been provided full text transcriptions of the interviews. After carefully selecting excerpts for this study, the quotations were sent to each participant in order to confirm that their voices were authentic and represent their lived experience inside the ESOL classroom. Additionally, the participants could object to any of the findings if they chose. This process also allowed me to clarify any lingering questions I may have had during the writing process and ensure the truthfulness of my findings.

From the perspective of Lincoln and Guba (1985), transferability can be thought of as a way of achieving a type of external validity that describes a phenomenon with thick, rich description (Menard-Warwick, 2014). The next three chapters have been designed to provide detailed portraits of the participants' lives. In order to illustrate dependability, this study drew upon the previous work of Arva and Medgyes (1999) and Dimova (2011) to exemplify how previous findings have applicability in other contexts.

Confirmability is concerned neutrality, or the manner in which the findings of the study are shaped by the participants' responses. Confirmability was maintained by having two faculty members with different specializations mentor me during the writing process. My thesis advisor, Dr. Kimberley Brown, is a teacher-trainer and works within in the 
field of Applied Linguistics. She has a keen understanding about ELT and the role of NNESTs. Dr. Priya Kapoor, is a professional ethnographer whose primary area of research is within the field of Communication. Dr. Kapoor's position as an ethnographer, as well as position outside of the field of Applied Linguistics lends to the credibility of the findings.

By being mindful of Lincoln and Guba's evaluative criteria for establishing trustworthiness, I have sought to craft a study that upholds qualitative ethics. I have purposely been transparent throughout the writing process and have shared all aspects of the data collection with the two participants. I have sought advice and guidance from two professional qualitative researchers and have structured the design of this study around key principles in qualitative research. It also should be noted that this study has incorporated the use of multiple theoretical lenses in order to gain a balanced interpretation of each participant's view of self inside the classroom including World Englishes, Language and Intercultural Communication, and Critical Applied Linguistics.

\section{Limitations of the Study}

One of the most obvious limitations of this study is its sample size. Findings are not generalizable to other settings and conditions. A second limitation is all data collected for this study was self-reported; there was no triangulation with observation or use for example of written artifacts such as lesson plans. Again due to time constraints, classroom observations were not included in the methodology. A full-scale ethnography was beyond the scope of this M.A. thesis project.

Chapter Four presents a portrait of Anna and Chapter Five presents a portrait of Jasmine. I have chosen to keep these profiles separate in order to capture the integrity of 
each participant's life history. Thus, each chapter provides a forum for each speaker to articulate their individual lives as NNEST navigating between cultural and linguistic barriers. In each of these chapters, information from the three interviews with Anna and Jasmine is interwoven in order to present a panoramic view of their lives as cultural agents and bilingual speakers. Following the presentation of portraits in these chapters, discussion of findings and commonalities between the subjects is examined in Chapter Six. 


\section{Chapter 4: Jasmine's Portrait as an English Language Teacher}

\section{Introduction}

This chapter presents a portrait of my participant Jasmine, as an English teacher and an English learner who continues to navigate her life across cultural and linguistic borders. The coming subsections incorporate Jasmine's description of her relationship to English as a learner and as a teacher, her commitment to education, and how she perceives her life experiences as an ESL teacher. The first section details the historical role English has played within Jasmine's life. The next section explores Jasmine's life living in two languages, noting how her perception of self as a bilingual speaker has shifted while living between two linguistic borders. The third and fourth sections of this chapter are concerned with how Jasmine understands the role of English education throughout her life and provide a contextual framework to Jasmine's interpretation of English language education in her home country and in the United States. The fifth section of this chapter builds upon Jasmine's understanding of self as it looks at how she perceives herself today as an English teacher and how she upholds particular standards in her teaching philosophy. The sixth section explores Jasmine's interpretation of self in relation to how she believes others see her as a colleague, as a teacher, and as a bilingual speaker. In the seventh and final section of this chapter, I look at Jasmine's thoughts on fluency, accuracy and intelligibility and how these relate to the World Englishes paradigm. 
The History of English in My Life

Jasmine strongly identifies as a teacher. Her love of the education system is apparent in everything she does and all of her life choices reflect her commitment to English education. Jasmine believes that through educating others she has the ability to change individual lives. She trusts that English education can be a tool of empowerment and that a life of service is as equally enriching to her as it is to her learners. Teaching English gives meaning to Jasmine's life.

In each of our three interviews, Jasmine spoke candidly about her life in English. Jasmine's first memories of the English language began when she was thirteen years old. Jasmine, like many children her age in her hometown, attended a private school and had the opportunity to study English. Jasmine fondly remembered always liking the English language and enjoying her studies. Jasmine told me that since she was an adolescent, she has always wanted to be an English teacher. As an undergraduate in her home country, Jasmine chose to pursue a degree in English Language and Literature. Like the majority of English departments, Jasmine's class schedule consisted of literature classes and structure of English classes. Jasmine always looked at these classes from the perception that she was going to be an English teacher saying:

I think that everything I learned about English was with the idea that I was going to teach it someday. You know because I've always wanted to be an English teacher. So, I guess that my learning is kind of connected to my teaching in that way. Things that I've learned I was always thinking, "Oh, this is important because I need to teach this someday." (Interview 3)

After completing her bachelor's degree, Jasmine began teaching English in both the public and private sector. As a recent graduate, Jasmine had a deep conviction that through English education she would be able to make a huge difference: "I just 
graduated, [and] I had this idea that I was going to change the world" (Interview 1). Though Jasmine continued to hold onto this sentiment, it took on a different shape as she began teaching English in her home country. As she progressed as a teacher, Jasmine realized that she could empower her students and help them build life skills, but she was not going to change the system as she had once thought.

Jasmine also realized that her role as an educator shifted when she taught in different contexts, noting that the public and the private sector were very different from each other. Jasmine remembered that while teaching in the public sector she worked extremely long hours and the English teachers had limited resources. To make matters worse, the students were disinterested in English language education:

The big problem was that in the public school, people do not want to learn English. They were there because they made them. We didn't have a textbook because the school...They thought that buying English textbooks for the students was a waste of money. They should invest in other disciplines and they didn't have any textbooks. If I wanted to make copies and things like that, I have to pay for them just by myself. (Interview 1)

However, Jasmine's students at the private school behaved differently and Jasmine enjoyed teaching in this context. Jasmine explained that the students at the private schools had more motivation to learn English and were committed to their studies. Yet, often there was a crossover between students in the public and private sector. In our first interview Jasmine shared:

The funny thing is that, some students that I had in the public school in the morning, I had in the private language school in the afternoon and in the evening the same students. In the private language schools, they were the most motivated students ever. At the public school because there were so many of them and many of them...their friends don't want to show that they were interested. (Interview 1) Though Jasmine remembers working long hours, she always loved teaching. 
In the private school she remembers feeling as if she could "teach all day," but that sentiment did not crossover into the public school (Interview 1). In the public school, the students were often mean and caused Jasmine grief. There were other differences between teaching in the two schools. At the public school the classes were only fifty minutes and Jasmine remembered having up to forty students in each class, while the classes at the private school only had seven or eight students and these classes lasted two hours. The difficulties of teaching at the public school took a toll on Jasmine.

Jasmine did not have to work as an English teacher in the public school system for very long. Within a month of her employment, the public school developed a computer-assisted learning program to further educate their teachers. Computer-assisted learning was just starting to surface in her home country as a mode of education and very few teachers were computer literate at that time. Jasmine was one of three teachers who applied for the program. She began a new career path as a teacher-trainer. Between her two teaching positions, Jasmine was able to interweave her two interests: language education and computer-assisted learning.

Jasmine also shared that teaching in these two different contexts helped guide and direct her professional development. After working as a professional educator and a teacher-trainer for six years, Jasmine entered a Master of Arts program in Applied Linguistics and Language Studies. Both Jasmine and her now husband were enrolled in graduate programs in their home country when he then received confirmation that he had been accepted to a graduate program in the United States. After his acceptance, Jasmine decided to apply to a graduate program in the same city as her then boyfriend. Once Jasmine received confirmation that she had been accepted and that she would receive 
financial support from the university, she transferred universities. As her departure date approached, Jasmine shared that she was so preoccupied with completing tasks in order to leave that she never had the opportunity to question her decision to move to the United States.

When Jasmine began her academic career in the United States, she envisioned herself going back to her home country and working in education as teacher trainer. However, once in the United States, Jasmine began volunteering as an English language teacher in a community ESL setting. Jasmine realized how much she loved teaching English and her perception of her future began to slowly shift. Today, Jasmine has taught English in the United States for over thirteen years. Since arriving in the United States, Jasmine has completed both Master of Arts and Doctor of Philosophy degrees, chaired an ESL program, created a new ESL program at another community college and has demonstrated her commitment to English language education though continued teacher training seminars and conferences. In the next section, I will explore the way Jasmine interprets her life living in two languages.

\section{Living in Two Languages}

As a bilingual speaker living outside of her home country, Jasmine has experienced how the role of her first language has lessened as her second language has gained predominance in her everyday interactions. Yet, Jasmine indicated that both languages are deeply intertwined in her perception of self. Jasmine finds herself in a third space where she feels that she doesn't fully belong in the United States and she doesn't fully belong in her home country. Jasmine has a clear understanding of who she is as a bilingual speaker living in a monolingual English context. 
Analyzing her life as a speaker of two languages, Jasmine commented on the degree to which English now dominates her life linguistically. In her home country, Jasmine only spoke English in academic settings, whether as a student or as an English instructor. Though she had thought of herself as a fluent English user in her home country, once immersed in the English language, Jasmine began to understand her language limitations:

When I came to the United States, it was actually, the first term in my graduate program [that] was pretty challenging... [We] had a teacher that first term also that wanted us to do a lot of things in class... He taught methods and he wanted to show us all kinds of methods possibly available in all of his classes. One minute, we were sitting down and then two minutes later, we had to stand up and find a partner... He used to have real techniques to find partners and every time it was a different technique. I had no idea what was going on. I always had to wait for people to do something and then I will just follow... After a while I got more comfortable with English and then I started using more English than [my native language]. (Interview 1)

Jasmine furthered the above sentiment noting that she did not interpret her comprehension as a setback, but a part of the overall academic process, which would only further her development as an English language teacher saying:

In [my home country], I would only speak English with my students in the classroom. Most classes that I taught in [my home country] were [for] beginners, level one and level two. There wasn't that much to say. It was really basic, so I know I didn't have a lot of opportunities to practice English in [my home country]. That's one of the main reasons why I decided to come [to the United States]. I thought that I needed that in order to be a better teacher and to be able to teach higher levels as well, and be confident when teaching those. It was pretty hard, because I didn't understand basic things, but I didn't really think it that way. I was very optimistic that, "OK. It's going to work out and I'm going to learn. I'm here, I'm going to learn and I'm going to do better." It's not like, "Oh! I don't understand what is happening, so I'm never going to be able to be an English teacher." That actually never crossed my mind. I'm optimistic. I think that it's personality. (Interview 1) 
Jasmine explained that her confidence as an English speaker developed quickly as she never looked at her progression as an English speaker from a negative space. Jasmine also shared that being in a new environment was a source of excitement and she had so many other challenges such as being immersed into a new culture and beginning her graduate studies that her performance as an English speaker did not dominate her thoughts.

Today, English is the predominant language in Jasmine's life. She is a fulltime English instructor living in the United States. Jasmine estimated that she lives over eighty percent of her life in English. Though Jasmine speaks English with the same degree of accuracy as her NEST counterparts, Jasmine noted that there are still slight nuances in the English language that do not always come easily to her. She describes this phenomenon in her speech as a lack of language or a lack of context saying:

[It is the] things that you don't usually say, for example, you know the expression that, "it's raining cats and dogs," right? When have you ever used this expression? Never, but it's there because you've learned it. I don't have that. Those little things I don't have. So then when people talk to me and they use expressions that are rarely used, and they don't give me a context, I cannot get [it]. Most of the time people do give you a context without really realizing it. That's when I rely [on additional context]. I rely on that, then I can understand the information. When people use expressions like these idioms, [or] idiomatic expressions that are rarely used. I don't have this background as a child. I didn't learn that. Not knowing that and not being able to be part of the conversation because I don't know that. That's a struggle. (Interview 1)

Yet, Jasmine recognizes how her comprehension of the English language has come full circle and she is able to navigate her life as a bilingual speaker of two languages. What was once challenging to her no longer holds the same place it once did in her communication and Jasmine is generally comfortable in both languages. However, 
Jasmine shared that she feels she is better able to articulate herself in one language or the other depending on the context:

At first it was pretty challenging but now I am comfortable in both languages, depending on the context. If I have to talk about feelings for example, how I feel, then it's pretty challenging to say that in English because I rarely do that in English. If I have to talk about work in [my native language], I have a really hard time because many things that I've learned I have learned in English. I don't even know what they're called in [in my native language]. Yeah, so depending on the context, I'm more comfortable in one language or the other. (Interview 1)

This shift in Jasmine's understanding has caused her to feel a disconnect, both linguistically and culturally. Jasmine explains this feeling by saying:

I'm at a stage now that I don't really think I belong anywhere. When I'm in the United States, I'm an American citizen, but I don't really consider myself [a American citizen]. I wasn't born here, this is not my culture. There are many aspects of this culture that I really like and I want to and I do have. When I go back to [my home country], I go once a year to see my family, I don't belong there either. It's where I grew up, but there are so many aspects of the culture that I have and I'm going to carry with me forever, but there are so many things that I don't like. I don't really belong anywhere. (Interview 1)

Jasmine further explains this feeling in the context of her home country, noting that sometimes she cannot easily navigate from one culture or language to another because of the disconnect between the languages:

Every year that I go [to my home country], I can see that happening more and more. Sometimes I'm talking to people there and I forget words in [my first language]. That's something that they don't really understand. They think that I'm faking it. Because if you haven't experienced it before, if you live in another county for one, two years that doesn't happen. It didn't happen to me. It started recently. It has to be several years before it actually happens. I don't want to ask, "How do you say that?" again, because they think that I'm just showing off. Especially when people ask me, "Oh, so what is it that you do?" When I try to explain the word "community college," there is no translation for community college. Then, how do you say that? If I say in [my first language] "I work at a community college" and I use this word, "Oh, yes. She's showing off, she's speaking English now." I have to avoid this. I can't say it in that community. That's how language plays a role. You have to pretend that you are, so then people 
don't think that you are faking it. You're actually faking it by letting them think that you're not. (Interview 1)

Jasmine acknowledges that her lived experience is quite different from the experiences of her friends and family in her home country and this also affects the way they interpret her behavior in her first language. Jasmine also understands that they do not have the context of living in two different societies where the language shifts the discourse. In order to effectively communicate in her first language, Jasmine feels that she has to consciously make decisions about her utterances before she conveys her thoughts. Thus, Jasmine is always reminded that she does not feel like she fully belongs in her home country or in the United States.

Jasmine has learned to manipulate both languages to fit her needs as a bilingual speaker. In English, she has learned to listen for underlying meanings, while in her first language she has learned to sometimes simplify her speech and move away from descriptors that others might wrongfully interpret. As Jasmine adapts her language to meet the needs of her listeners, she has built her own personal understanding of self as a bilingual. This section has sought to illustrate Jasmine's life in two languages. In the next section, I will explore Jasmine's life as student, focusing on the role that professional development had on her as a graduate student.

\section{Higher Education and Teacher Training}

Jasmine's academic career spans transnational borders and though her area of study changed as a graduate student, her commitment to English teaching and honing her craft were always foreshadowing her success. As a graduate student, Jasmine was able to 
define her position as a teacher and develop her critical thinking skills as a researcher. In the coming section, I will explore Jasmine's professional development through academia.

While residing in her home country, Jasmine completed an undergraduate degree in English Language and Literature. In her home country, Jasmine did not formally learn about teaching methodology and she did not begin her career as a teacher until she finished her degree. Without formal instruction, Jasmine did not understand who she aspired to be as a teacher or what was expected. While teaching in her home country, Jasmine remembers that her main objective as a teacher was to ensure that her students enjoyed learning English. However, over the course of her academic and professional career, her understanding of what was important inside of an ESL classroom changed. Jasmine describes this shift in her teaching philosophy saying:

Teaching becomes so much harder after you know what you are doing. Because in [my home country] I had no idea what I was doing, but it was not hard. Yeah, so my students would be like [Latin Americans] in general. I know it's a stereotype, but most [Latinos] really like songs, and so then I would bring songs to every class. If you asked me, "Ok, what is the purpose?" My response would be, "I don't know just they are really happy when we have songs." So it was, you know. But, I was really happy. They were happy. They were not learning much, but they were happy. [But] they were not learning much. I know that they were not. And then I came to the U.S., and then I started getting training and then I realized that teaching is actually really hard. And, I started to focus more on learning...I'm not so worried about pleasing students, as long as they are learning something. (Interview 2)

As a graduate student, Jasmine began to learn how to weave pedagogy into practice. In the beginning of her graduate education, Jasmine taught an ESL class at a local library. Jasmine was enamored with the diversity of her students and she found herself learning how to teach classes to language learners from various cultural and linguistic backgrounds. Moreover, her students also had various levels of English 
proficiency. Jasmine fondly remembers her experience teaching at the public library as one of the most defining moments of her academic and professional career as she was able to weave her own experiences as a NNEST to support her students learning objectives. For example, prior to coming to the United States to study, Jasmine had to complete the Test of English as a Foreign Language (TOEFL). While teaching at the public library, Jasmine encountered numerous students who were preparing for the TOEFL in order to continue their academic pursuits. Jasmine felt well-equipped to support their academic endeavors having already successfully completed this English language proficiency exam. Jasmine remembers feeling a sense of accomplishment and confidence in relation to preparing her students for the TOEFL. Jasmine knew that time she spent with her students in the library helped them move towards their goals as English speakers. However, Jasmine also came to the realization that her goals as an EFL teacher in her home country did not match her goals as an ESL teacher in the United States:

When I was in [my home country], I thought that my goal as a teacher was actually help students enjoy learning English. More than actually teach them anything, you know. Because in [Latin America] you have to learn English in order to get a better job... So, we had lots of students in [my home country], who are there and they don't want to be there. And they don't enjoy learning English. They think, it's, you know, it doesn't make any sense that they are there...I thought my main goal as a teacher was actually help them start learning, you know start enjoying their learning experience. And that's why I think that I wasn't, well, I wasn't that worried about the learning part, first because I didn't have any training, but also because of these environments. Now, here [in the United States] when I see myself right now like I think my goal, besides teaching, besides helping them learn is to actually empower them, you know. I can empower my students here because they feel sometimes that they are not capable, that they cannot function and here they are afraid of meeting American people and that they are going to make fun of their accents. You know, so then finding ways for them to be in places with American students in a safe environment, so then they feel more confident about themselves. Going to a doctor and being ok 
explaining and trying to encourage them and say, "Ok, you know I've been learning English for a long time, I'm an English teacher, I have an accent, what is the problem of having an accent? You know as long as you are, as people understand what you are saying." (Interview 2)

Empowerment became one of the focal points of Jasmine's teaching philosophy. In fact, throughout all three of our interviews, Jasmine commented on the degree to which empowerment has become one of the central themes in her teaching objectives, regardless of her students' English level or skillset. Jasmine still wants her students to enjoy learning, but believes that gaining practical skills within in the language is of greater importance. This profound belief that empowering students can actually change their lives was at the root of her graduate studies:

I started teaching the students in the library. I just noticed that I was making a difference. That really inspired me because the students that I was teaching in the library were just really like, teaching them to take the TOEFL exam and teaching them how to read, all of these things that I was making difference. I thought at that time, that's what I really wanted to do. I changed my mind. When I came to the US, I wanted to train teachers because I was doing that in [my home country and] I really liked it. (Interview 1)

Towards the end of her MA program, the university opened a Doctor of Philosophy program. Jasmine decided to apply and was accepted. She went into the program thinking, “'Ok, I'm going to see what happens.' You know, because if I want to be a teacher educator I need to have a Ph.D." (Interview 2). Prior to relocating to the United States, Jasmine had envisioned herself as teacher trainer. But, her experiences teaching at the library caused Jasmine to reconsider her career path:

When I was living in [my home country] I taught EFL and then I started teaching teachers how to use computers. And that's when I became interested in being a teacher educator. And when I came to the U.S. that's what I had in mind, probably because that was my last job there and I was really excited about it. It was, you know, the first time I had taught teachers and I kind of felt important, for a little bit of time... So, like I came to the U.S. and then I did the M.A. program 
and met all these wonderful ESL students in the library and then I started changing my mind a little bit, but I'm like, "Well, I'll do the Ph.D. program and see how it works." (Interview 2)

As a doctoral student, Jasmine worked as teaching assistant and taught ESL. She shared that even though a lot of her responsibilities as a TA were the same as an English language instructor, she felt secure in her role as a TA and treasured the relationships she built with her cohort. She noted that the majority of the other TAs were also non-native English speakers and as a cohort, they felt very comfortable asking for support from each other and collaborating on projects. In turn, they were able to build upon their strengths and seek advice from each other and also from their superiors.

As a doctoral student, Jasmine felt that she progressed both academically and professionally. One of the highlights of her doctoral program was learning how to write academically and to conduct academic research:

I actually really, really learned how to write a paper, a research paper in the Ph.D. program. Like, I really understood what exactly people were asking of me. You know because we had to do that constantly, and I was constantly working with an advisor, which I wasn't in the M.A. program so much. So she actually took the time. All the things that we teach our students in [our upper division writing classes] because nobody had ever taught me how to write a paper. You just learn, you know like nobody had ever taught me what a thesis statement was or a topic statement [was]. I think our students were really lucky to be learning all this before they go to college because I didn't. So, my advisor actually took the time to sit down with me and said, "Ok you know you are repeating ideas here, you're not using your sources so well. Why are you using this source? What is the purpose?" And then I was like, "Well, because I need more sources maybe." "Well, that's not really how it works." So, I think it was a really good learning experience for me. (Interview 2)

Today, Jasmine teaches these same skills to students in her advanced writing classes in order to prepare them for the next stage of their lives:

I was discussing that with a friend; a colleague the other day, that most of the time when we are teaching [advanced writing], which is our highest writing level, most 
of the time you are actually not teaching English. You are teaching them how to do research, how to go online and make sure that, what the website is reliable, where, you know, look at these and don't believe everything you read. You know try to find arguments for things, this is all, you know it's not about English at all. And many students don't have that for many different reasons. They haven't been to school so much, or they come from countries where critical thinking is not emphasized...But if they want to go to, I think that the English part they can get much easier way than actually learning how to and it's interesting because when students come back after they go to [college level] writing or [college level] reading they come back and they say, "You know what, I'm much more prepared than the American students are in the class." Because the community colleges, many of them, many students come back to school after being away for twentyfive years and they haven't really been to school... So they, the students, feel very confident, they know how to organize an essay, organize ideas and they know where to find ideas. (Interview 2)

Helping students develop life skills has become a key element in Jasmine's teaching philosophy. Jasmine has found a way to use her previous experiences as a graduate student to build a foundation for her students going onward in their own academic pursuits.

After completing her doctoral degree, Jasmine came to the realization that she wanted to pursue a career as an ESL instructor. Working with students in the library, along with her experiences as a TA, drastically shaped her career goals and she knew that she was happiest inside of the English language classroom:

It was a really good experience, but then even though I don't regret it, I think it was really good. I suffered a lot, like any other Ph.D. student but I think it was really good learning experience. But what the Ph.D. program taught me was that, "No, I don't want to work at a university and have to write papers all the time that's not for me, that's not what I want to do with my life. I don't want to have this pressure." I love doing research. I love doing research with my students, things that work and things that won't work. I don't have the patience to actually sit down and write about it. You know. Consistently, I could work on a project and maybe perhaps write about it. You know, but one thing in five years... That's not really what I want to do. And then when I was in the Ph.D. program I taught in the [ESL program] at [my university] and then I really liked it, because as a TA you do pretty much everything that a teacher does. I was responsible for my 
class... I decided at the end of the Ph.D. program, "Ok, I don't want to become a professor, I want to work with ESL students." (Interview 2)

Jasmine has gone on to have a successful career as an ESL teacher in the United States, and while she still participates in conferences and publishes articles, she is able to place her emphasis on her students' needs. In this section I have described Jasmine's transformation through higher education. As illustrated above, Jasmine found her strength as a teacher in the ESL classroom and this commitment to education is something that has continued to grow since her graduation. In next section, I will describe Jasmine's professional development after completing a Ph.D. and I will also explore how Jasmine perceived herself as an educator prior to her graduate studies.

\section{English Language Teaching}

This section illustrates the manner in which Jasmine understands her experiences as an English language teacher teaching in two different countries. Together, Jasmine and I explored how she has grown as an English instructor and how the similarities and differences between the United States and her home country have shaped her overall understanding of self. Jasmine has spent over half of her life involved in international education and her tacit understanding of self as an English language teacher will be explored in this section.

In our first interview together, Jasmine shared how teaching in her home country is distinctly different from teaching in the United States. For Jasmine, one of the key differences between teaching in the United States and her home country was being able to share knowledge through sharing the same first language with her students. She shared the idea that, "We could always rely on the first language if things got complicated" 
(Interview 1). Jasmine illustrated that in order to convey a meaning of a word now, she may spend five to ten minutes on the Internet using Google Translate to support her learners who all have different first languages. Jasmine also stressed that sometimes even after putting this amount of effort into defining a given term that some students still may not understand what the word signifies.

Jasmine also found that the relationships between teachers and their students in her home country are different fundamentally due to cultural and social differences. Jasmine shared a personal account to illustrate the difference between the two cultures saying:

I remember I went to a workshop once in [my home country]. I was in [my home country] and it was for teachers in [residing in my home country], in that specific context, and wanting to teach teenagers. Sometimes teenagers don't really want to be there. Sometimes they have some problems, emotional problems at home. The person who was giving the workshop, she actually used as a strategy to touch people and say, "Okay. How can I help you?" and actually touch because by touching you are expressing. You are showing that you care. You cannot touch anybody here so then these kinds of things. My students would come to class and hug me and kiss me, and everything is okay. It's perfectly acceptable to do that, to give your teacher a hug. Here, you cannot do that. I'm sure that when I teach here I probably do things that some students may not be comfortable with, not that I kiss and hug anybody here, but maybe I say things that may be considered inappropriate in some culture. In [my home country], I was totally comfortable. I knew that what I was doing was acceptable by everybody. (Interview 1)

These subtle differences with language and culture have made Jasmine more aware of her behavior as a teacher and how she interacts with students. Jasmine has learned to blend how she interacts with her students to fit American standards, which do not mirror the cultural practices of her home country.

Jasmine also commented on the magnitude of hours she worked as a teacher in her home country in comparison to the United States. Her days were split between two 
different institutions, which made her days stretch from early in the morning to late in the evening. She taught eight different sections of English a week at the public school and cycled through hundreds of students. In the evening, she taught at the private school to augment her income. To compare, Jasmine explained how her life as an ESL instructor looks in the United States noting that though she teaches fewer credit hours she puts a lot of detailed thought into each of her classes. She now puts more energy into her class objectives and she, herself, is constantly learning which in turn makes her a better teacher saying "You look at the lesson plans and the things that you created two years ago, you're look at it like, "What was I thinking?" You know how you change and how you see things in different ways" (Interview 1). Thus, Jasmine is always improving and evolving as an educator.

In addition to working long hours in her home country, Jasmine now feels that she did not have enough experience to teach her classes in a manner that matches with her expectations today. In addition, the majority of English classes were geared towards lower level English learners and Jasmine shared that the public schools are poorly equipped to teach English. In her case, the public school didn't even have a book:

When I had these really long days, I didn't know what I was doing. Not that I know exactly what I'm doing right now, but I have a better idea. At the time, I had no idea what I was doing. I would probably just follow the book, but we didn't have a book [at the public school]. At the private language school, we had a book. At the public school, I would sometimes bring an activity. I used the same activity in all eight sections. I prepared it once, and then I just used it. It didn't take me that long, because I generally know what a lesson plan was. I had an idea what I was going to do and then, I did it. (Interview 1)

Jasmine indicated that across both teaching contexts many teachers do not feel that they have job stability, as the job market is constantly fluctuating. And even though 
Jasmine has not had to face this obstacle in the United States, she remembers having this insecurity in her home country. She stated, "In my situation here, I do have stability. I didn't in [my home country]. At the public school you do have stability, but then you have a crappy job" (Interview 1). In relation to the United States, Jasmine explained that she was sheltered as a graduate student and did not understand the reality of how hard it is for teachers to find secure positions as ESL instructors. Jasmine is acutely aware of the struggles other English language instructors face in regards to employment and recognizes that her current position is unique as she has a fulltime position. She did not hesitate to mention that others may have endured different circumstances in relation to the job market here in the United States and abroad, in places like her home country. Jasmine also stated that even though teachers collaborate in her home country and in the United States, the manner in which teachers collaborate is distinctly different. In her home country, Jasmine said that she was constantly working with fellow teachers:

We did, a lot, even though all the teachers that I worked with had no clue. But that's something that was a big theme in [Latin America] too. Like we're always, "Oh what are you doing?" Because we all used the same book, it was all beginners... So we had a bunch of levels one, two and three classes and we all used the same book so then, "So I'm teaching Unit 2 today do you have anything?" "Oh yeah I had this." And we did parties together and you know create like Halloween... We had a treasure hunt at the zoo. You know, we had so much fun... And then I asked myself, "All the work that we had was it really worth it? Did they actually learn that much from that activity?" Some but, like you know really those things were things that we could have done in the classroom and it would have been ok...It was more like socializing for everybody than actually learning. I think that is something that is part of the culture too. You know, like working together, collaborating, having this community. It's something that I always had in [my home country] in any settings, anything that you do you look for other people. You know, it's a community-orientated culture. (Interview 2) 
In the above passage Jasmine provided a scenario in which she collaborated with her peers in order to support her students' academic needs. However, Jasmine also was reflective about the actual usefulness of activities that she and her colleagues created. Jasmine's overall understanding of the education system has shifted as her goal as a teacher is not necessarily related to her students' constant enjoyment but actually gaining proficiently. Jasmine believes that people in her home country have a more inherent need to be together, which she considers is not common in the United States. For Jasmine, working with others is embedded in the culture of her home country.

Jasmine also indicated that she collaborates with her colleagues in the United States. Yet, the manner in which she interacts with her colleagues differs from her experiences in her home country:

I think and I feel that many people not at [my school] necessarily but many people have this idea, the idea of collaboration is not very clear, right to many people. You know, like I think that many people think, "Oh ok, so we have this task, we have five steps, you do one, you do two, you do three, you do four and I'll do five. Then we'll meet again in a month and put it all together." And they call it collaboration. I don't really see that as collaboration so I think that many people believe that they are collaborating when they are actually dividing tasks. And sometimes dividing tasks is important, as you don't have time. But, what I feel the most. That it is important to meet and to actually collaborate, "Ok let's do this together, how do you think we should do it. This is how I think we should do it, what do you think would be best..." (Interview 2)

In the above passage, Jasmine articulates how the collaborative process is different in the United States, noting that often times her peers consider dividing tasks as a way to collaborate on a project. Yet for Jasmine, dividing up tasks is literally just that without the additional benefits that collaboration can bring. Jasmine also shared that people in the United States seem to be equally satisfied just teaching and do not have the inherent need to work with others. However, if they are invited to work on a project they 
would also be equally happy to collaborate on a project. Jasmine explained, "If I don't have this contact with people, I cannot work. I cannot function. So, it maybe personality, maybe culture, I don't know. It is maybe both" (Interview 2). Jasmine has found that when she shares similar approaches to teaching, she has been able to work with teachers in a manner that has strengthened her skills as a teacher. Jasmine prepares for these interactions and in turn, this causes her to, "Think more critically about things because I am going to meet with that teacher so we're going to discuss things. It makes me a better teacher" (Interview 2).

Jasmine also explained that though teachers participate in professional development, the model of continued teacher education varies from country to country. In her current setting, Jasmine stated that her professional development is nurtured by supervisors who constantly want to offer further support to their teachers. Jasmine said that she feels very supported in her current in her position saying, "I have a boss who's really encouraging. When I have an idea, he's always very supportive, 'I want to go to TESOL, can you help'? 'Yeah, let's find a way to help.' 'I want to do this project.' ‘Okay, how can I help you?'” He's very supportive in all kinds of ways” (Interview 1). However, Jasmine did not feel the same kind of support while teaching in her home country. This kind of support from administrators allows teachers to achieve their personal goals and this reflects onto their students, allowing them to also be more successful.

Finally, Jasmine shared that one of her favorite things about teaching in the United States is the diversity it brings into the ESL classroom. Jasmine articulated this sentiment by saying, "I teach people from all over the world. It's really fascinating to get 
to know people from all over and different cultures" (Interview 1). As an English language teacher, Jasmine has displayed how keenly aware she is of her transformation as an English language professional. Teaching and studying in two different countries has provided Jasmine with a panoramic understanding of the international education system and how she can incorporate her own beliefs about teaching into her classroom on the micro and macro scale.

In this section, I have commented on the degree in which Jasmine understands how she has progressed as a professional English language teacher over the course of her career. Furthermore, I have illustrated Jasmine's understanding between the similarities and the differences between the United States and her home country. In the following section I will explore Jasmine's teaching philosophy, and how she weaves it into practice. I also explain how Jasmine's career has unfolded in last eight years to reflect her commitment to English education both in and outside of the classroom.

\section{A Teacher and Her Philosophy}

The following section is concerned with how Jasmine's professional development as an English language educator has shaped her teaching philosophy in and outside of the classroom. Together, Jasmine and I explored what attributes are most important to her as a teacher and how she has grown professionally to meet her students' needs, while implementing life skills. Thus, Jasmine's teaching philosophy weaves together ESL classroom instruction with student autonomy and empowerment.

Jasmine is acutely aware of how she has progressed as an English language teacher. When asked to define the term "teacher" Jasmine's first utterance addressed this shift saying that, "it definitely has changed, and now I don't know if it's only because of 
the country, but also because when I came here that's when I started actually learning about teaching" (Interview 2). Through her memories, Jasmine was able to articulate that she once believed that her job as a teacher was to "help student enjoy learning English" (Interview 2). Jasmine explained the reasoning behind this belief by stating that in her home country people are motivated to study English in order to receive job promotions or to receive higher paying positions as it is necessary to learn some English to advance professionally. It is almost as if English is the stamp of approval on a resume, because regardless if the job requires English proficiency or not, a person with English speaking and writing skills will out-qualify the non-English speaker.

The belief that enjoyment is the first priority and learning is the second priority shifted once Jasmine began learning about teaching pedagogy. Now Jasmine understands that teaching goes beyond instruction. Jasmine illustrated that teaching is about teaching life skills and empowering students through knowledge saying, "It's about empowerment. Empowering students. It's about helping them think critically. That's why it's so complicated, because most of the time you are not teaching English. You are teaching so many other things" (Interview 2). In our third interview, Jasmine elaborated on the idea of empowerment noting:

I don't know if it connects to learning now, but another thing that comes to my mind, is that every time I think about being a teacher in [my home country] or here, or any environment that I have experience in, there's always this idea that I am helping someone do something. And I'm making a difference, somehow. And that is really important to me. So then in [my country], it was helping people find a job, a better job. In [my American university] when I was working in the library, it was to help people you know, survive in the United States. And here when I'm teaching this term for example, is to help students get a degree, one day. And also function in the country and to be respected as, so they are, you know because of the language. For me it's not about, it's the actual language is not so, that important as learning strategies, as learning how you need, what is expected from 
you and you need to learn this language because this is expected from you. Because this is how they are going to respect you because this is how you are going to get a better job. You know it's all connected. (Interview 3)

Later in this same interview, Jasmine explained that through constantly interacting with her students, she is better able to understand their needs and convey her rationale for teaching things that may otherwise go unanswered. By hearing her students' reactions to classroom objectives, Jasmine believes she is further supporting the role of empowerment in her classroom:

I think that the most important thing for me is, when I teach and I think that is what I would tell [pre-service teachers) is to know your students in a way that you know what their goals are and what they need from you so trying to design your class based on what your students need. And constantly ask them and get feedback from, like "is it helping you? Is it really what you want from this class?" And sometimes they are probably going to tell you, "No, what I want from this class is an A." And, then you have to make sure you know how to not consider these kinds of comments. But for example, "I'm explaining something this way, does it really make sense?" You know, get constant feedback from the students and make sure what they are learning makes sense to them and to whatever their needs are. Maybe they are not aware of what they need in order to accomplish their goals, but if you know what their goals are you probably know what exactly, they need. (Interview 3)

Jasmine also understands that her students will not always like the subject matter and that sometimes classroom instructions are difficult. The need Jasmine once felt to ensure that her students were enjoying class has changed. Jasmine still wants her students to enjoy learning, but she also realizes that there will be elements to learning a language that are not always easy or pleasant:

Sometimes the students are not happy. I have a [upper division reading] class this term, and for some weird reason they do not like to learn vocabulary like they think, "Ah, this is so boring. I don't like it." I think if I were teaching many years ago, I would be, "Ok, so let's do something else." But now, I'm like, "Well, I know this vocabulary is important." I know these are basic words that they don't know... I know they will thank me in ten years, so we are doing it. "I'm sorry you're going to be very unhappy but we're learning vocabulary." (Interview 2) 
Jasmine also recognizes that she and her colleagues have different strengths inside of the classroom, which also implies that they embody different teaching styles. Jasmine has always felt comfortable using technology in and outside of the classroom to help her students succeed. She attributes her comfort with computer assisted learning to her position as a teacher trainer in her home country. Jasmine has continued to implement the use of technology in her classroom. She shared that she builds each of her lesson plans on PowerPoint in order to keep her lessons structured. Teaching with technology is one of Jasmine's strengths and she recognizes that other teachers have different strengths in the classroom. Jasmine also believes by integrating technology into the classroom she is ensuring that her students walk out of her class with life skills that will support their future endeavors.

Jasmine offers her students explicit instructions, as she wants them to understand the learning objectives of each class and why she has chosen a certain activity. Jasmine shared that she only began this practice in the past few years but believes it supports learning by clarifying her rationale. She also explained that she takes this approach in all of her classes, regardless of English proficiency. Thus, being clear with her learning objectives supports learner autonomy and also allows them to understand the pedagogical underpinnings of her instruction. Jasmine recognizes that feedback is a two-way street that offers students and teachers alike a way to interpret the classroom objectives. Jasmine approaches feedback with the hopes that it is supporting her students' understanding of the classroom dynamics. 
Jasmine explained that one of the outcomes of providing explicit instruction is that students are able to understand the value of what they are learning inside of the classroom. As indicated above, some aspects of learning are harder than others, and students need to be able to see the value in what they are learning and why the teacher is focused on certain learning outcomes. Jasmine offered insight to her rationale by saying:

Studying vocabulary can be very tedious and I know that some of them don't want to, but it's important. So, and then giving them opportunities to express that, I guess. And then if they still say, "Oh I still think it's really boring." I'm like, "Well, I hope one day you will change your mind." But I'm finding situations, opportunities to explain to them, "Ok did you see how this person used this word? Can you imagine if this person was using the word 'stuff'? He wouldn't be the same, you know, power with the statement." And then maybe one day they will see that. (Interview 2)

It is important to Jasmine that her students are able to understand that even though a given subject is challenging it is still necessary.

In this section, I have explained how Jasmine's teaching philosophy has progressed over the span of her career. Today, Jasmine understands that learning can be difficult and it can also be rewarding. Jasmine has clearly stated that she seeks to weave English language education with life skills in order to empower her students and prepare them for the future. In the coming section, I will explore Jasmine's understanding of perception. First, I will examine how Jasmine interprets how her colleagues see her. Next, I will explore how Jasmine believes her students perceive her and finally I will explore Jasmine's self-perception.

\section{Self-perception and Identity}

In order to explore the role of identity as a non-native English speaker, it is essential to discuss the role of perception. Throughout our time together, Jasmine shared 
how she perceives herself as bilingual speaker of English, and how she believes others view her as a NNEST. Thus, this section in concerned with the role of identity and perception. In the coming pages, I explain Jasmine's personal understanding of perception in relation to self and others.

Although Jasmine is aware of the plethora of research that indicates that NNESTs are often treated differently due to language variation and other various assumed differences, Jasmine shared that she has never been explicitly Othered due her status as an NNEST:

As a non-native speaker, I've never felt that any teachers have treated me differently, I think at the beginning when I started teaching here I was the one judging myself and I was the one asking myself, "Can I really do this?" I was assigned right at the beginning to teach a higher level communications class. And I felt very anxious, "I'm not qualified to do this, why don't they give me the grammar class, that's I'm good at that, the writing class I can do that." But communication. Not so much. I don't think I can do this. But nobody has ever approached me... actually quite the opposite. (Interview 2)

Jasmine attributes her limited experience working in different contexts to her sentiments about the treatment of NNESTs in English language education. Jasmine indicated that it is hard for her to assess how NNESTs are treated in a broader sense. Jasmine illustrated that she is aware of the topic of NNESTs as a research area saying:

TESOL has an interest section that is called Non-Native Speakers teaching English and sometimes I read as part of their NNESTs section group and sometimes I read articles that people write about and I have seen a lot of discrimination in there. Like, we don't know if it's the way they perceive it, because I was really hard, you know, on myself, when I started. (Interview 2)

However, Jasmine is not entirely convinced that each reported occurrence of Othering is directly related to being an NNEST. In fact in her experience, the feeling of 
Othering has been attributed to a lack of cultural understanding coming from the person

who is feeling judged. Jasmine shared one of these experiences, saying:

I had a student a long time ago and it really, I still remember her. That she came to class crying... She came to class crying and then, you know, I asked her to step outside and said, "What is going on?" "Oh it was because my child was discriminated against." I'm like, "Ok so what happened?" "Yeah, so she went to daycare and she is sick, like, you know, she was sneezing so when I went to pick her up they had isolated her into a room, she was just a kid right? And then closed the door and nobody could get in. It's because she's Hispanic." I'm like, "Well, I think it's not I think you know about American culture and germs." So, you know, I explained to her how germs are really important. And people are very careful about germs, like you cannot drink from the same cup as somebody else. You know in [my home country], everybody drinks from the same cup it's not a problem at all. And if you are sick, you just come to work and then you sneeze, you know. And it's not part of the culture. So then I explained to her germs and you know when you sneeze you actually have to do this and make sure nobody sees it and she's like, "Really? Ok so you think it's not because she is Hispanic?" I'm like, "I am very sure it's not because she is Hispanic." And then she felt much better, so the discrimination was all in her mind. (Interview 2)

Jasmine believes that it is necessary to question the individual understanding of cultural differences before making assumptions that they are being Othered due to race or language variation. However Jasmine does believe that Othering does occur in relation to language and that this also has an effect on how individuals perceive themselves:

And I'm not saying that all that non-native speakers are not discriminated against. I think that probably in many places in the United States they probably are. If they have a true reason to do it. But maybe, in some cases it comes from inside. Because I've discriminated against myself several times. (Interview 1)

After Jasmine completed her graduate studies and began her career as an ESL teacher, she had presupposed assumptions about the kinds of classes she would be assigned to teach due to her variety of English. Jasmine describes how she felt when she first taught a communication class and how she now copes with class content that is she is not completely comfortable with: 
When I taught my first pronunciation and communication class here, at [the community college], that was my first communication class that I had ever taught in my life. Integrated skills was a different thing, mainly a communication class. I felt that I was not qualified to do that. [I thought] they should have a native English speaker teaching this class and have me teach the writing class, because I know how to do that. With my first class, I think I did a really bad job, because when you don't feel confident, then you look for things that you feel confident and they are not necessarily what the students actually need...I remember once I also taught [an intermediate] communication class, and there was an intern in the class. I used him as a model. We were doing some kind of sound and I would say, "Look at him, look how he does it!" (Interview 1)

Jasmine elaborated on this same feeling of doubt in our second interview, saying:

When I started teaching here I was very sure I was only going to be assigned reading and writing classes because I knew I could do those but you know. Even now sometimes when I teach higher-level communication classes I'm still not $100 \%$ confident. I use to look for things that I was more comfortable with. Now, you know, if there is something that I'm not comfortable with then I look for YouTube videos, I bring a guest speaker, you know. I find ways around it. If I'm not comfortable, there is some sounds that I still cannot differentiate you know like it's very subtle but if I'm teaching those then I will bring somebody with me or will find a YouTube video... And the students think it's really great. I never tell them the reason why, right, "I'm bringing a video because I don't feel comfortable with these sounds myself." But they like the variety too. (Interview 2)

Several times throughout our time together, Jasmine touches on this notion of not being secure in her non-nativeness and how she self-discriminates. Jasmine shared that when she first began her teaching career in the United States, she thought that her employer would only assign her classes such as grammar, reading, or writing. However, the chair of her department assigned her a communications class. Below Jasmine articulates how she felt when she began teaching the class:

When I was assigned to teach a communications class I kept telling myself that I'm not capable of doing this. I'm going to go to class and all my students are going to ask me, "Why are you doing this? You're not a native speaker." You know, and not, quite the opposite. They never said anything like that. But I was the one panicking and my department chair had confidence in me, he assigned me for this class, you know and I was the only one who was not confident so where is 
the discrimination is inside of me, there wasn't any kind of discrimination. (Interview 2)

In our third interview, Jasmine explained that her fear and self-discrimination made it hard for her to ask for the support of her peers during the first couple years of her employment saying:

My first year or even two years, I wouldn't ask anybody any questions because I felt, and who knows if it was going to be true or not, but in my mind if I asked, "Okay, I don't know what this means," people are going to look at me like, "What is she doing here?" You know, "She shouldn't be here. She doesn't know this word," Which can be silly now, but it wasn't at the time. And now I feel very comfortable. (Interview 3)

Jasmine also explained that after she was first hired and she realized how competitive the job market was that she began to question her position as a full-time ESL teacher, how her peers felt about her, and the committee's choice in offering her employment saying:

When I got the job here maybe there was a lot of, there were a lot of people thinking, "Ok she's not qualified." But I've never felt this way because when I applied for this job I had no idea how competitive it was and many people at [the community college] applied you know who were already working at [the community college] applied and then this person just came and got their jobs. You know so I'm sure that probably people looked at me and thought, "Ok this person looks like she's fifteen, English is not even her first language, what is she doing here?" I'm sure [they thought that]... (Interview 2)

Jasmine began to question if her employment was directly related to the need to

promote diversity on campus and was she the best candidate saying:

When I applied for this job, I had no clue how competitive it was. And then when I actually started I found out that it was very competitive and most people I was working with, they wanted that job. So I guess that put more pressure. "Why did they choose me? Were they crazy or something?" But then there's one other thing that I hope, I really, really, really hope that it didn't happen but then you keep asking yourself, "Did they choose me because I'm a non-native speaker and they want diversity?" You know? "Was I not the best candidate but they chose me because they wanted some diversity?" You know? So then it brings more 
insecurities. "Okay, maybe I wasn't the best candidate for this job, but among the non-native speakers I was or something and who knows what happened." (Interview 3)

In our first interview, Jasmine alluded to this same feeling, noting that she questioned whether she deserved her new position as a fulltime teacher: "When I found out that many people had applied for this job and didn't get it, I felt that I didn't deserve it. I felt that I didn't deserve it also because I was a non-native English speaker" (Interview 1). Jasmine shared that the feeling of not deserving her position only lasted for a short amount of time, yet she felt a continuing inherent need to prove herself. Jasmine decided that she had to work harder than everyone else, in order to prove to herself that she could do anything that she set out in front of her:

Yeah, and then [I was] working so much harder than everybody else. I wasn't competing with anybody else. I was just, I think, trying to prove myself and I really like everything that I do so I guess that helps but then I think I've done so much stuff that now I'm really tired and you know, for some years I just worked like crazy and I was involved in everything you can imagine... I just worked like crazy partly because I wanted to prove myself I think and partly because I really liked it. (Interview 3)

As an English language professional, Jasmine has a long list of accomplishments. Jasmine has chaired a department, has coordinated regional conferences, and developed a new ESL program at another campus. Jasmine feels that her hard work has paid off saying:

I've worked a lot for the department. I've done a lot of stuff. I was department chair for four years. I've organized tons of stuff, so I think that I feel that people see me as someone who is contributing to the department... I guess I've proved myself. I think that most of it is because I'm a non-native speaker. I think that maybe if English were my first language, I wouldn't feel so much pressure. (Interview 3) 
And even though Jasmine recognizes that her self-discrimination stems from her

own insecurity, and that she feels confident about her English language instruction,

Jasmine still sometimes carries the fear that she is inadequate:

Being a non-native speaker in the classroom, I still don't feel any problems with it. Sometimes when I meet someone new, co-workers, the insecurities come back sometimes. And, maybe because of that and also many teachers here want to have a full-time job and then sometimes I think well maybe, maybe they may think that they think they should have my job because I'm not a native speaker of English and out of the five full-time members we have here, I'm the only non-native speaker. (Interview 3)

Jasmine now feels secure about her position as a teacher and has noted that she feels supported by her colleagues. Yet, there are instances where her self-doubt and inner discrimination affect how she perceives herself.

Jasmine indicated that other teachers have commented on her English proficiency.

Jasmine generally recognizes these as genuine compliments, but she sometimes cannot help but question the sincerity behind the compliment:

And then here at [the community college] lots of people [teachers who] have said, "Oh I wish I could speak another language as well as you do or...." And students sometimes, students don't comment as much because I think, like I was telling you, many of them don't really know. Their level is not high enough to notice. So, I think they don't really think about those things. So of course part of me is really happy and part of me is always like, "Ok are they serious? Or they're just being nice." Yeah, of course getting compliments is always really good, they make you feel good about yourself. But then, you're always like, "So what is really good for them? What does it mean for them?" You know like, do they mean, it's good because they can understand what I'm saying? Or it's good, you know? So you never know what actually what they mean. I think that they don't say that in a sarcastic way. At least I haven't noticed it but, what is good? ... So, you never know. So it's good, in a way. It's always good to have a compliment. But I never take it that seriously because I don't know exactly what they mean. (Interview 3) 
Yet, of all the compliments Jasmine has received about her English proficiency, there was one defining moment in which Jasmine clearly understood what was being conveyed to her by one of her university mentors:

I've had lots of [teachers] at [the community college] have told me, "Wow your English is pretty good." I think that the one that I liked the most, the one that I always carry with me is when I defended my dissertation. And one of my committee members told me like, "From all the native speakers, the non-native speakers that I read dissertations from I could see your command of academic language, written language is native-like." So that for me was like a big thing, a huge thing. I'm like, "Ok I can write. Check!' ...But that teacher, in my dissertation defense I knew exactly what she meant when, by that comment. In an academic dissertation, in academic English you are native-like. So it was very specific at her compliment. (Interview 3)

Throughout our interviews, Jasmine commented that her students generally are unable to tell that she is a non-native speaker. She believes that students are generally more comfortable with teachers who do not have obvious accents and this has helped her inside of the ESL classroom:

I know that some students are not 100 percent comfortable when they have a nonnative speaker when they can notice an accent. Most students don't really see a problem with me teaching them, because they only find out that I'm not a native English speaker after a while. They're not at the level that they can notice an accent. (Interview 1)

As illustrated previously, Jasmine used to fear that once her students realized that she wasn't a native speaker that they would reject her in specific teaching contexts such as communication courses. And even though she acknowledges that her students are not always comfortable with NNESTs, they are unable to detect her NNEST status. However, once her students find out that she is an NNEST they see her non-nativeness as a positive attribute stating:

I don't see [being an NNEST] as a problem, I don't... I think some students see it as a benefit. And I think, because some students have told me like that, "Oh yeah 
so you're going to be a good teacher because you know what we're going through." [or] "You know what we're going to have problems with so you know what..." So they see it as a benefit, sometimes. I think there are benefits and disadvantages too. Like in the communication class, like I was saying, I think it could be a drawback but like for example when I am selecting vocabulary for them to learn. I feel, and I may be wrong but that's how I feel, that I can choose words that my intuition is a little, maybe a little bit better than a native speaker's intuition in terms of which words are more important for them to learn. Because if there is a word there that I've never heard of before, that I've never used or never heard of and you know it's probably not going to be that important to them at that level, that they are learning. (Interview 2)

Jasmine also commented that her students are often surprised when they find out

she is a non-native speaker. Sometimes this builds a sense of solidarity she has shared their experiences as learners and they want her help to develop learning strategies:

When they find out that I'm not [a native speaker], then usually they are, "Oh, really? So, you came here when you were like two or three years old?" "Oh, no. Actually I was 25." "Why, you were 25!" Then, they actually ask me, "So, what is it that you did? How did you study? What are some strategies that you've used?" (Interview 1)

Jasmine generalized that after her students find out about her non-native status that they usually ask a few questions and the topic never resurfaces again. Thus, her students see the value in being taught by an NNEST, though it does not play a huge factor in how they perceive her or her instruction.

Jasmine shared in our second interview that she has experienced Othering by her students in relation to gender. Though, this occurrence was indirect and not meant to be hurtful, Jasmine has strong feelings surrounding her emotions. Yet, Jasmine attributed this incident to cultural differences. Below Jasmine shares an instance of Othering saying:

I had an incident in the spring, that so we have thirty teachers and one male teacher, right? And then the student approached me, he's from [the Middle East], I know it's a stereotype but that is where he was from. And he approached me 
and he said, "Oh yeah I've heard, I was in the tutoring center and someone told me that there is a teacher here who has a Ph.D. And you don't need a Ph.D. to work at [a community college]. There is one teacher in the ESL program who has a Ph.D., it's probably [the male teacher] right?" Like out of thirty teachers there is one male teacher. Of course he has to be the one with the Ph.D.... They don't mean to do that, it's part of their culture, it's part of their belief system. It really irritates me but you know, I have felt that a few times. (Interview 2)

Jasmine is aware that there is a difference in how she perceives being a NNEST in relation to her colleagues and her students. Jasmine has felt the need to prove herself to her colleagues, where she is able to hide her NNEST status with her students until she feels confident disclosing her language difference. Yet, when she first started teaching at the community college her youthful appearance used to be cause her discomfort and she felt that she had to prove herself:

Being a non-native English speaker is one thing and I think that I sometimes have to prove myself to people who work with me. But then my students never find out that I'm from another county until I tell them so I don't feel the non-native speaker teacher thing in the classroom so much. However, now it's not that much of a problem anymore, but when I started teaching here, I was 31 and I looked like I was 20. And then I had a hard time for the students to accept me as a teacher... And, then who knows if it was a big deal for them or not? Maybe they just said, "Wow you are a teacher." Just because they were really amazed and then it was not a big deal. But for me it was like they said that because they think I'm not qualified. You know they never actually told me, explicitly, "Oh you are this young, you shouldn't be a teacher." They never said that. Not even close. But because, you know the way that they said it, I already took to as something really negative. I think it depends on the context. With my co-workers, definitely being a non-native speaker, but with the students and the classroom, the age part. (Interview 3)

Thus, in different contexts Jasmine has felt the need to protect herself from other people's opinions and perceptions. Jasmine recognizes that her appearance used to also be a source of insecurity. However, with age and professional development, Jasmine has created a reassuring self-dialogue that allows her to reflect on her self-perception and the 
perception of others. Thus, Jasmine has learned coping skills to help her process her understanding of self in the context of language learning.

This section has provided a detailed account of Jasmine's perception of self in relation to her position as an NNEST. In the preceding pages, I have sought to explain how Jasmine's own understanding of non-nativeness has propelled her as an academic, as a professional language instructor and as a colleague. Jasmine displayed a keen awareness of her own perception in regard to others and demonstrated that she selfdiscriminates, though she has never felt explicitly Othered. In the final section of this chapter Jasmine and I explore the role of the World Englishes paradigm in the ESL classroom reflecting on fluency, accuracy, and intelligibility.

\section{World Englishes and English Language Education}

In the coming pages I address Jasmine's position on the World Englishes paradigm in regards to fluency, accuracy, and intelligibility. As an English language learner and English language teacher, Jasmine has specific criteria she wants her students to understand about language performance. Jasmine also posits that her own experiences as a learner and living in the United States has affected her teaching philosophy when looking at what is necessary and sufficient for students to understand about fluency, accuracy and intelligibility.

As an English language teacher in the United States, Jasmine shared with me that she does not believe that the World Englishes paradigm has a place in ESL classroom. Simply stated, the goals for a student studying and living permanently in the United States often times looks different than a student studying English in an English as a foreign language context. For Jasmine the differentiation in context means that: 
We are more concerned about grammar rules, more concerned about expectations, and in the American culture, not in the world, you know, [not] how are you going to use the language in other contexts... The students that I have this term, all three classes that I'm teaching this term, they, most of the students want to go to college in the United States so that's what I'm focusing on. So, if they do make mistakes, that even though they are, if when they make those mistakes it still doesn't really matter I still understand what they're saying and their friends understand what they are saying, then still they have to fix that so they can be more successful in college. You know, the goal is a little bit different. I don't really have the world Englishes in mind when, or the notion of or the language English in mind when I'm teaching the lower levels, but what I have in mind is, "Ok, what I've read this person said, can I understand what she or he said and if they go to a supermarket or to a doctor's office, will that person be understood." I guess that's what, you know, I've never actually thought about World Englishes, but it's kind of the same in a way, you know, It's is this person comprehensible, is the pronunciation good enough that the person will be okay and successful in the conversation? Is the grammar okay if they say, "He speak" instead of, "He speaks," is it a big deal? You know, in academic English, it is. In [the introductory levels], not so much... I think I've never had the World Englishes, thinking about the World Englishes notion, but it's more about the person being comprehensible and the environment that they want to be comprehensible. (Interview 3)

Jasmine understands her students' goals and ties to align their goals as English speakers in a way that reflects their academic and professional goals. For, Jasmine the World Englishes paradigm does not support her classroom objectives though she sees how it may be similar to her goals of lower level students. Jasmine believes that her role as an educator is to set the standard of how a speaker ought to sound:

I think that when we are in the classroom here, because we are preparing students, many of the students to go to college. Then we have a set of norms that we have to follow, right? So then if they are in [introductory courses] their goal is just to survive in the country then it's not really a big deal but the students that I have this term are all academic, with academic goals. So then, I don't think it does play a role in that case because we are trying to teach them whatever is needed for them to be successful in college and the world Englishes is not going to get them there. (Interview 3) 
Jasmine firmly believes teachers need to adjust their curriculum to meet their students' goals and this is reflected in how she approaches fluency, accuracy, and intelligibility:

I think it depends on their goals. It depends on their level, like what they are ready to do at that level and ready to understand and then even in the lower levels, yes, it's not a big deal, they are not going to not move up to [intermediate level] if they say, "He speak," because that takes a long time for them to learn anyway. But, at the same time, we're trying as much as we can to teach them what is more acceptable in the United States, in their environment because if they want to continue and get a job, depending on the mistakes that they make with the language, even if they are comprehensible, there are lots of stereotypes associated with certain mistakes and they may not be taken seriously and people may not rely on the depending on the kinds of mistakes they make. So I think it is important but it's not going to prevent them from moving up a level. (Interview 3)

As an English language professional and a learner of the English language, Jasmine is keenly aware of the negative stigma that comes along with being a non-native English speaker. Jasmine seeks to move her students away from negative stereotypes and to allow them to embody the English language.

Jasmine also articulated that she does not expect her students to sound like native English speakers. Jasmine wants to meet her students' individual goals as speakers to ensure that they are comprehensible:

I'm not expecting the students to be, to sound like a native speaker, I don't sound like a native speaker. I'm not expecting anybody to do that. I don't think you need to sound like a native speaker. But, I think that depending on what they're objectives are, if they talk to someone and the person is constantly asking, "What, sorry, what?" That can be pretty annoying to the person, to my student and whatever my student is saying may not be taken seriously. So they do have to speak, I guess, at a level that people are not constantly asking them, "What, I'm sorry, can you say that again?" I guess that for me, that is what intelligibility is. (Interview 3)

Jasmine wants her students to be comprehensible English speakers who are confident when they speak. As demonstrated in her teaching philosophy, Jasmine firmly 
believes that her role as an educator is to empower her students. One piece of fulfilling

this goal is to ensure that they are able to move beyond their accent and be able to navigate their lives through English as comprehensible speakers:

I think it's all related to that, it's all about being taken seriously. I think that our students, when they apply for a job, depending on the job, there are many jobs that most of the workers are from other countries, I guess that doesn't apply so much, but some other jobs that they apply for, I think that just being from another country and having an accent is already enough for them not to be taken seriously so they have to prove themselves constantly, right? And, I felt like doing that, I felt like that, I think several times. Maybe not because people treated me differently but because you have a lot of pressure on yourself to do well and then you're like okay, "I'm doing this job, I'm teaching English. English is not my first language. Okay, maybe I shouldn't be here so I have to be better than anybody else, everyone else," You know. So I think that the students have to face that too and then being intelligible is something that is very important in that case. (Interview 3)

Jasmine said that fluency is woven together with a students' understanding of the

subject area and skillset:

Fluency actually can apply for all skills. And it really depends on the level too. I'm teaching [an upper] level reading [class] right now and I want them to read. Not only do they have to understand what they're reading and learn the vocabulary and all this but also read fast. So, that is fluency but I'm not going to be so worried about them reading so fast when they are in a lower level. (Interview 3)

Jasmine also shared that what she wants her students to understand about fluency

and accuracy depends on the activity saying:

And when I'm teaching communication, depending on the exercise, depending on the activity we are doing, they have to focus on fluency or they have to focus on accuracy depending. You know, depending on the level. Also, it depends on the level the kind of activity, I think that we should vary that in the class. "Ok, now we're going to have a discussion. It doesn't matter what kinds of grammar mistakes you're going to make because we're going to focus on fluency but now we're not going to worry so much about fluency. We're going to make sure that they put all the endings and verbs in the correct way." So it depends. (Interview 3) 
Thus, how Jasmine approaches fluency, accuracy and intelligibility largely depends on the students' English level and the goals of the curriculum.

As an English language professional, Jasmine sees the value of her students learning to be comprehensible speakers of the English language. She does not expect her students to eradicate their accents, nor does she think it is necessary to sound native-like. However, Jasmine does see the value in teaching standard American English and keeping to American norms in the ESL classroom. This section has illustrated how Jasmine interprets World English and the role of fluency, accuracy and intelligibility in her classroom. Thus for Jasmine, the three terms work together to provide her students with a greater understanding of self as English speakers.

This chapter has sought to paint a portrait of Jasmine as a bilingual speaker of English who is deeply aware of her fluid and complicated identity. Jasmine has demonstrated that she lives in a third space where she does not feel that she really belongs anywhere. Yet, her commitment to English language education internationally has grounded her teaching practices in the United States. In order to provide a contextual understanding of Jasmine, I have explored the historical role English has played in Jasmine's life, followed by Jasmine's interpretation of her life crossing in and out of two cultures and two languages. I have also explored Jasmine's understanding of her education in relation to being and ESL teacher. I also provided a glimpse into Jasmine's perception of self in regards to how she believes others see her as an NNEST. Finally, I shared Jasmine's understanding of the World Englishes paradigm in her ESL classroom. In the next chapter, I will follow the same pattern, only this time exploring the lived experience of Anna. 


\section{Chapter 5: Anna's Portrait as an English Language Teacher}

\section{Introduction}

This chapter presents a portrait of Anna as a multicultural agent who teaches English as a second language. Anna is one of two participants whose participation in this study made it possible for me to consider the role of NNESTs' perception of self in relation to bilingualism and culture. In the first section, I explore the historical role English has played in Anna's life, focusing on her personal narrative and the experiences that led her to become an English language teacher. In the second section, I explore Anna's life living in two languages, noting how language weaves together different roles and understandings of self in relation to context and location that each language has played in her life. The third and fourth section of this paper are concerned with how Anna interprets the role of English education throughout her life and how she situates herself as a NNEST learning and teaching in an Inner Circle world. These sections draw heavily on her descriptions of the role that higher education has played in her movement from one position to another. These sections also highlight the similarities and differences between teaching in the United States and teaching in her home country. The fifth section of this chapter moves through Anna's perception of self as an English language teacher and how this is reflected in her teaching philosophy. In the sixth section of this chapter, I explore Anna's interpretation of self in relation to how Anna believes others perceive her as a colleague and as a teacher. Finally, in the seventh section, I explore Anna's interpretation of the World Englishes paradigm in English language education, specifically looking at fluency, accuracy and intelligibility. 
The History of English in My Life

Anna identifies as a Latin American woman. Anna was born in the southern hemisphere and conveys a strong connection to South America through her description of self, in relation to her morals and her cultural identity. Anna often refers to herself as a Latin American mother and the role her South American descent plays in her personal life, as well as the decisions she makes as an English language teacher. Anna is deeply connected to her role as an English teacher and her role as a mother. Anna is also deeply aware of the role age plays into her insight and understanding of the world and the way she participates with others. Nationality, age and motherhood are central to understanding Anna's life as it pertains to the English language.

Anna's first memories of the English language began during her secondary school education. Anna was enrolled in a private all-girls Catholic school due to her parents' commitment to ensuring that their daughter had a well-rounded education. Her parents not only wanted her to learn how to speak English, but they also thought that it was important that she had ballet and piano lessons. Anna remembered that her English class met twice a week and she enjoyed grammar because it reminded her of mathematics, as they both share a structure that is applicable and that can been seen in patterns.

Even though Anna remembers liking the structure of English, her first memories in the English language classroom were not positive. Anna's first English teacher was not a kind person and Anna attributes this negative sentiment to her lack of total comprehension in English. Her instructor was unable to answer questions about the English language and was unkind to her students. Anna mentioned an incident that happened in class when she asked the teacher what was the context or meaning of a 
certain word or phrase and the teacher responded, "Well, I'm not going to answer you. You have to find out." Anna whispered to her classmate stating, "I don't even think she knows it "(Interview 1). Anna said that her teacher "She heard what I said [to my friend] and she gave me an awful hard time until the end of the year" (Interview 1).

At the end of the academic school year, Anna's family moved to another city that was about an hour away from their former residence. Anna transferred from the all-girls Catholic school she had been attending to a Marist Catholic school where there were more male students than female. Anna enjoyed her new classes as they reflected more of her academic pursuits such as engineering. But the one thing that stood out to Anna was what happened when she walked into her English class and waited for the teacher. Anna remembered, "But when the English teacher came in, it was the same woman... So she had also moved to this other city "(Interview 1).

This negative sentiment stayed with Anna through her secondary education. She recalled, "In a way I hated English... until I realized that the problem was not me or the language. It was the instructor "(Interview 1). However, Anna was a good student and took her studies seriously. At seventeen, Anna began taking courses at the university and had already enrolled in a professional degree program when she found out that she had been nominated for a ten-month English language scholarship in the United States. Anna was forced to make a decision between continuing on her career path in her home country or going to the United States where she would be enrolled as a senior in high school. Anna concluded:

I had to decide, like in a month, if I was going to quit school and go back to high school. Or if I was going to give it [the scholarship] up. Well, you know, I thought that the university was going to be there, and this was like a chance for me... to 
have a different experience and I spent one year in La Crescenta, California, which is near L.A. (Interview 1)

This experience proved to change Anna's entire life. While in California, Anna began to enjoy the English language. She had the flexibility to enroll in classes that she was interested in and this reflected how her appreciation for the English language developed. Anna expressed that she had wonderful instructors, and these experiences shaped who she would become as an English instructor, though at this point of her education she was unaware of how her educational pursuits would change:

Well, when I went to high school here, [in the United States] I had all that idea of the teacher I had, but when I was here I had wonderful teachers in high school. My American literature teacher was amazing. Even the drawing teacher was great, and I was the only girl in class. But everything was in English, you know he liked me so much, the last day he gave me, he used to make like Indian jewelry, and he was a very serious man, you know, "Anna, come here I have a present for you. I made for you." You know, all these little things that I said, they made me enjoy the language, made me enjoy the culture and that's what... you know, it's your role as a teacher. So, that's how I feel. It's not like language can be separate from the rest. (Interview 3)

After her ten-month experience abroad, Anna re-enrolled in the professional program that she had left behind to study in the United States. It was at this time that Anna began what would become her career as an English language teacher. Anna began teaching English as a foreign language at a local language school. She was only nineteen years old, pursuing her university degree during the day and teaching English at night. Even after Anna graduated with her Bachelor of Science degree, she continued to teach at the same language school. Anna's first stint as an English language teacher spanned across a six or seven-year period. For Anna, teaching helped her overcome her shyness. Her students were at similar ages and she developed a good rapport with them. Anna's interest in the English language also continued to grow. Being an English teacher fueled 
Anna's desire to gain a better understanding of the English language. As she continued to teach, she also sought to obtain skills to make her a better teacher. She took a variety of different international tests to support her teaching and her English education.

Eventually, Anna chose to leave her teaching position in order to focus primarily on her professional development. She was offered a job working with the city government and spent the next two years working in the public sector. It was during this period that Anna came to the realization that she wanted to further her education and return to the United States. Anna moved to Boston, Massachusetts. Anna shared with me that she hated the professional program that had originally brought her to Boston and chose to terminate her studies. However, it was during this period that she met the father of her children and their relationship lasted over six years. While away from her home country, Anna immersed herself in the South American community in Boston. Anna noted that the majority of people living in this community did not speak English: even though Anna was not teaching English, she was always helping with translation. Anna acted as a translator in numerous settings, including court hearings and at doctor's visits. Once Anna's relationship with the father of her children dissolved, she returned home to South America.

Once back in her homeland, Anna realized that she could no longer continue to work in her profession due to the time constraints of being a full-time mother to an infant and a toddler; the idea of traveling from one city to another and living out of a hotel room which was a requirement of her job was not sustainable as a single parent. In order to meet the needs of her children, she decided to pursue a teaching certificate. In her own 
words, Anna described her situation and reasoning to move towards a career in English education:

I had to do something that I would be home every night, that I could be close to the girls and that is when I decided to go back to school and get a license to teach English as a second language. I was able to challenge the classes and in one year I got my license. (Interview 1)

Completing a teaching certificate generally is a four-year process. But, because of Anna's previous independent study, she had completed the majority of the coursework. The majority of the classes she had to take in order to complete the requirements were outside of the realm of English. Anna had to complete courses in teaching methodology, psychology and governing rules and regulations that were put in place by the state. Before her graduation, Anna already had a teaching position secured at one of the international schools in the region.

After graduation, Anna was employed at three different English language schools in order to make ends meet. In our interviews, Anna only discussed her employment at two of the English language schools: an international school and a national center. The international school only offered instruction in English in the morning, while the national center offered classes in the afternoon. Anna made sure that her children were enrolled at the schools where she worked to ensure they were receiving English education as well as education in their first language.

Eleven years after completing her teaching certificate, Anna had already worked for thirty years and was eligible for retirement. However, Anna decided to leave retirement and return to teaching. Anna shared, "I thought I was going to enjoy, you know, being retired and I missed teaching so much so that is when I decided to get into a 
MA program (Interview 1)." Anna again uprooted her life and moved back to the United States. Anna has completed a Master of Arts in Teaching English to Speakers of Other Languages in the United States and has been teaching in an ESOL context for three years.

\section{Living in Two Languages}

Anna shared her own personal understanding of what it means to her to be a bilingual speaker navigating life in two languages. Both her native language and the English language play very distinct roles in her life. This change in language use can be attributed to her surroundings and the people she comes in contact with. When Anna resides in the United States, the dominant discourse surrounding her is English, and when Anna resides in her home country, her native language becomes the dominant discourse around her. Yet, Anna explained that each language has always played a role in her life and though it varies from context to context, that does not imply that she is ever separated from one language or the other.

Anna describes her native language as the language that ties her to motherhood; it is the language she prefers to use while communicating with her children. Even after living in the United States for six consecutive years, Anna notes that, "I still speak my native language at home with my daughters, because it's ours. It's you know... it's, how do you say? The language that bonds us" (Interview 1). Anna also shares how it feels to communicate with her children in English, mentioning "I think it sounds strange speaking English with them... Even though we mix the two [languages]" (Interview 1). For Anna the role of motherhood is directly tied to her native language. It is irreplaceable. In Anna's own words, "The language that I reinforce being a mother is always in [my native language]" (Interview 1). 
In addition, Anna believes that her partner, who does not speak her native language, has an understanding of who Anna is in her first language. Anna understands that language moves beyond lexical meanings into sounds and tones. She explains this by saying, "He gets the, you know... The words and by the tone of my voice... Yeah, he knows... (Interview 1).”

Throughout our conversations, Anna addressed that English, like her native language, has specific roles in the way she communicates. Anna provided many examples of her use of different languages. One of the examples that Anna highlighted was how she makes a conscious choice to swear in English. Anna does not swear in her first language because she feels that English swear words do not convey the same meaning as those in her L1. Anna stated that, "I think the impact in English is nicer" (Interview 1). Anna also explained that differentiating between the two languages helps her embody her different roles:

I think that it's good because you can appropriate the language that you feel more comfortable. So the nurturing language for me is [my native language], the swearing language is English. (Interview 1)

Anna indicated that as a bilingual speaker, she sometimes experiences convergence between the two languages. She acknowledges that this phenomenon is subconscious: "Working from one language to another, sometimes it's so unconscious that you turn to someone and speak in the other language... As if this person would be able to understand you in [another language] or in English” (Interview 1).

Since she was an adolescent, Anna has always lived her life in two languages. In our interviews, Anna indicated that the role of each language has fluctuated throughout her life. For example, when Anna is in her home country, English dominates her 
profession, but the use of English stops there. "Well, the things is, nobody speaks English in [my home country] and even if I had another job that required English, besides teaching. If I were like in international business, the use of English would stop there. So, for me it was very specific, like teaching English in class" (Interview 1). The division between English and her native language was clearly drawn within the international school setting in her home country. Anna described the school setting and explained how the students had started using the English language when they were two or three years old:

It was very interesting that for some things, they used in English. Like, having lunch. They could know what lettuce was but when they got home, they would even say lettuce instead of the word [in the first language.] (Interview 1)

The convergence of the two languages also played a role with Anna's children. Anna attributed the interference of English to the role of the international school system, "Some things they would tell and use the English words in [my L1] context... but is was because they were in the American school" (Interview 1). Anna furthered this feeling by stating that, "But, the daily routine in [my country], there is nothing that involves English (Interview 1).

Anna also reflected the role of bilingualism when she was living in Boston. Anna was engulfed in two different cultures and learned the importance of using each language. Anna stated that: "Boston had a very large [home language] community and you know, over there I would navigate from one language to another" (Interview 1). Looking back on her experience in Boston, Anna also noted that the majority of Latin Americans she knew residing in the United States didn't know how to speak English and spent the 
majority of their lives living in their native language. Anna gave the example of her children's babysitter stating:

She [the babysitter] had lived for ten years in Boston. She watched television [in her native language]... she read the newspaper [in her native language]. So, if she had to schedule a doctor's appointment, I would do that for her because she didn't know. (Interview 1)

Anna was also fascinated by how the two languages shifted to meet the needs of its speakers. Anna went into detail about how members of her community would modify the two languages to fit their needs. Often times they would borrow different English words while keeping the grammar structure of their native language. Anna explained this phenomenon noting:

They would borrow the root of the verb. And you would know what they are saying, but it's like, it's something that if you went back to [my home country] and said it that nobody would understand it. (Interview 1)

Anna shared that all these nuances between her two languages peaked her interest and helped her bridge her identity as a bilingual speaker.

In our third interview Anna reflected on the role of bilingualism throughout the entirety of her life. Anna noted that as her second language expands her first language shrinks. Anna's first language used to occupy her spoken discourse. However, this communicative space is now being occupied with her second language. Anna stated, "[English] is expanding, in terms of, not just skills but also the way I move around, the way I use the language" (Interview 3). Yet, Anna also shared the idea that even though language usage shifts and one discourse may become more dominant than the other, it does not eradicate the language that is not being used as frequently. For Anna, "You can always have both languages. It depends on the circumstances" (Interview 3). This self- 
awareness of language in different contexts has helped Anna articulate her lived experiences.

\section{Higher Education and Teacher Training}

In this section, I visit how Anna has navigated her life as a student in two postbaccalaureate programs including a teaching certificate program in her home country and an MA TESOL program in the United States. Throughout our time together, Anna discussed the differences and similarities between the English education system in the United States and in her home country. Anna clearly articulated the strengths of each program and how her multifaceted education has led her to become the English language professional that she is today.

Anna's career as an English language teacher precedes both experiences in higher education. As indicated in the previous section, Anna began her teaching career while she was an undergraduate student. Anna taught English for a total of eight years before transitioning into another line of work. Anna chose to go back into the education sector after becoming a mother. Anna completed a post-graduate teaching certificate in her home country. Anna then went on to teach for eleven years. Due to her age and the amount of time she had worked in both professions, Anna had already retired as an English language professional before she entered an MA TESOL program in the United States.

Though there was a large lapse in time between Anna's two post-graduate programs, Anna was able to articulate the two major differences between the teaching certificate program in her home country and the MA TESOL program in the United States. Anna explained that the teaching certificate program did not stress the importance 
of the theoretical side of teaching and that she did not realize its importance until she was enrolled in a graduate program in the United States. However, the strength of the teaching certificate program was its ability to provide its students with more formal practice teaching in a classroom. In other words, Anna felt that that certificate program placed its emphasis on the practical implementation of teaching without fully formulating the way research informs pedagogy while her graduate studies lacked hours spent teaching inside a classroom. The follow passage demonstrates the lack of theory in the teaching certificate program she participated in:

[In my home country] I never had to go through articles, and you know... It was more like you were being spoon-fed. That's what happens, not that you analyze and you tell me what's happening... like here [in the United States.] (Interview 3)

As a graduate student, Anna found herself immersed in the theoretical underpinnings of pedagogy and practice. Anna's interest in the theoretical aspect of teaching began to surface. Anna described a shift in her interests as a teacher, noting she was now able to correlate how theory and practice simultaneously inform one another creating an education continuum. Being able to understand and apply the pedagogical underpinnings to teaching became a foundational piece in Anna's academic and professional career. Anna described this evolution in her professional development stating:

[As a student in my home country] I had more practice than education, formally speaking... like in reading articles and knowing all kinds of theories... I had more practice and less theory. I feel that the program [in the United States] completed my education. I feel that it not only gave me a theoretical grounding but also guided me on continuing learning. I mean... I enjoy reading an article in certain areas, or you know? This for me... was not so important before. I think I was more a teacher for inspiration and right now, I think that I value the theoretical more than in the past. (Interview 3) 
Even though Anna had already retired as an English language instructor, Anna shared that graduating from an American university with an English teaching degree gave her a sense of pride that she had never experienced before saying

It [completing a graduate program in the United States] gave me a sense of accomplishment. You know, being able to teach a language that's not yours in another country. It gives you some kind of private satisfaction. (Interview 2)

For Anna, completing a graduate program in the United States reinforced her ability to teach English and the way she interpreted herself as an English speaker. Anna shared with me that this sense of pride as an NNEST is something that she tries to convey to her students. Anna understands what her students are going through as English learners and she can share her experiences in higher education as motivation:

Well, the feeling of pride is... I don't know if it's not just... it's only pride but it's also, the ability to transfer that to my students, like that, 'You can do it.' That's what I think, you know, but it doesn't... it's also a little pride, you know, like, "Ok, I accomplished this." You know. Like, in two years I finished this degree. It's like I put my mind to straightforward and I said I knew it would be a big challenge and I got it. For sure, whoever goes through a program knows that even if you are a native speaker, it's not easy and... I felt really confident on what I was doing... So, it gives me a certain satisfaction and pride in this. (Interview 2)

Anna's experience in two post-baccalaureate programs has helped Anna understand the importance of theory and practice. Anna has been able to redefine who she is as an educator by correlating the strengths of each of her programs and using them as the underpinnings to her teaching practices. In the coming section, I explore Anna's life teaching English in two contexts.

\section{English Language Teaching}

This section looks at the way teaching in two different geographic contexts has shaped Anna's overall understanding of herself as English language teacher. Anna clearly 
articulated how teaching in two different contexts provided her with a multi-dimensional understanding of English education and has further developed understanding of self as English language instructor. Through her own experiences living, learning and teaching in two different contexts Anna has explored the differences between the United States and her home country. Anna's commitment to her professional development, along with her ability to cross cultural borders, has provided her a multidimensional view of her life as an English teacher. This shift in understanding will be exhibited in the coming section.

Throughout our time together, Anna expressed that there are similarities and differences between teaching English in her home country and in the United States. However, Anna attributes some of the differences she is experiencing teaching in the United States to the changes that have occurred over the course of her life. Anna correlates some of these changes in her perception to her age, having previously retired as an English language professional, knowing that she does not have the same level of responsibility now that both of her children are grown adults. Anna shared that she does not have the same kind of pressure as a teacher and as a mother that she once did. This feeling is reflected in how she perceives what life looks like for an English teacher in her home country in comparison to what teaching English looks like in the United States. Anna described what her routine looked like as a single mother teaching English in her home country:

I was a single parent, raising a family and paying all of the bills. And well, in the morning at seven-thirty, I would be at the international school... the kids would start with breakfast there. The school would go from seven-thirty A.M. to four o'clock and then they had extra classes. They could leave at six-thirty P.M. So, at seven-thirty A.M., we would start classes and I would teach all levels. And 
depending on my class, like I was the head of one of the classes... but would go to another, so we would teach, grammar, reading, writing, listening, conversation, social studies that was related to American history. Also, the kids had nutrition, we would prepare plays for events like Thanksgiving... We would have the Pilgrims and the Indians. So that would be until twelve o'clock. Twelve o'clock because English was just in the morning and then they would study in [their native language]. I would teach, go and I had classes in the afternoon, like three or four times a week. I would teach at the Catholic school in the K-12 as well. Right there, the environment was totally different. I would have up to forty-three students in the class. (Interview 1)

As a full-time teacher in her home country, Anna shared that she often felt a sense of guilt if she was not working. For Anna, teaching felt like a constant commitment that required some of her time every day saying, "Lesson plans were Saturday and Sunday, I would feel guilty if I were not working. I would leave Sunday my house to go to my Mom to have lunch and then, you know, so I was working like, everyday.” (Interview 1)

Now that Anna's children are raised and she already has a retirement package from her home country, she does not feel the pressure to work full-time. Anna has made the conscious decision to be a part-time ESL teacher. Anna is aware that this decision has affected how she understands English language education in the United States. She also understands that different teaching positions in the United States are similar to her experiences in her home country:

No, so it's so much easier here [in the United States] compared [to her home country]. I mean, but I think it has to do with my life now, because that's why I don't even want to apply to be a full-time teacher. Because I have heard that there are some places that you work like as I used to work in [my home country]. Like you have to have twenty hours in the classroom and then you have to prepare for class, so it's twenty hours in the classroom, plus the preparation. (Interview 1)

Anna also expressed that the amount of work each teacher endures may be similar in both contexts depending on the school setting, but a key difference between her home country and the United States is a teacher's income: 
I think that it's easier here I'm in a different stage, but if you are going to be a teacher, you know, I think it's going to be the same thing. The difference is that probably you are going to be better paid here. But teaching and preparing classes, I think in any country, if you are responsible, it is hard... To be a good professional is hard. (Interview 1)

Even though Anna has more time to herself as a part-time ESL teacher, and she feels that she has fewer time constraints then she did in the past, Anna still expresses that her commitment to teaching has not changed. Anna has a deep understanding of what it means to her to be a good teacher and this is reflected in her work ethic. For Anna, being a teacher in either context is an act of selflessness:

You have to give up a lot of your personal life. I mean it's not just a work that you go to... like you teach and you leave. You go to the office, you teach and you go home... and so you have to be patient and you have to be ready to give up Saturdays, Sundays, and holidays. (interview 2)

Anna stated that just because the teaching setting may change because of physically being in a different geographic location, it does not entail that the way a teacher teaches will change and it does not negate what being an educator requires. In her own words:

I'll be a teacher here, I'll be a teacher there. Ok, I'll give up my Saturday nights here. I'll give up my Saturday nights there. I'll try to be a role model here. I'll try to be a role model there. I think that the difference is where you teach your students. You have to be flexible and adapt to each situation. (Interview 2)

Over the course of our time together, Anna did make some distinctions between teaching in the United States and her home country. As mentioned above, wages for teachers seem to be significantly higher in the United States than in her home country, but in Anna's opinion wages in the United States do not necessarily correlate to a higher standard of living. When Anna compared the cost of her education in her home to the standard of living, she was able to point out a key difference. In her home country, Anna 
was able to create a certain standard of living that she does not think is possible in the United States. Thus in her opinion, the United States does not place the same value on education:

Well it's hard, it's like. Well getting a full-time job is really hard, I think it's been challenging these days. Also, even though, in [my home country] I was kind of underpaid, but I was kind of underpaid in a way that I had a house that [was] paid for. I had a brand new car, you know and right here, I have a masters and your pay can be forty thousand dollars a year. I mean go serve cocktails in a bar and you make more money, so I don't think there is recognition for the investment you make in your career because you'll be paying your student loans for ten years. And forty thousand [dollars] for me is like in other areas is like anyone with a bachelors can start with that. So in a way I think that for teachers it's not very motivating. (Interview 1)

Anna illustrated how the differentiation between wages looks between the United States and her home country saying:

If you compare someone making forty thousand dollars here and someone like in [my home country] working full time as a teacher at a university salary, you would have more than what you have here. I was a single parent and I bought a house and paid for [it]. I had a car. My kids had braces that you know [but here] with forty thousand dollars I would share a room, I would have to share a house with roommates, I mean you know, and all this medical, I had full benefits there like you know, I never thought about. So, I think and I pay my student loans so I think that, you know I have a status here but I don't think that the pay corresponds to what it should. (Interview 1)

Anna also commented that teachers in the United States have more access to educational resources, which in turn makes developing curricula easier. Anna articulated that teaching in an English speaking country gives teachers access to a plethora of teaching material that teachers do not have in countries where English is not the first language. This access to materials supports learning objectives and makes English language teaching more approachable from a teacher's standpoint:

I will say that in the U.S. ok, you have more resources so even for example when I walk into Dollar Tree and I see all those things for teachers and I think, 'Oh I 
wish I had that, those in [my home country] when I was a K-12 teacher.' (Interview 1)

It is not uncommon for teachers teaching in English-speaking countries to take the access they have to materials for granted.

Another key distinction Anna made between the United States and her home country was the relationship between teachers in relation to collaborating and in-service education. Anna explained that teachers exchange more information with each other in her home country. She feels that there, teacher collaboration is a more common practice in comparison to the current setting that she is teaching in. Anna also noted that building a sense of community by the administration was a common theme that she has not experienced to the same degree in the American education system:

In [my home country] we were, like [at] every school I worked, there was more interaction. Like, we had weekly meetings with coordinators at all three schools [I worked at]. We had weekly meetings, we would exchange a lot... that even made me have those teachers as best friends. (Interview 1)

However, Anna also explained that her understanding of teacher collaboration is solely based on her current teaching context and she is aware that her interpretation may be skewed because she is a part-time teacher by saying:

I don't know if it's because I'm not teaching full time, but I felt a lot that we're not having this kind of [support]. A lot of things are done online [by the administration and teachers]. So, I have orientation when I stared working, we had a teachers training online, like week-by-week we had to but I think that the human part was more evident. I miss those hours of contact...It's like the teamwork is really important even though you are going to teach your class, individually. These interactions, these exchanges of information, these exchanging of ideas, 'Oh I did this, this worked for me'. So in a way I think also, we're in a different era so you can do that online and we do. (Interview 1)

In her reflection, she explained that she realizes that communication has changed with the rise of the internet and its dominance in how we communicate. However, Anna also 
noted that collaborating does not have the same connection to human interaction that it once did. Anna is still able to share ideas with her colleagues but often times it looks and feels different:

For example, I've been teaching a class even though there is for each level or each subject, there is like a head [teacher]. You can usually get together with a few teachers and exchange what you have been doing. It's something that you can promote yourself. I mean in any environment that you work, there are people that you to feel closer and that you can, you know? So I think that it's a matter of you doing it. (Interview 1)

Anna shared that in any setting you will find people who you feel closer to and in turn it becomes more comfortable to exchange ideas and classroom experiences. Thus, the role of collaboration has changed in relation to professional development and inservice teacher training. Anna explained that in her home country, teachers exchange information in informal settings, while here, in the United States, Anna learned the importance of continual education in the form of professional development. Anna explained that participating in conferences, reading current studies and conducting research was something that was very new to her when she entered her graduate program in the United States. Moreover, this continual quest for knowledge within these parameters is a new experience for Anna in relation to her past teaching experiences:

Something else that I really appreciate here on teachers is that the majority of us are trying always to improve in terms of, you know, taking courses and participating in organizations. I think that's great, something that I didn't see many [teachers in my country doing]. Like, I think that here they are more careful about their professional development [here] than in [my home country]. (Interview 2)

For Anna, teacher development looks different in the United States because, "We were not just sharing papers, we are more sharing more experiences...We can share experiences by attending conferences, [and] presenting at conferences" (interview 2). 
Anna also shared the she thinks teaching in the United States is more competitive than in her home country.

Anna stated that in-service training and continuing education has importance in her home country, but the manner in which it is delivered is different saying, "So my routine there was like we all shared the same schedule. We shared the same breaks, and we had Fridays dedicated to meetings and exchanging experiences and preparing tests" (Interview 2). Anna also commented that different schools had different expectations for teachers and the way they received in-service training:

What I thought was really good about the binational center is that they made you progress, like first of all you had to take the TOEFL twice...every two years and keep a high score. Also, in the beginning of each semester we had lectures and we had teacher-training programs, we had workshops, we had projects. I really liked it... There were some years that I would go and teach evenings because I really enjoyed the environment there. (Interview 2)

Anna also identified how student populations are different between her country and the United States. In her home country, Anna primarily taught children, though she did have adult students at the binational center. Anna shared that,

"I think the differences are more on the age of the students, [and] the monoculture of the students" (Interview 1). She said that one of her favorite aspects of teaching in the United States is the diversity she experiences inside of her classroom:

Well, I love to see students from all over the world, I think that it is so interesting to be in contact with all these different cultures, with different learning styles which makes it a little challenging so I think that is the plus, get to know people, like the first time that I had... a Muslim girl in my class, that I could not even see her mouth, like how am I even going to teach this girl, if I can't, like I can't even read her lips... So all these challenges, all these cultural variations, I think it's really exciting and really neat. So, that's what I really like about teaching here. (Interview 1) 
Anna shared that intercultural communication and competence is one of her favorite areas of research and this aspect of teaching in the United States and she tries to build the idea of cross-cultural communication into her teaching practices.

Finally, Anna shared that English language education is dominated by non-native speakers teaching-English in her home country. Over the course of her career Anna did not have a lot of experiences working with native speakers until she relocated to the United States. Anna explained that:

There are not many native speakers you know even at the American school where I taught. The Principal was from South Africa, but she was the only native speaker. And we had people who had different experiences like being an exchange student in the U.S. like me, or England or in Australia. And so, over there we didn't have native speakers. (Interview 1)

Anna's lived experiences as an English teacher in two different parts of the world have provided her with a multidimensional understanding of English education. Anna's understanding of English education crosses hemispheres, which provides her with a deeper understanding of cross-cultural communication. Her keen awareness of self as a learner and as a teacher illustrates how she is able to place herself in different contexts while being physically positioned in the United States. This in return, gives Anna a multicontextual interpretation of learning and teaching objectives that she can apply to fit her students' needs. In the coming section I visit Anna's understanding of self as an English educator.

\section{A Teacher and Her Philosophy}

In the previous sections, I have visited the historical role of English in Anna's life, illustrating how she interprets living in two languages and how the English education system has shaped how Anna perceives herself. However, I have not yet looked at Anna's 
understanding of self as an educator. In order to better understand Anna as a multicultural agent, it is necessary to explore Anna's interpretation of self in regards to her teaching philosophy. In this section, I describe key aspects of Anna's personality in relation to how she views herself as an English educator.

In our second interview together, Anna shared how she defines the term teacher. Anna explained that teaching is what you choose to do as a profession while the term teacher defines what you choose to incorporate into your teaching repertoire, which also incorporates your behavior in and outside the classroom. Another key distinction for Anna was the belief that teachers are role models to their students stating:

I believe that teaching is what you choose to do and when you teach you don't teach just English. I don't know if it's because I came from the K-12 system. You are a role model. So, I think that I can be a role model as an English instructor, I can be a role model as someone who struggled to learn English. (Interview 2)

Equally important to Anna's interpretation of the term teacher is the idea that teachers do not change who they are due to context. Once people establish who they are as teachers, this becomes the base of their teacher identities and it does not change due to location, or school affiliation. Once teachers develop into who they are as educators, it becomes an inherent part of their psychological identity. From this position, teachers may adapt their curricula to fit the needs of the students or to support the wants of the school, but the heart of the teacher remains the same:

It's like I'm not going to teach differently or behave differently because I'm here or there. Maybe, I can adapt a little bit to my student's learning styles... but who I am as a teacher, I'll be anywhere... Even if I'm not teaching, I'm thinking about what I will be teaching. You know, I think it is part of who I am. That's what I think, you know, you can call it instructor or you can call it...but it's like the idea of what a teacher represents and I don't think, I think if you choose that as a career, it's part of you. (Interview 2) 
Anna's portrait of a teacher is a person who understands that her profession is deeply embedded into their psychological understanding of self. Furthermore, the most effective teachers all have certain degrees of empathy and patience inside of the classroom:

You need a lot of patience, you have to be someone who is committed to learning for the rest of your life, you need to be...very... How can I say it? Empathic, empathy, I think is empathetic. It's a key component, it's like you know, you need to put yourself in your student's shoes, in their struggles... (Interview 2)

Educators need to be able to practice compassion and understanding when viewing their students' strengths and weaknesses as language learners. Anna clearly stated throughout our interviews that understanding who her students are is a crucial element within her teaching philosophy. Anna stressed the importance of teachers needing to be able to identify with their students as learners. Anna illustrated that this understanding comes from her own struggles as a language learner and this belief is further fueled by her students' positive feedback that they feel close to her because she understands them. Anna displayed a deep understanding of what her students endure to learn the English language. Throughout each interview Anna continually built upon the notion her identity as an English learner is deeply woven into her teaching philosophy. This common thread is intertwined into her understanding of self and helps her be more empathic to her students' needs. Anna also explained that her awareness of her students' struggles allows her to see the questions being posed inside their heads:

I feel confident about teaching and what I think that is a plus. I can really, I don't know if it is a problem a matter of empathy but I can see like a question mark in my student's forehead. I mean I'm not just there to give a lecture. I'm there to see, you know, being in the same path so I'll support you and you can do it. So I think that's the difference between a non-native English speaker, you know, I think that is even like if you are on a mission, like I feel like... You know, what I think like you can do it, I'll support you and I've gone through that and you can do it. (Interview 1) 
Another essential piece of Anna's teaching philosophy is her ability to be compassionate to her students' needs outside of the classroom. The shift from teaching children to adults is apparent in her approach, as she is aware that her students have lives that unfold outside of the English language classroom. Anna noted that she is willing to offer accommodations if they are able to convey their needs. For her adult learners, school is just a single component of their lives and Anna wants them to succeed. Anna gave a real life example of this saying:

So, today there was one of my students, he didn't bring his paper. And I'm teaching research writing and today was like the due date for paper one; [the] first draft. He showed up in the office and he said, "I don't have the paper for you, you know my mother is here. She wants to go shopping, she goes to the zoo, I haven't missed one class but after class I need to give my mother some attention but she's leaving on Friday." So, "Ok today's the due date, what are you going to do?" "I'm going to work Saturday all day long and give in the paper." So, in a way am I going to punish him? Or am I going to grade him at the same level of the one [student] that has sent me 1,000 emails saying, "Oh, ok, oh I didn't bring it to class, but as soon as I get home I send it to you. Oh I can't believe what happened to my computer. I deleted my paper." Or you know, things like this. So, I think that you need to understand your students, I think that's really important. Like, but I think you have to have very good common sense, you need to be aware that you are a role model, an example. Ok, I think that you have to monitor your behaviors, you have to monitor your reactions and that's why I say that patience and understanding are very important. (Interview 2)

An additional key component of Anna's teaching philosophy is the importance of taking the time to know each of your students on an individual level. Anna revisited this theme throughout the interview process, and each time she stated that by knowing your students on a personal level, you are able to meet their personal learning objectives while maintaining the structure of the classroom objectives:

So you need to build rapport with your students. I think the first thing they need is to trust you. And, if they trust you and you have this connection, it's going to be much easier to impose certain rules in the classroom. Or to demand certain things, 
I think it is more important to say, "I'm very upset with you, I didn't expect that from you" than say, "you have a zero because you didn't do it." (Interview 2)

Cultural understanding has become a key component of Anna's teaching philosophy. Anna stated that the role of cultural competence as a teacher is a new development for her. Anna shared that awareness to differences in cultural norms became prevalent while teaching in the United States. As a teacher in her home country, the importance of intercultural communication was not as inherently important because the population she was teaching was primarily mono-ethnic. Anna recognizes her shift in cultural understanding as a growing interest that she would not have been able to pursue in the context of her home country. Cultural learning has helped Anna shape her teaching objectives away from conventional standards of teacher-student interaction.

Anna wants students to know that she is approachable and she wants to offer them additional support. This desire to offer her students additional support stems from her own experiences as an English language learner. She also wants her students to realize that she will continue to support them as they continue on in their personal academic pursuits. Anna believes this commitment to her students is one of the reasons her students continue to reach out to her after their time in the ESL class is over. Anna is driven by the compliments her students give her and she believes that her students often feel strong connections to her as a teacher and as a role model because she can relate to their experience as learners:

[A lot of students say that] "Well, I miss you because you understand me." And, I think that the point is that, "You went through this and you are understanding our situation." Not that I'm... I'm easier, but I'm more flexible. As I was saying like about this excellent student whose mother is here [refer to the quote above], I think also that I'm able to see things from my student's point of view as a learner 
and the point of view as a teacher. You know, I was a learner. And sometimes I don't understand the way things are done. (Interview 2)

Again, Anna explained that her role as a second language learner and her commitment to the English language is something that she wants her students to understand as a positive attribute. Anna finds strength in her non-native speaker status. Anna enjoys her English accent while speaking in English and believes it has significance by saying, "That's your trademark, your accent" (Interview 1). Her accent, along with her attitude illustrate the idea that "if I can do it, you can do" (Interview 2) illustrates how language variation can be powerful in the classroom. Anna seeks to empower her students so that they have the inner strength to face their challenges.

This section has sought to provide insight to who Anna is as a teacher. Anna understands that her position as a language learner and as an English teacher is empowering to her students and can help shape their understanding of the learning process. For Anna, language learning is a life-long commitment and she hopes to instill this same belief in her students. In the next section, we will explore Anna's beliefs about how others view her as a teacher and an English speaker.

\section{Self-perception and Identity}

Over the course of our time together, Anna and I revisited what it means to be a bilingual speaker and also what it means to be a non-native English speaker teaching English. As illustrated thought the subsequent sections, Anna has a sense of pride that surrounds her perception of self as a bilingual, non-native English speaker. Furthermore, Anna has a deep understanding that she is a role model to her students and being a nonnative English-speaker is empowering to her students. Yet, Anna shared that sometimes 
she feels that being a non-native speaker may change how others perceive her. In the coming pages, I will explore Anna's understanding of how others perceive her in relation to being a non-native English speaker.

Throughout the interview process, Anna and I spoke in depth about her experiences as a NNEST living in the United States. During these conversations, Anna noted that she has never been explicitly Othered due to her accent or perceived language difference. Yet, when I asked Anna if she had ever been implicitly Othered, Anna shared that she had indeed felt the implicit undertones of being Othered during her graduate studies. Anna described one particular experience as a critical incident that has stayed with her and continues to weigh heavily upon her and her decisions as an English language teacher. In her reflection, Anna shared that this incident occurred in one of her teaching methods classes. Every TESOL program has a teaching practicum attached to its requirements. During the first sequence of the teaching methods courses, a guest speaker came into the classroom to recruit students to teach English in a community ESL setting for a practicum attached to a TESOL program. Anna shared her experience stating:

Well, she said that, "Alright, you should sign up to [teach in at the] practicum," and somebody asked, "But I'm not a native speaker," I was not the one, it was somebody else. "No problem, you are going to teach immigrants. If you were teaching at the [university] with students that pay, that bring a lot of money or pay a lot, then you wouldn't be OK, but in this setting you can sign up. (Interview 2)

Anna explained that this one interaction left her with the negative feeling that she would never be able to teach at the university level. Anna said that her initial reaction was, “That made me feel, 'Fuck!' Sorry... 'What am I doing here!' My money is good, so where is this fucking campus that is so... They praise diversity. Diversity is the money that we bring. They are very narrow-minded" (Interview 2). 
This experience had such a profound effect on Anna that she thought about leaving the program, "At that moment I felt like quitting grad school. So, what am I doing here?" (Interview 1). When I asked her how she overcame these negative feelings, she said:

Talking to other students in the program. You know, sharing my frustrations at home. And for a certain point... it's part of who I am. It's like, "I'm not going to give up," because it's not me to give up. Also, I took these courses for other reasons. And I'm not going to be a quitter because I have to be an example, for my children. And if I committed to finish this course, I'm going to the end, until the end. (Interview 2)

Anna never taught in the practicum. Instead, Anna made the conscious decision not to participate in the teaching practicum and to find a way to empower members of her community. Anna still needed to accumulate teaching hours in order to complete the teaching component of her degree. Anna knew that she wanted to invest into her community and support language learners in her neighborhood. She when to an elementary school close to her house and spoke to the principal. Anna shared the following:

[I thought], "I'm not going to pay for practicum. I'm going to empower my community for free. I'm not going to get paid, but I'm not going to pay for that... When I realized that I wouldn't teach for the practicum and I needed teaching hours. I wanted to teach and have the experience so I went to teach in my community here in [the United States]. I went to an elementary school and I showed my credentials, I took my resume and I said 'if I can help you I am available in the evenings.' And they said they had a group of parents that could really benefit from further English instruction. I taught for five terms... And we became a community. (Interview 3 )

Anna taught in the community for five semesters. In that time other students from her university taught with her and she developed and implemented a curriculum for her students. Anna never thought twice about her decision not to participate in the teaching 
practicum and was satisfied with her community ESL class. From her experience at the university, Anna thought that she would never work at the university level in the U.S. because of the hurtful comment one person made in her methods class. However, one of Anna's colleagues, who was also an NNEST contacted her and told her that a local university was hiring:

In our third interview, Anna revisited how she felt when she went to the interview. During this conversation Anna added a few more details, saying:

Well, when I went to the interview, I went with the idea "I don't know what I'm doing here." Because one of the instructors came to the class and said, "Well you can take practicum to teach the immigrants." Like community ESL you know but, "Not in the [university] because those international students pay a lot." So I had that in mind, even you know, I told in the interview, "I don't know what I'm doing here. I drove all the way [from another city in the Pacific Northwest] for this and honestly..." You know I think I was so honest that, you know... (Interview 3)

Anna has now taught at the university level for over two years. Although now she feels confident in her role as an NNEST on a campus that supports diversity, her first memories were bittersweet. Anna remembers:

Well it's something progressive, you feel, term by term, you feel better, you feel. You know... The first term, I was walking on eggshells. Ok, I mean, you don't know what to do, you don't know if you are going to have any students that are going to ask to be transferred to another class because of your accent or... (Interview 3)

Looking back over her experiences so far, Anna noted that she has felt supported as an English teacher. Anna no longer questions how academic directors perceive her. Though this progression was gradual, Anna was able to articulate that even though she questions herself, her directors always offer her support. She also shared that throughout 
every step of her employment she has felt encouraged to teach classes that didn't originally have the confidence to teach:

Well, I was kind of anxious, because of I had been told before. But this staff was really supportive, like those who hired me, like I [told] you about [my coordinator], that was in the committee... she was my first coordinator there..., you know, I had the best support and... And like it's my sixth term there. I was teaching Grammar II, Grammar III, and then all of a sudden I get an academic writing class and I said, "Well." [my coordinator said] "Oh yeah, you went through the process, I'm sure you'll do beautifully just let me know if you need anything." (Interview 3)

Anna also recognized that through the continual support from the managing staff Anna has been able to become the kind of English teacher she always sought to be. In simple terms, receiving support from her supervisors has had a profound effect on her:

So all this built up [my] confidence, and you feel comfortable in the environment. So, I don't want to think about leaving or going anywhere else. I really feel good. Because I felt very well supported and, you know... (Interview 3)

Anna's insecurity about her accent and the variety of English she speaks also caused her grief when she first started teaching at the university level. Anna feared that her students would reject her and would want transfer into a different class because she was not a native English speaker:

When I start teaching and I [thought], "Will any students leave my class and go to another teacher because I'm not a native speaker?" ...I thought, "Well." Well, maybe it was still in my mind what that teacher said that they pay a lot of money to come and... Remember that I told you about when I was in Methods and she said, "Well the high up students pay a lot of money to have..." But never... (Interview 3)

However, feelings of inadequacy due to her accent started to dissipate as her confidence as an English teacher in the United States developed. Anna now feels confident as a NNEST and likes to make her students aware that English is not her first language: 
I like to pronounce my name as it sounds in [my first language], so I like to say [my name], and I like to see their reaction because especially if I have [students from my home country] in class, they kind of pinch each other. But I don't say any word, you know. And... so usually I don't say anything, like on the first class. But... I kind of mention and they realize that I'm not a native speaker, but I like the reaction... 'Oh that's great. Where did you learn English? Oh!' You know and...it's funny because they also have a very positive... vibe about [my country]. You know, I don't see anyone that doesn't like it. (Interview 2)

Now, Anna is able to use her role as a non-native speaker to mentor her students. She also is able to use the English language as a comic relief:

Oh ok, so it's funny when they ask how long have I been studying English and I said, "Well I start studying English when I was ten, eleven and now I am fiftyfive." "Oh my God, it's going to take that long to learn English?" And I said, "No, I'm a very slow learner and by the way I didn't like English, you know so..." "Oh you didn't so I still have some hope as you do." "So, don't worry. You know." (Interview 2)

Yet, Anna still is aware that she still has insecurities surrounding her speaker identity due to her non-native-ness and she cannot decipher if it is her own insecurities, or if the feelings are valid. From this position, Anna has insecurities that surround the language and how others treat her:

You know, so even though I don't know if I discriminate myself, like that I felt a little insecure or, you know, but I can see that not everyone but some people can doubt your ability... Some teachers, you know what I mean... I don't know, it might just be my personal...you know... you know it might be my... It might be something (Interview 2).

These feelings linger in Anna's professional life and make her question her position with newly hired staff members. Anna shared that sometimes she feels like she is being judged by newly hired ESOL teachers who have recently graduated and are just entering the field. When I asked her to elaborate about this feeling she said:

I don't know. I think that some, I don't know if it's the attitude on some young just graduated that, well you know. Something sometimes in the teacher's lounge or something that... You know, but maybe it's their own attitude. It's just the 
feeling I get. It's not something that I can point or say. That I think some that their faces are the same to everyone or just me, you know. (Interview 2)

Yet, Anna is deeply aware of the effect of her insecurities and is extremely reflexive in her self-analysis. She has sought to develop coping strategies to help move away from her own these feelings of inadequacy:

Ok I think that, you know something that helped me a lot to overcome a little bit of, “Am I good for that?" You know, “Or not?”[Is] when [I] participate in international conferences. (Interview 2)

By focusing on self-development, and using her non-native-ness as a strength in the English language classroom, Anna has crafted her own voice as an English educator. Knowing that TESOL International has a whole interest section that looks that NNESTs

helps Anna connect with others who share her same struggles and reminds her that she is not alone.

This section has sought to explain how Anna interprets how her colleagues and students perceive her. The section also demonstrates how Anna is constantly exercising reflexivity to understand herself and those around her. In doing so, Anna is better equipped to explain how her perceptions have come into play and have affected her as an English language teacher teaching in the United States.

\section{World Englishes and English Language Education}

In developing my research questions, I wanted to explore how my participants understood the role of English as a global language in relation to language variation and instruction. As Anna is a non-native English teacher, her views on the values of different varieties of English are of great importance to the thesis. In order to explore Anna's interpretation of English language variation and instruction I sought to elicit her feelings 
on fluency, accuracy and intelligibility. This section is primarily concerned with Anna's interpretation of the World Englishes paradigm and how it is reflected through English instruction. In the coming section, I will explore how Anna understands the role of fluency, accuracy and intelligibility inside of the ESL classroom in relation to the World Englishes paradigm.

In the final interview, I wanted to explore the role of World Englishes in relation to Anna's teaching practices. In order to do so, I asked Anna to contemplate the phrase "English belongs to all those use who use it" (Kachru, 1988, p.1). Anna instantly said that she understood English as a global language, which is now used in a multitude of different contexts to meet the needs of its speakers.

I think that if you use it [English] properly, even the differences in accents they kind of give it a spice on that. You know, so when I see an Asian man doing businesses and, you know... And all the situations, I think that it belongs to everyone. If you think about $90 \%$ of the [web] sites are in English. And it's the universal language that you can communicate. And, I think if it is something that is taken universally, it belongs to everyone. (Interview 3)

Next, I asked Anna contemplate the same quote, "English belongs to all those who use it," and think about what this quote means in the English language classroom. Anna stated:

Well, I think it is the thread that you build to each one of your students. No matter what culture they are from. So, it's a commonality that you have and it's the means of communication, because language is communication. Well, let's think about your classroom as the globe. When there are all these dots, ok. So in a way, these dots, if you're in a classroom you can, you know, build connections. It's like reuniting all these dots. And English is the thread where, you know, you unify all these dots. That's how I feel. (Interview 3)

Anna shared that she believes she can use the role of the English as an international language to motivate her students. She also shared that English can bridge different 
communities and cultures, thus building a sense of intercultural competence and awareness in the ESL classroom.

One of the key concepts in understanding Anna's position on language variation in the ESL classroom is the role of "fluency." Anna explained that she believes fluency is something that is acquired through use and experience. Anna also noted:

When I talk about being fluent I even kind of joke with them and I say, "Well, have you dreamed in English yet?" So, that's the first step that you realize that you are acquiring a language. It's something unconsciously. So that's how I think, that it's something that's progressive and you expand with the time. But I think that there is no limit, so you can learn your whole life and you, you know, until, you know, I don't think there is a limit for fluency. (Interview 3)

Anna furthered her explanation stating that fluency is a gradual process and is something that expands over time. From this perspective, fluency is acquired over time and it is necessary for students to have patience with themselves in order to understand their improvement.

Another area that Anna and I discussed was the role of accuracy in ESL education. Anna explained that the notion of accuracy varies according to the subject that is being focused on. For example, the way a teacher approaches accuracy will change depending on the subject matter. For example, if a teacher is teaching grammar or structured writing, then the role of accuracy is more prevalent than a teacher teaching speaking. Anna elaborated on this idea saying:

I think it depends on the level of my students. So, I try not to correct directly because I think a lot about the effect I felt too. But there are some things that you cannot just pass by. Something that really bothers me is like indirect questions like, "Can you tell me what time it is?" instead of, "What time is it?" I mean, "Can you tell me what time is it?" ...So things like that, they sometimes bother me more than others. But it depends, I'm teaching guided research writing now. Accuracy is... it's an academic paper that is important, you know. Even using the APA style so the level of detail that is required, is enormous. But, if I'm teaching 
Listening and Speaking II, I'm glad that they can express themselves even with mistakes. So, I'm not that picky on their mistakes. But even the mistakes I try to paraphrase or say something. You know, I wouldn't just pass by. I said, 'Oh, do you mean this?' But without correcting, you know, straight afterwards. Because I'm very careful about how they might take that. (Interview 3)

Anna also explained that intelligibility like accuracy is dependent on students' overall language comprehension. Teaching intelligibility is reliant on the focus of the class and varies day-to-day. For Anna, teaching intelligibility becomes more important for higher-level students, as intelligibility is a part of the progression of language learning. Anna articulates that intelligibility, like fluency and accuracy expands over time. For Anna, fluency, accuracy and intelligibility are directly related to the idea that English is universal and it adapts to fit its speakers' needs:

Well, I think it has a lot to do with English as being universal, you don't expect the same level as a native speaker. I will never get that, and you know. And, so I think you have to be flexible and judgmental, "Is this going to affect communication?; or "Is this being something that's totally out of what it's expected?" So, I think that it's very important that you follow what is expected of that student in that level. (Interview 3)

Anna also stated in relation to fluency, accuracy and intelligibility that it is important to give students positive reinforcement during the learning process:

I think that you should always praise when they do some... don't be so judgmental. But praising is something that makes every learner feel better or good about themselves. I like to make notes, you know... if they do well on a paper or some other task. (Interview 3)

For Anna, building confidence in the classroom is equally as important as teaching her students about fluency, accuracy and intelligibility. As illustrated above, Anna is deeply committed to her students' success and seeks to remind her students that English is a global language. In doing so, she addresses that there will be variation among 
speakers and this is not a hindrance in their ability to be comprehensible English speakers.

This chapter has sought to paint a portrait of Anna as a multicultural agent, who lives her life in two languages. In order to do so, I have explored the historical role English has played in Anna's life. I have also described how Anna understands her life in two languages and in two different cultures. Finally, I looked at Anna as teacher and explored what she finds to be important in the ESL classroom. In the next chapter, I explore Jasmine and Anna's understanding of self in relation to their individual teaching objectives, perception of self in others eyes and the role of language variation in English language education. 


\section{Chapter 6: Discussion and Conclusion}

\section{Introduction}

This thesis paints individual portraits of two bilingual speakers who have successfully navigated their lives as NNESTs living in an English-dominated society. Though each chapter was structured to mirror the other, Jasmine and Anna's personal narratives are vastly different. During the writing process, I held onto the belief that stories, like social identities, are co-constructed (Menard-Warwick, 2014). To speak to the authenticity of this study, I asked Jasmine and Anna to review the individual narratives that I constructed to ensure that their voices were upheld. With the support of Jasmine and Anna, I am able to share their experiences and offer a glimpse into their lives as English educators. While creating Jasmine and Anna's individual narratives, I made the conscious decision to present Jasmine and Anna in separate chapters to illustrate how the construction of identity is assigned and claimed (Blackledge \& Pavlenko, 2001). By separating the narratives of their lives into individual chapters, it becomes apparent that many of their shared experiences have involved interactions with a broken system. I maintain that the implicit Othering that both Jasmine and Anna endured, along with their continual bouts of self-discrimination, are a direct result of discriminatory practices within English language teaching.

Though Jasmine and Anna share similarities in their historical past, including a shared nationality and first language, the way that they have dealt with implicit Othering within the United States education system and the degree to which they have selfdiscriminated are extremely different. The first two guiding questions address the differences in Jasmine and Anna's behavior, noting that their personal experiences as 
NNESTs are reflected within their teaching philosophies. Furthermore, what Jasmine and Anna want their students to understand about English language variation stems from their own personal experiences as NNESTs. Their teaching philosophies carry a deep sense of what it means to be empowered educators. Jasmine and Anna illustrate that through their own experiences as NNESTs, they can integrate English education with a larger subset of skills that will in turn empower their students. Jasmine and Anna's interpretation of self as non-native speakers is deeply intertwined with their pedagogy and supports student autonomy.

Next, I explore the guiding question that propelled this study, namely that of teacher identity. As previous research has indicated, identity is dynamic and continually negotiated (Jackson, 2014). For the purpose of this study, I define identity in two ways. First, identity is both assigned (ascribed) and claimed (avowed) (Jackson, 2014; Oetzel, 2009, Varghese et al., 2005). The construction of identity entails the negotiation between how one sees oneself and how one is seen by others (Blackledge \& Pavlenko, 2001; Menard-Warwick, 2014). Secondly, understanding that identity is a negotiated process entails that the recognition of "language teacher identities develop in connection with the social contexts where they have learned, used and taught languages" (Menard-Warwick, 2014, p. 3; Varghese et al., 2005). I reason that through the construction of identity, Jasmine and Anna have both crossed into spaces where interculturality surfaces and creates a third space where they are able to see "the world through the eyes of others, while being aware of one's own cultural assumptions" (Menard-Warwick, 2014, p.121; Kramsch, 1993; McKay, 2002). 
I argue in the following section that the education system is a repressive structure that not only does a disservice to its students but also to its teachers. At its apex, scholars like Skutnabb-Kangas (1981) look at this reinforcement as a type of structural violence. While neither Anna nor Jasmine characterized their learning and teaching experiences in such strong terms, I believe both Jasmine and Anna demonstrated times they had been treated unequally. Throughout this thesis research I have identified the problems associated with contextualized systemic inequality. When it is reproduced again and again it becomes repressive, affecting generations of teachers and learners. In relation to ELT, the differentiation between NESTs and NNESTs is deeply embedded in academia and upholds colonial practices that position NNESTs and their students "within a classist division that relegates second language speaker to a secondary status" (Pennycook, 2010, p. 38). In the context of the internationalization of education, English education along with Western varieties of English can be constructed as a cultural byproduct, which becomes a commodity on the international market. In the United States, proponents of English-only campaigns within bilingual education further exemplify that the "native speaker fallacy" is alive and well in the education system thus allowing discriminatory practices to be upheld in the public sphere. Appadurai reminds us that we are living in the late modern area of globalization and with it we have seen the "transformation of the consumer" through "commodity flows" which creates the "worldwide dissemination of a plethora of creative, and culturally well-chosen, ideas of consumer agency" (as cited in During, 1999, p. 229). In terms of language use, this consumer agency elevates Inner Circle varieties of English within international education: the West not only commodifies 
English education but fetishizes Western cultural practices to separate its standards from the Global South.

In the final pages of this chapter, I look towards the future of English language education and I maintain that the way we interpret English language teaching across international borders has the potential to do a disservice to our learners. As described above, English language education is a part of a global mechanism that supports the flows of people and information from one geographic space to another. As our world becomes more interconnected, there will be more NNESTs providing instruction and they will become the ideal role model. We must move away from models of English that hinder learners' understanding of what it means to be an intelligible and comprehensible speaker of English. Only then we will be able to put an end to the discriminatory practices that divide speakers based on language variation.

\section{Revisiting the Guiding Questions: Teaching Practices}

Throughout the pages of this thesis, I demonstrate that even though Jasmine and Anna share similar socio-historical narratives including nationality, first language, and experiences as NNESTs in the United States, the way in which they approach English language education is vastly different. My interviews with Jasmine and Anna illustrate that teachers make different pedagogical choices in relation to how they understand their own learning experiences and their students' needs. Moreover, it becomes apparent that personal choice is really dependent on the teacher's understanding of self within the structure of an institution. Thus, teachers have to make pedagogical choices based on the learning outcomes of a given institution. The two guiding questions that allowed me to address teaching pedagogy, the role of language variation in the English language 
classroom, and what Jasmine and Anna want their students to understand about accuracy, fluency and intelligibility were:

1. How do NNESTs understand their teaching philosophies inside the English language classroom?

2. How do NNESTs understand how their language proficiency and variety of English affects how they teach English (in relation to others perspectives of them as intelligible speakers of English)?

The framework that these two questions provided is essential as it connects the participants' own English language education to a larger context that can be defined as “empowered educators.” Judith Westphal Irwin explains that:

Empowered educators are persons who believe in themselves and their capacity to act. They understand systems of domination and work to transform oppressive practices in society. They respect the dignity and humanness of others and manifest their power as the power to actualize their own unique humanity. They are strong, practical and compassionate as they work individually and with others to support the self-realization of all persons in their classrooms, schools and communities. (1996, p. 13)

Jasmine and Anna have made conscious decisions about the way in which they teach English. Throughout our time together, Jasmine and Anna have demonstrated their "capacity to act" and their need to move their students away from "oppressive practices in society" (Irwin, 1996 p. 13). Though Jasmine and Anna take different approaches to English language education and the oppression they have endured as learners, English language educators and foreigners living in the United States, they have found ways to teach their students life skills that will support their self-awareness and help them in the next stage of their academic and professional development. As NNESTs studying and teaching in the United States, Jasmine and Anna have had to learn to move away from 
negative stigmas associated with non-native speakers. In relation to teacher identity, effective teachers understand that there is a "discursive faultline" within the English education system and their students will have to learn not only how to navigate within the system, but build autonomy as students and as English language speakers (MenardWarwick, 2014, p. 2). Menard-Warwick teaches us that:

As teachers increase their own awareness of the interconnections between language, ideology, culture and identity, they will be better able to make informed decisions about locally appropriate English language pedagogies. (2014, p. 28)

From this perspective it becomes evident that Jasmine and Anna understand the way language, ideology, culture, and identity have be woven throughout their lives and this is reflected in their pedagogy. By acting as empowered educators who are aware of the discursive faultlines that are embedded into the American education system, Jasmine and Anna believe they are able to teach their students how to become empowered learners. In doing so, Jasmine and Anna become the ideal role models for their learners.

As an empowered educator, Jasmine believes one of her responsibilities as an English educator is to teach her students how to move away from negative stigmas associated with non-native speakers. During our time together, Jasmine said that certain pronunciation and grammar errors carry negative connotations in the United States and she does not want her students to be Othered because they speak a marked variety of English. By teaching standard American English norms, Jasmine teaches her students how to move away from discriminatory tendencies in the United States, as well as how to navigate their lives in a Western society dominated by native speakers. In turn, Jasmine believes that her students will be able to compete on the American job market and within the American higher education system with native English speakers. Jasmine carries the 
sentiment that standard American English is the only variety of English that will allow them to successfully assimilate to American norms.

However, empowerment does not stop with standard American English. For Jasmine, English language education acts a medium to the development of a subset of skills that can be applied to everyday life. As an educator, Jasmine carries the conviction that English language education moves away from actual language instruction towards integrating life skills and critical thinking skills. By integrating life skills into her curriculum, Jasmine understands that she is preparing students for life outside of English education. Jasmine believes that her students who complete the entire English language sequence may have an advantage over native English speakers who have not been taught of to structure their writing or who are returning students. As a graduate student, Jasmine realized the value in learning how to write academically and she, like her students did not always enjoy English education. However, Jasmine now has a multi-dimensional view of what her students need to accumulate in order to be successful as English speakers and onward into their professional careers. Regardless if Jasmine's students find value in what they are learning within the English language classroom, Jasmine believes that they will be thankful for the skillset they developed as they move forward in their lives as comprehensible English speakers.

Anna also holds the belief that as an educator it is her responsibility to link English language education to a larger set of life skills, which will in turn empower her students. Anna ascribes to the principles and practices of teaching English as an international language. Furthermore, Anna believes that building intercultural competence is an important component of English language education. Anna indicated 
that she wants her students to understand that they will interact with many different English speakers who may not speak a native variety of English. Anna wants her students to understand that the English language is universal and they will have to negotiate meaning with native and non-native speakers alike. Anna tries to tie cultural pieces into her instruction so that her students can see English from a global perspective and also understand how they fit into a globalized society. In doing so, Anna is essentially teaching intercultural competence and moving away from discriminatory practices within English language education that prefer the native speaker and Western cultural practices to placing English within a global paradigm.

Anna sees her status as an NNEST as a way to empower her students. Anna stated that she believes she is the ideal model because she intuitively understands her students' struggles. Anna wants her students to be aware of her status as an NNEST as soon as they enter her classroom. In order to exhibit her own language variation, Anna shared that during the first day of class she purposely pronounces her full name with a strong accent so that her students can hear the phonetic difference in the sound quality. Anna takes the power out of negative stereotypes associated with non-native speakers and shows her students through example what she wants them to understand about being a comprehensible speaker of English. Anna's transparency makes her stand out from her colleagues and she is able create connections with her students based on their shared experiences as English language learners. Anna carries the conviction that transparency about her status as an NNEST helps her display sensitivity to their daily struggles. Anna's own struggles as an English language learner helps her identify her students' issues with the English language. Anna explained this intuitive knowledge as being able 
to metaphorically see a question mark above her students' heads. Regardless if Anna explicitly remembers what aspects of English were difficult to learn, Anna still has a recollection of what her life felt like as a learner and how her own experiences influenced her decisions to continue to live her life between two different countries which are linguistically and culturally different. Her own experience as an English learner has given her a sense of understanding that helps her chart learning behaviors and she can provide instruction that is conducive to her student's learning objectives.

Jasmine and Anna's socio-historical journey as English language learners and as bilingual teachers working across linguistic borders illustrates what Irwin calls "empowered educators" who have the ability to empower their students (1996, p. 13). Both of my participants displayed a keen understanding of self in relation to the educational systems that they hard participated in. Their experiences as English language learners and as global citizens show us what the essence of an empowered educator entails. Furthermore, Jasmine and Anna clearly want to empower their students and help them develop a skillset that is not tied specifically to English language education. Peter McLaren defines student empowerment as:

Students learn to critically appropriate knowledge existing outside their immediate experience to broaden their understanding of themselves, the world and the possibilities for transforming the taken-for-granted assumptions about the way we live. (1989, p.77)

By moving into spaces outside English language education, Jasmine and Anna are building student autonomy that will support their future endeavors. Moreover, Jasmine and Anna have taken their own experiences and shaped them into teachable moments that bring awareness to a broader understanding of the world and their students' placement 
within it.

Language education has often focused on privileging of the monolingual native speaker (Phillipson, 1992). However, as our world becomes more interconnected, we need to move towards a more culturally appropriate understanding of who is the ideal model for English language learners. David Graddol indicates that there are three types of English speakers in the world today: native English speakers, second language speakers and English as a foreign language speakers. Both native speakers and second language speakers account for 375 million speakers each, while the largest player among English speakers are the foreign language users who account for 750 million speakers. Graddol states that, "Native speakers may feel the language 'belongs' to them, but it will be those who speak English as a second or foreign language who will determine its world future" (1997, p. 10). It is logical to conclude that NNESTs who are empowered educators should act as role models internationally, not only to their students, but also within ELT, as they combine "language, ideology, culture and identity" to English education (Menard-Warwick, 2014, p. 28).

\section{Revisiting the Guiding Questions: Identity}

This section is concerned with the way in which NNEST occupational identity is shaped by discriminatory practices within English language education. In order to explore Jasmine and Anna's understanding of identity it was necessary to explore their lives from a socio-historical context. By exploring Jasmine and Anna's lived experiences throughout their professional careers, I was able to co-construct the evolution of each participant's teacher identity by asking:

3. How do NNESTs understand their identity as English language educators? 
A central premise of my research is the belief that identity evolves over time and space. Discussed in previous sections of this thesis is the conviction that identity is a dynamic process that is continually being renegotiated (Varghese el al., 2005). Many scholars agree that identity forces individuals to claim social positions for themselves while having different social constructs placed upon them (Blackledge \& Pavenko, 2001). Identities are formed during the socialization process and are composed of verbal and nonverbal messages (Jackson, 2014). Both Jasmine and Anna have described cases of Othering, sometimes verbal and sometimes deeply embedded in unspoken discourse. Predominant themes in English language policies and initiatives have supplied a multitude of unspoken cues that separate Jasmine and Anna from their native-speaking counterparts. Clearly, when Jasmine and Anna speak about the different degrees of implicit Othering that they have endured as NNESTS, one can only assume that simply knowing that there is a divide within ELT places a feeling of being inferior to the native speaker model of English language education.

Jasmine and Anna show us that occupational identity can become deeply entrenched in our decision-making processes. Previous research also indicates that within the negotiation process, identity becomes porous due to the manner in which it is assigned and claimed (Varghese et al., 2005). Both Jasmine and Anna made conscious decisions in relation to the implicit Othering they experienced. For Jasmine, the need to be the best at her profession became apparent in her professional development due to the silent implications of being an NNEST. Jasmine sought to silence her own insecurities by overcompensating for her "non-nativeness." Moreover, Jasmine said that she selfdiscriminates. However, Jasmine also examines others' interpretations of discrimination 
noting that lack of cultural competence can make a seemingly critical incident be no more than a cultural misunderstanding. From this perspective, Jasmine is constantly secondguessing her own judgments and finds herself in a space where she no longer feels as if she belongs anywhere. As a U.S. citizen born in Latin America, Jasmine's interpretation of self crosses into different geographic and cultural spaces. When visiting family in her home country, Jasmine stated that she feels that she has to translate her thoughts into her native language before speaking in fear that others will take her words out of context and perceive her actions as "showing off." Jasmine currently resides in the United States, and even though there are many things that she appreciates about her life in America, she shared that she has not fully assimilated into U.S. society. For Jasmine, there are cultural differences such as her need to interact with others that are not so persuasive in American culture. Thus, Jasmine's cultural membership crosses linguistic and national borders.

Anna's narrative also illustrates that identity becomes deeply embedded in the decision-making processes. For Anna, a turning point in her graduate studies occurred when it was announced in one of the program's teaching methodology classes that nonnative speakers would be permitted to participate in a community ESL practicum, as it was not directly connected to the university's intensive English program. Anna said that this was the first time she had been implicitly made aware of the supposed difference between classes of English teachers. Anna shared that that this one experience left her second-guessing her self-worth as an English language educator and questioning her commitment to English language education. However, Anna came to the conclusion that she already knew who she was as an educator and she would not let the discriminatory practices within ELT stop her from achieving her academic and professional goals. Anna 
made the conscious decision not to participate in the community practicum offered by her university. Instead, in order to incur teaching hours and combat her feelings of inadequacy, Anna decided to start her own community ESL class within her own neighborhood. Anna shared that this experience reestablished her commitment to English education and helped her move away from the negative stigmas about her status as an NNEST.

In relation to English language education, Jasmine and Anna both shared that they did not realize that there was a division among NESTs and NNESTs until entrenched in the American education system. Once aware of the divide, Jasmine and Anna felt the inherent need to redefine their positions within the education system. Understanding that identity is constantly being negotiated and that the pillars of the Western education system carry colonial dichotomies between the colonizer (Self) and the colonized (Other) it is easy to infer that NNESTs receive the brunt of discriminatory practices (Canagarajah, 2005; Pennycook, 2001; Phillipson, 1992). Simply put, aspects of both ascribed and avowed identity can take the form of neo-colonial practices in ELT. When referring to Jasmine and Anna, it became clear that they had to find ways to redefine their space as English language teachers. Jasmine stated that she had not felt the social stigmas related to being an NNEST until she was working as a full-time English instructor. Once inside the institution, Jasmine felt judgment being placed upon her from colleagues who had also applied for her full-time position. Jasmine developed the belief that she was not as strong of a candidate and had only been selected because she was the strongest candidate from the NNEST pool and because the institution wanted to illustrate its commitment to diversity. Jasmine also shared that during the first years of her 
employment she was uncomfortable asking for support with teaching materials, as she did not want to be perceived as someone who struggled with the English language. Jasmine also felt angst about how her students would react when they realized that she, like them, was a non-native speaker. Jasmine's self-doubt can be directly attributed to silent forces within English education.

Anna's narrative also describes how the Western education system carries negative connotations that stem from colonial dichotomies that create tensions between how identity is assigned and claimed. For Anna, the struggle to redefine self began during her graduate studies and continued into the next phase of her professional career. After completing a Master of Arts in TESOL, Anna questioned what kind of teaching position she would be able to obtain after being "implicitly" Othered in her graduate program. Anna's strength and resistance became evident when examining how she responded to discrimination in her graduate program and onward in her professional career. When asked to apply at a local university, Anna openly asked the hiring committee why she had been selected for an interview as they were well aware of her status as an NNEST. However, once inside the institution, Anna experienced the same insecurities as Jasmine, noting that she feared how her students would react knowing that she was an NNEST. Over time Anna has found the strength in her own voice to combat the negativity that she endured as a graduate student and tried to combat her insecurity by illustrating to her students that English language education is an ongoing process, but fluency is attainable. Anna is the ideal model for her students.

The construction of teacher identity is dependent on the academic structures that educators participate in throughout the process of their education and onward into their 
professional careers. Menard-Warwick argues that in relation to English language teachers, occupational identity "is develop[ed] in connection with the social contexts where they have learned, used and taught languages" (2014, p. 3). When teachers cross linguistic and cultural borders, they shift into a space where their identity transcends one culture into a space where they are willing "to see the world through the eyes of others, while being aware of [their] own cultural assumptions" (Jackson, 2014; Martin \& Nakayama, 2008; Menard-Warwick, 2014 p. 121). In connection with Jasmine and Anna, it becomes apparent that they have crossed into spaces where interculturality has surfaced and has created a third space where they are able to navigate their lives in two languages and two cultures (Menard-Warwick, 2014). Moreover, Jasmine and Anna are able to ascribe who they are as teachers while renegotiating the implicit undertones of discrimination that they endure in order to act as English language teachers in the United States. Thus, the continual process of ascribing and avowing identity feels implicit to Jasmine and Anna rather than explicit from the ongoing evolution of teacher identity.

\section{Conclusion: Internationalization of TESOL}

It is widely known that the education system is driven by capital. Internationally, the university system is commonly perceived as a global business that sells the transfer of knowledge and skills on the international market (Chowdhury \& Phan, 2014). The rise of globalization has led to a niche-marketing scheme within the university system that allows students to travel to another country and attain these same products only in a different setting. The notion that the 'West is the best' was set in place during the colonial period and has arguably established its rein within the international education model. Western education brings with it a sense of superiority that supersedes its cost. 
International student fees often times double or triple the cost of attendance and bring in billions of dollars. Chowdhury and Phan (2014) tell us that international education is Australia's fourth largest export industry earning 15.6 billion dollars in 2011, while the United States earned nearly 22.7 billion dollars during the 2010-11 academic school year from the international student sector alone. Smallman and Brown (2015) support this argument, noting that during the 2011-12 academic school year, China, India, South Korea, Saudi Arabia, and Canada sent the largest number of students to the United States to study and in total 764,495 students came to the United States to study in 2011. In 2011, this number grew to 819,644 students residing in the United States for academic study.

English language education fits nicely within the international education model as it brings with it different standards of what English learners may want to acquire. Furthermore, once in the system, international students may go on to finish their studies at the same university where they completed their English language classes. Thus, English language education can act as a more contextual piece within the larger frame of the international education market. As English language educators, both Jasmine and Anna felt compelled to study in the United States. Jasmine said that she had always wanted to study in an English-speaking country in order to be a better teacher. Anna shared this same sentiment noting that completing a graduate degree in the United States gave her a sense of accomplishment that she would have never been able to attain studying in her home country. Additionally, their experiences as students and teachers in the United States illustrate the predominant role international education has played within their sense of self as educators and within their teaching philosophies.

Jasmine shared that her perception as a teacher shifted once she began a graduate 
program in the United States. Prior to entering the United States, Jasmine had no formal teacher training, however she had worked eight years as an English educator. Jasmine carries the inherent belief that she did not know what she was doing and her main focus was trying to please her students and make English education enjoyable. Jasmine further explained that after she entered the American university system and began studying in a teacher-training program that her overall teaching philosophy shifted to meet the students' needs as learners. She was less concerned with their overall enjoyment and more concerned with their actual learning. Jasmine's inherent belief that she did not have a firm understanding of English language teaching also affirms her belief that her colleagues in her home country lacked the pedagogical underpinnings to be successful instructors. This solidifies the notion of the 'West being the best' and Jasmine has come to fit within Western parameters of the internationalization model by simply believing that she lacked teaching skills and was an ineffective teacher before entering the American education system.

Jasmine's current teaching philosophy aligns itself with Western teaching practices as she stated that standard American English is the only variety of English that belongs in her classroom. Jasmine carries the conviction that acquisition of standard American English as opposed to fluent intelligible accurate accented English moves students away from negative stereotypes that are associated with nonnative speakers. Jasmine recognizes that her students will be competing for employment with native English speakers and that they have to be able to demonstrate that they are just as capable of performing the same tasks and interacting in the English language. Jasmine teaches life skills that equate with success in a Western system. Her own experience as a foreigner 
living abroad is deeply reflected in her teaching philosophy. She implicitly teaches her students how to assimilate to American language standards. Demographically, Jasmine teaches at two-year community college and her students are learning English as a second language. The majority of these students will be permanently residing in the United States and they need to learn how to navigate their lives both in and outside of the classroom. Jasmine believes by helping her students assimilate to American way of life that she is empowering them and supporting their academic and professional goals.

Anna also associates part of her success as a teacher to Western standards of higher education. As a graduate student Anna found herself immersed in theory in contrast to her experiences in the education system in her home country. When comparing the two educational systems, Anna stated that in her home country she was "spoon fed" theory. While attending graduate school in the United States Anna said that she learned how to think critically and formulate her own opinions. However, it is unlikely that Anna solely acquired critical thinking skills while residing in the United States. Anna practices reflexivity in all areas of her life and as a graduate student she learned to mix theory into practice. Prior to entering the United States, Anna taught in K12 sector and her teaching objectives were not rooted in adult education. Thus, Anna's theoretical shift cannot only be attributed to the American education system as she also changed her overall genre of study. Perhaps the graduate program she attended in the United States was deeply rooted in theoretical practice and helped her redefine the role of theory in the classroom. However, it is unlikely that Anna did not have theoretical principles that influenced her classroom objectives. Putting theory into practice has become a major theme in Anna's teaching philosophy. However, I argue that the 
theoretical underpinning was already in place and Anna now has a greater understanding of how to implement it into her practice.

Anna carries a great sense of accomplishment knowing that she has completed a graduate program in the United States. Anna noted in our time together that this feeling of pride would have been unattainable in her home country. By completing a degree in an English-speaking country, Anna has proved to herself that she can successfully navigate her life as an English speaker in the English-speaking West. Arguably, the sense of accomplishment Anna felt when she completed a graduate program in the United States separates her as English teacher who has been educated in the West and upholds the West's academic standards. Thus, Anna feels that by completing a professional degree in the West she is better prepared to teach the English language than she was prior to entering the American university system. Anna builds World Englishes theory into her teaching objectives. For Anna, it is necessary to include English variation in her classroom. Anna wants her students to understand that English is a global language and can be molded to fit its' speakers needs. Anna currently teaches at the university level. The majority of Anna's students are residing in the United States temporally and will be using English as the medium to communicate with other non-native speakers. Even though many of Anna's students will go on to complete professional degrees in the American university system, Anna believes that they need to understand what the English language looks like demographically. Thus, Anna can support her pedagogical decisions and deliver English instruction that upholds her own beliefs about cultural diversity in English education.

Jasmine and Anna's teaching philosophies clearly reflect what skills they believe 
are necessary to communicate effectively in the English language. Anna realizes that her classroom is primarily composed of international students. International students studying in the university system have higher tuition costs and generally come to the United States to invest in their future as there is an inherent belief that they will be more sought-after on the international market by obtaining a Western degree. On the other side of the spectrum are Jasmine's students, many of whom aspire to continue on in academics but will stay in the United States. Jasmine understands that they need to learn academic skills before entering the university in order to be able compete with other students. To gain a wider perspective we can look at Jasmine and Anna's former teaching context noting that their South American students were only enrolled in private English classes in order to obtain "better jobs." Across contexts, the English language is being bought and sold to the highest bidder. Though many scholars argue that English no longer is the property of the English speaking West, the internationalization of higher education is still importing and exporting English products and services from the English speaking West (Altbach \& Knight, 2007; Chowdhury \& Phan, 2014; Ha, 2013; Huang, 2007; Yang, 2011). Both Jasmine and Anna fit within the internationalization framework as learners coming to the United States to gain TESOL certification and as educators working within the American higher education system. The self-doubt and implicit discrimination that Jasmine and Anna have experienced inside the American education system are real. Numerous scholars have argued that, "TESOL curriculum, textbooks and materials have a hidden agenda of assimilation into the White culture or contain racial stereotypes" (Chowdhury \& Phan, 2014, p. 15; Kubota 2001). Being confined to this system would cause Jasmine to carry the belief that she had to be the best and adhere to standard American norms. It 
caused a skilled practitioner, such as Anna, to second guess her decisions and back away from a system that created a feeling of inadequacy. However, both Jasmine and Anna have found ways to move through repression and support their students' academic success.

Appadurai suggests that today we are living in the late modern era of globalization, and with the rise of globalization we have seen a shift from Marx's "fetishism of the commodity" to the "production fetishism" and the "fetishism of the consumer" (Appadurai, 1999, p. 229). For Marx, the fetishism of the commodity placed intrinsic value on a given commodity in order to create interdependence between the consumer and those who owned the means of production. Appadurai moves Marx's fetishism of a commodity into the context of a globalized society by noting how production fetishism occurs when "production has itself become a fetish" and fetishism of the consumer occurs when "the consumer has been transformed through commodity flows" (Appadurai, 2001, p. 596). In relation to the international education model and English language education, it becomes clear that by placing an emphasis on Inner Circle varieties of English, the TESOL community upholds which varieties of English should be the model for international commerce and which teachers become idealized within that market structure.

In the context of the United States, it is evident that bilingual education reinforces the differentiation of English speakers in American society. Proponents of English-only education serve to demonstrate that the ideal speaker is a monolingual English speaker who speaks a Western variety of English. Nationally, there have been numerous accounts of state-imposed legislation that idealize the native speaker. In 2010, the state of Arizona 
removed teachers from K-12 classrooms if they had a "heavy accent" and there were students learning English (Diniz de Figueiredo, 2011; Oboler, 2010). Bilingual education has constantly been under attack and demonstrates that there is a clear divide on what varieties of English the American people want their children to learn. People who speak marked varieties of English are subjected to discrimination and are Othered within the United States. Though English language variation does not receive the same kind of media attention as racial tension between minority groups, it is still evident that racism is intertwined with language policy. These silent forms of discrimination affect how nonnative speakers understand themselves within the education systems that they serve. In the case of the NNEST, it becomes evident that in order to navigate the Western education system one must assimilate their values to accommodate for their language variation.

The education system as a whole is broken. The Western model assumes that its standard of education is the best. In regards to English language education, international students want to study English in Western countries where the dominant discourse is English. However, by placing an emphasis on which standard of English should be normproviding, we are damaging the role of bilingualism and multilingualism through denigrating other varieties of English. The predominant discourses of English are deeply intertwined in the colonial past and set the precedence of what varieties of English are sought after and which varieties are marked as inferior on the international market. Thus, the internationalization of English education is doing a disservice to English learners and their non-native instructors by differentiating which varieties of English are the best. 
Applications for TESOL

The voices of NNESTs provides a contextual understanding of what English language learners endure to become intelligible speakers of the English language. Furthermore, the individual narratives also illuminate the struggles that they face once they become fluent and comprehensible speakers. One of the messages conveyed throughout this text is the idea that NNESTs are appropriate role models for English language learners. By documenting the lived experiences of NNESTs, researchers can contribute to the collective voices of non-native English teachers internationally and can visually interpret what is appropriate and necessary to understand about English variation. I argue that NNESTs should be who the TESOL community look towards for effective teaching practices in relation to language variation. Both Jasmine and Anna noted that their colleagues often ask them for guidance about teaching grammatical structures that are difficult for learners to understand, and also ask them questions about what learners need to understand about communication inter-culturally. From this standpoint, if we do not add more authentic accounts about NNESTs and second language acquisition we are doing our learners a disservice. Learners need role models and individuals who can convey that it is possible to learn the English language. Students need to see NNESTs not a translators in the classroom but as fluent, accurate and intelligible speakers so that they do not idealize the native speaker as the only speaker and set unrealistic goals for themselves. Moving away from the native speaker as the model speaker, we gain a pluricentric voice that is representative of all varieties of English. 
Directions for Future Study

The two portraits of Jasmine and Anna have sought provide a glimpse into the way two NNESTs perceive their teacher identity in relation to being bilingual speakers teaching English in the Pacific Northwest. Due to the narrow scope of this project, it only seems fair to suggest its expansion. The personal narrative of NNESTs ought to explore on a larger level and I believe that this study could be further developed through the collection of other personal accounts.

I also propose that this study ought to be continued in other contexts internationally and cross-culturally. With the continual rise of NESTs teaching in Outer and Expanding Circles, is necessary to build dialogue between these two groups and look at how English language education is affecting teachers' perceptions of self from both the position of the NNEST and the NEST. In order to move away from the colonial past, I maintain that we must create a dialogue about the misperceptions linked to such ideologies as the native speaker fallacy and English as a commodity. Thus, we have the ability to gain a better understanding of ourselves through sharing our lived experiences and moving away from stereotypes in English education.

It is equally important to suggest adding the voices of present and former language learners and individuals working in TESOL education but outside of the classroom such as coordinators and administrators. By providing a pluralistic view of TESOL education, we can add authentic accounts and multilayered interpretations to the discussion on English language education and empower our learners. TESOL as a whole would benefit from a multi-dimensional perspective of NNESTs lives as educators 


\section{Concluding Thoughts}

The goal of this project was to tell the individual stories of Jasmine and Anna and to provide a glimpse into their lives as two highly fluent, comprehensible and intelligible users of the English language. While piecing together Jasmine and Anna's individual stories I was overcome by the similar beliefs that they held about English education. Yet, Jasmine and Anna made distinctly different decisions due to their teaching philosophies about how to best meet their learners' needs. In other words, Jasmine and Anna believe that their key role as English educators is to empower their students, yet they take different approaches to reach this goal. This section seeks to tie together the overarching message that Jasmine and Anna so clearly articulated throughout the interview process. By revisiting Jasmine and Anna I hope to provide the final contextual piece to their individual journeys to display a panoramic portrait of who they are as educators.

To conclude our time together, two of questions I asked in the final interview sought to tie Jasmine and Anna's teaching philosophies to future English educators. I asked both participants to share a visual representation of what English language education looks like to them. I also asked them if they had a piece of advice for preservice teachers. Jasmine and Anna's responses were thoughtful and provide a multilayered glimpse into how they understand education. For me, Jasmine and Anna's statements are the closing sentiments of their interpersonal portraits yet tie them together to illustrate what English educators ought to be composed of.

When asked to provide a visual representation of what her life looked like as an English educator, Jasmine simply responded:

Every time I think about being a teacher in [my home country] or here, or any 
environment that I have experience in, there's always this idea that I am helping someone do something. And I'm making a difference, somehow. And that is really important to me... so, for me it's the word empowerment. (Interview 3)

I asked Anna to share something I could visualize that represents English education. Her response carried a similar connotation saying:

I would draw two people holding hands, because sometimes one is pulling the other. It's a matter of being supportive [and] it's a matter of building a connection. Sometimes I need to be pulled as well. Because I'm a teacher but, [also] I'm a language learner. So, something that ties you together is to find the support... And you push and you are pushed, because my students make me study. They make me prepare for the class. I'm constantly learning. (Interview 3)

The statements above illustrate that Jasmine and Anna are deeply committed to English education and illuminate their desire to help others. Throughout this experience both Jasmine and Anna shared that being a teacher indicates a commitment to ongoing education. Jasmine and Anna also alluded to the notion that as English educators they have to teach life skills that incorporate so much more than grammatical structures. Their jobs as educators are to prepare students for the next phase of their lives. Simply put, teachers bridge together their love of learning to their of teaching, which supports a continuous cycle of giving and receiving.

As individuals we are all interconnected. The future is reliant on those who choose to educate the next generation. As illustrated in the previous section on globalization of education, there are inherent flaws within TESOL, as English is arguably bought and sold to the highest bidder. As educators we need to continue to move towards a more compassionate model of English language education that puts our learners first and the market second. The next generation of teachers will face the same challenges that current educators face inside the classroom. When asked to reflect on their past experiences and share advice for the future teachers, both Jasmine and Anna held the 
same truth: know your students. In Jasmine's words:

I think that the most important thing for me is, when I teach and I think that is what I would tell them is to know your students in a way that you know what their goals are and what they need from you so trying to ...to design your class based on what your students need. And constantly ask them and get feedback from, like is it helping you? Is it really what you want from this class? (Interview 3)

Anna held the same sentiment saying:

Take the time to know your students. Be aware of your students' different learning styles and cultural backgrounds, because that is the way that you are going to build a common thread and a connection. I take the time to build a relationship before imposing tasks. (Interview 3)

By taking the time and embracing who their students are as individuals, Jasmine and Anna are able manipulate the classroom objectives to meet their different students learning styles. A teacher will be more successful identifying their learners' needs and crafting curricula to meet the classroom objectives if they listen to what their students say. Thus, teacher-student interaction and continuous feedback support the communicative learning process. Throughout the pages of this thesis Jasmine and Anna have both demonstrated their commitment to English education and have illustrated that NNEST are not only able to navigate as comprehensible English teachers but thrive in the English language classroom. Identity is continually negotiated and how NNESTs understand themselves directly affects our learners' perceptions of self. By supporting one another we move away from racial stereotypes and discriminatory practices that separate and divide us as speakers and users of the English language. In doing so, we move towards a more culturally salient form of English education that allows English to "belong to all those who use it" (Kachru, 1988, p.1). 
References

Amin, N. (1997). Race and the identity of the non-native ESL teacher. TESOL Quarterly, 31(3), 580-583.

Appadurai, A. (1996). Modernity at large: Cultural dimensions of globalization. Minneapolis, MN: University of Minnesota Press.

Appadurai, A. (1999). Globalisation and research imagination. International Social Science Journal. 5(160), Blackwell, UNESCO, p. 229.

Appadurai, A. (2001). Disjuncture and difference in the global cultural economy. In M.G. Durham \& D.M. Kellner (Eds.), Media and cultural studies: Keyworks (pp. 584-603). Oxford, UK: Blackwell Publishing.

Altbach, P.G. \& Knight, J. (2007). The internationalisation of higher education: Motivations and realities. Journal of Studies in International Education 11(3-4), 290-305.

Arva, V., \& Medgyes, P. (2000). Native and non-native teachers in the classroom. System, 28(3), 355-373.

Barry, C. (2011). English language teaching in Brunei: A view through a critical lens. RELC Journal, 42(2), 203-220.

Berns, M. (2005). Expanding on the expanding circle: Where do we go from here? World Englishes, 24(1), 85-93.

Blackledge, A., \& Pavlenko, A. (2001). Negotiation of identities in multilingual Contexts. The International Journal of Bilingualism, 5(3), 243-257.

Braine, G. (Ed.) (1999). Non-native educators in English language teaching. Mahwah, NJ: Laurence Erlbaum Associates.

Butcher, C.A. (2005). The case against the 'native speaker.' English Today, 21(2), $13-24$

Canagarajah, S.A. (1999). Resisting linguistic imperialism in English language teaching. New York: Oxford University Press.

Canagarajah, S.A. (Ed.). (2005). Reclaiming the local in language policy and practice. Mahwah, NJ: Lawrence Erlbaum Associates.

Castellanos, D. (1983). The best of two worlds: Bilingual-bicultural education in the US. Trenton. NJ: New Jersey State Department of Education. 
Charmaz, K. (2006). Constructing grounded theory: A practical guide through qualitative analysis. Los Angeles, CA: Sage.

Chen, T., \& Barnett, G. (2000) Research on international student flows from a macro perspective: A network analysis of 1985, 1989 and 1995. Higher Education, 39(4), 435-453.

Chowdhury, R., \& Phan, L. (2014). Desiring TESOL and international education: Market abuse and exploitation. North York, ON: Multilingual Matters.

Creswell, J. (2003). Research design: Qualitative, quantitative, and mixed method approaches (2nd ed.). Thousand Oaks, CA: Sage Publications.

Crystal, D. (1997). English as a global language. Cambridge, UK: Cambridge University Press.

Crystal, D. (2003). English as a global language. Cambridge, UK: Cambridge University Press.

Dimova, S. (2011). Non-native English teachers' perspectives on teaching accents and varieties. TESL Reporter, 44(1\&2), 65-82.

Diniz de Figueredo, E., H. (2011). Non-native English-speaking teachers in the United States: Issues of identity. Language and Education, 25(5), 419-432.

During, S. (Ed.) (1999). The cultural studies reader (2nd ed.). London: Routledge.

Edwards, J. (2009). Language and identity. New York: Cambridge University Press.

Graddol, D. (1997). The Future of English? London, UK: British Council.

Graddol, D. (2006). English next: Why global English may mean the end of 'English as a foreign language’. London, UK: British Council.

Greis, N. (1985). Towards a better preparation of the non-native ESOL teacher. On TESOL 84: Selected papers from the 18th annual convention of teachers of English to speakers of other languages. Washington, DC: TESOL.

Guba, E. (1990). The paradigm dialog. Newbury Park, CA: Sage Publications.

Holliday, A. (2006). Native-speakerism. ELT Journal, 60(4), 385-387. 
Huang, F. (2007). Internationalisation of higher education in the developing and emerging countries: A focus on transnational higher education in Asia. Journal of Studies in International Education, 11(3-4), 431-432.

Irwin, J.W. (1996). Empowering ourselves and transforming schools: Educators making a difference. New York, NY: State University of New York Press.

Isbell, D.S. (2008). Musicians and teachers: The socialization and occupational identity of preservice music teachers. Journal of Research in Music Education, 56(2), (162-178).

Jackson, J. (2014). Introducing language and intercultural communication. London, UK: Routledge.

Jenkins, J. (2009). World Englishes: A resource book for students (2nd ed.). London, UK: Routledge.

Jenkins, J. (2014). World Englishes: A resource book for students (3rd ed.). London, UK: Routledge.

Kachru, B. B. (1985). Standards, codification and sociolinguistic realism: the English Language in the outer circle. In R. Quirk \& H. G. Widdowson (Eds.). English in in the world: Teaching and learning the language and literatures. Cambridge, UK: Cambridge University Press.

Kachru, B. B. (1988). Teaching world Englishes. ERIC/CLL News Bulletin, 12(1), 1-4.

Kachru, B. B. (1992). Teaching world Englishes. The other tongue: English across cultures. $2^{\text {nd }}$ ed. Urbana, IL: University of Illinois Press.

Kubota, R. (2001). Discursive construction of the images of U.S. classrooms. TESOL Quarterly 35(1), 9-28.

Kubota, R., \& A. Lin (2009). Race, culture and identities in second language education: Introduction to research and practice. In R. Kubota \& A. Lin (Eds.), Race, culture and identities in second language education: Exploring critically engaged practice (pp. 1-123). New York: Routledge.

Kramsch, C. (1993). Context and culture in language teaching. Oxford, UK: Oxford University Press.

Lareau, A. (2012). Using the terms hypothesis and variable for qualitative work: A critical reflection. Journal of Marriage and Family, 74(4), 671-677. 
Leung, C., Harris, R., \& Rampton, B. (1997). The idealized native speaker, reified ethnicities, and classroom realities. TESOL Quarterly, 31(3), 543-560.

Lincoln, Y., \& Guba, E. (1985). Naturalistic inquiry. Beverly Hills, CA: Sage Publications.

Liu, J. (1999). Non-native-English-speaking professionals in TESOL. TESOL Quarterly, 33(1), 85-102.

Llurda, E., \& Huguet, A. (2003). Self-awareness in NNS EFL primary and secondary school teachers. Language Awareness, 12(3\&4), 220-233.

Martin, J.N., \& Nakayama (2008). Experiencing intercultural communication: An introduction, New York, NY: McGraw-Hill.

Matsuda, A. (2012). Introduction: Teaching English as an international language. In A. Matsuda (Ed.), Principles and practices of teaching English as an international language. (pp. 1-14). North York, ON: Multilingual Matters.

Matsuda, A., \& Friedrich, P. (2011). English as an international language: A curriculum Blueprint. World Englishes 30 (3), 332-344.

Merton, R.K, (1957). The student-physician. Cambridge, MA: Harvard University Press.

McKay, S.L. (2002). Teaching English as an international language: Rethinking goals and approaches. New York, NY: Oxford University Press.

McKay, S., \& Bokhorst-Heng, W. (2008). International English in its sociolinguistic contexts: Towards a socially sensitive EIL pedagogy. New York, NY: Routledge.

McLaren, P. (1989). Life in schools: An introduction to critical pedagogy in the foundations of education. New York, NY: Longman.

McLaren, P., \& Faramandpur, R. (2005). Teaching against global capitalism and the new imperialism: A critical pedagogy. Lanham, MD: Rowman \& Littlefield.

Menard-Warwick, J. (2014). English language teachers on the discursive faultlines: Identities, ideologies and pedagogies. North York, ON: Multilingual Matters.

Oboler, S. (2010). The dismantling of our future. Latino Studies, (8)3, 299-303.

Oetzel, J.G. (2009) Intercultural communication: A layered approach [Int'l Edition], New York, NY: Vango Books. 
Paikeday, T. (1985). The native speaker is dead! Toronto, ON: Paikeday Publishing Inc.

Pavlenko, A. (2003). "I never knew I was a bilingual": Reimagining teacher identities in TESOL. Journal of Language, Identity, and Education, 2(4), 251268.

Pennycook, A. (1998). Multilithic English(es) and language ideologies. Language in Society 37 (3), 435-444.

Pennycook, A. (1994). The cultural politics of English as an international language. London, UK: Longman.

Pennycook, A. (2001). Critical applied linguistics: A critical introduction. Mahwah, NJ: Lawrence Erlbaum Associates.

Pennycook, A. (2003). Beyond homogeny and heterogeny: English as a global and worldly language. In C. Mair (Ed.), The politics of English as a world language. Amsterdam: Rodopi.

Pennycook, A. (2007). Global Englishes and transcultural flows. London, UK: Routledge.

Pennycook, A. (2010). Rethinking origins and localization in global Englishes. In M. Saxena \& T. Omoniyi (Eds.), Contending with Globalization in World Englishes (pp. 196-210). North York, ON: Multilingual Matters.

Phan, L.H. (2008). Teaching English as an international language: Identity, resistance and negotiation. Clevedon, UK: Multilingual Matters.

Phan, L.H. (2013). Issues surrounding English, the internationalization of higher education and national cultural identity in Asia: A focus on Japan. Critical Studies in Education, 54(2), 160-175.

Phillipson, R. (1992). Linguistic imperialism. New York, NY: Oxford University Press.

Phillipson, R. (2009). Linguistic imperialism continued. New York, NY: Oxford University Press.

Ramanathan, V. (2005). The English-vernacular divide: Postcolonial English politics and practice. Plymouth, UK: Lexington Books.

Ray, J. M. (2007). Building the bridge as you walk on it: Didactic behaviors of elementary teachers in a dual language program. Teaching and Teacher Education, 24(6), 1658-1671. 
Ritzer, G., \& Dean, P. (2015) Globalization: A basic text (2nd ed.). Hoboken, NJ: Wiley.

Ruiz, A. (1988). Orientation in language planning. In S. McKay \& S. L. C. Wong (Eds.). Language diversity, problem or resource? A social and educational perspective on language minorities in the United States, (pp. 3-26). New York, NY: Newbury House Publishers.

Smallman, S., \& Brown, K. (2015). Introduction to international and global studies (2nd ed.). Chapel Hill, NC: The University of North Carolina Press.

Skutnabb-Kangas, T. (1981). Bilingualism or not: The education of minorities. Toronto: Multilingual Matters.

Tang, C. (1997). The identity of the non-native ESL teacher: On the power of status of non-native ESL teachers. TESOL Quarterly, 31(3), 577-583.

Tapias, A. (2008, October). Global diversity and intercultural competence development. Plenary at the First Annual IDI Conference, Minneapolis, MN.

Varghese, M., Morgan, B., Johnston, B., \& Johnson, K. (2005). Theorizing language teacher identity: Three perspectives and beyond. Journal of Language, Identity and Education, 4(1), 21-44.

Yang, R. (2011). Self and other in the Confucian cultural context: Implications of China's higher education development for comparative studies. Dordrecht: Springer Science + Business Media B.V. 
Appendix A: Informed Consent

Dear Participant,

I am a student in the Applied Linguistics Department at Portland State University. I would like to invite you to participate in a research project exploring the role of nonnative English speakers teaching English in the American ESOL context. I am specifically interested in the role of teacher identity, multilingualism and how this is reflected in instruction.

Your participation will include a series of three interviews that will last between forty-five minutes to one hour. The interviews will be semi-structured and will consist of fifteen to twenty questions divided into the following sections: basic demographics, (introduction, instructor background, and English proficiency), classroom identity, teaching philosophy and opinions about ownership and varieties of English used in the classroom. Each interview will be digitally recorded.

This current study is a comparative case study and it is essential that your participation remains confidential. In order protect your anonymity, I will ask you not to discuss your participation with other members of the TESOL community. There is a possibility that you may be vulnerable to someone's determining who you are and what you have said, but I will protect you from this possibility as much as possible by using a pseudonym for your name, and changing other self-identifying elements such as nationality, native language, employment, age, and gender. You will be provided with complete access to all of the data I collect including audio recording, transcriptions, my notes, and the analysis. You will be able to make any changes you want. All data collected (audio recordings, transcriptions, notes, and analysis) will be stored at Portland State University on a restricted computer that is password sensitive and is protected by PSU's Firewall System in a private office that only I have direct access to. All data will be kept for one academic year and will be destroyed once the study is complete.

There are two potential risks that you may encounter as a participant in this study are minimal. As mentioned above, your participation will remain confidential, however there is the risk of the breach of confidentiality. Due to the nature of the study and the interconnectedness of the TESOL community in Oregon it may be possible for individuals to assume your identity. In order to safeguard against this potential risk, all identifying information will be either omitted or changed. The second risk that you may encounter is possible psychological discomfort as you will be asked to discuss how being a non-native English speaker has affected your professional life including employment opportunities and perception of self as a ESOL instructor and as a speaker of English. You do not have to answer any questions that make you uncomfortable and may leave the study at any given time.

This study has the potential to increase the TESOL community's knowledge about NNESTS in relation to the occupational identity as English language teachers. This 
in turn could influence how NNESTs articulate their approaches to teaching and how they bring their understanding of different varieties of English in the ESOL classroom. In addition, this study seeks to add more authentic accounts of what the lived experience of NNESTs are and to explore the degree to which these academic structures promote inequality.

As mentioned above, your participation is completely voluntary, and you may refuse to participate or stop participation at any time during the study. If at any time you feel uncomfortable at anytime during an interview, we can conclude the interview or move on to a different question. If you choose not to participate or withdraw from the study during the data collection process your relationship with the researcher and PSU will not be affected. The data for this project will be shared with Dr. Kim Brown, Dr. Priya Kapoor, Dr. Kathy Harris, and Dr. Shawn Smallman, as they are the acting members of my thesis committee and will offer me guidance through the entirety of this project. The members of my thesis committee will be the only people who will be granted access to the data collected in this study. Dr. Kim Brown and Dr. Priya Kappoor are acting as co-thesis advisors and will be the only people involved in this study that will know your identity. Since this is a graduate thesis project results from this study will be shared with members of the Portland State University community and all identifying information will be changed to protect your anonymity.

I appreciate your participation in this study. If you have any questions regarding your participation as a research subject, you may contact the PSU Office of Research Integrity, $1600 \mathrm{SW} 4^{\text {th }}$ Ave., Market Center, Ste. 620, Portland, OR 97201; phone (503) 725-2227 or 1 (877) 480-4400; the researcher, Rosie David at PSU Office of International Studies, P.O. Box 751, Portland, OR 97207; email rosa@pdx.edu; or thesis advisor Dr. Kim Brown at PSU Office of International Studies, P.O. Box 751, Portland, OR 97207; email dbkb@pdx.edu. A copy of this consent from will be provided to you for your records.

Thank you,

\section{Rosa Dene David}

Please sign below of you are willing to participate in the research project outlined above.

Date:

Print Name: 
Appendix B: Demographic Questions

Please answer the following questions. If there is anything that you do not feel comfortable answering, please feel free to leave the answer blank.

How long have you been teaching in an ESL context?

Prior to teaching at this institution, did you teach in any other contexts?

What kind of ESL teaching qualifications do you have?

Do you regularly participate in any form of in-service training?

How many classes do you generally teach a term?

What levels of ESOL do you teach regularly?

What classes have you taught?

How long have you been teaching within this program?

What is the highest level of education you have completed?

What is your home country?

How many languages do you speak? 
Appendix C: First Interview Questions

1. What would you like your pseudonym to be for this study?

2. Walk me through your life as user of two languages

3. Walk me through your life as a teacher in your home country

4. Walk me through your life as a teacher here

5. What are the good things and what are the hard things about being an English teacher here in comparison to your home country?

6. Finally, can you draw me a picture of your language life history? Can you create a graphic of your life in these two languages for me? 
1. When you say the word "teacher" do the same images come to mind when you are teaching English here as when you are teaching English in your home country?

2. In your last interview you distinguished how you teach having completed a program to become a professional language educator, what concrete differences do you see?

3. In your current teaching setting, what aspects are parallel to the teachers around you and what things are different?

4. Have you ever been "Othered" at work?

5. Can you tell me a little bit more about your interactions with your student's in your classrooms when they find out that English is not your first language?

6. Are your collogues aware that English is not your first language? Can you tell me more about this? 
Appendix E: Third Interview Questions

1. You may have run across the phrase "English belongs to all those who use it," Can you think about this phrase once again, "English belongs to all those who use it" Tell me what comes to mind when you think about this phrase.

2. As you deliver instruction to your learners what is it that you want them to know and understand about fluency, accuracy, and intelligibility?

3. Have you ever had someone you studied with, worked with or who has supervised you ever commented on your production of English?

4. As a learner and as a teacher, looking back down your path is there one piece of advice that you would want to share with other pre-service teachers here or in your home country?

5. If you could represent your life as a language learner and a language teacher what kind of picture would you make? (You can either do this verbally, a list, drawing or chart)

6. Is there anything else about you life as a language learner and a language teacher that we haven't addressed that you would like to share? 